\title{
Critical Infrastructure Interdependency Modeling: A Survey of U.S. and International Research
}

P. Pederson

D. Dudenhoeffer

S. Hartley

M. Permann

August 2006

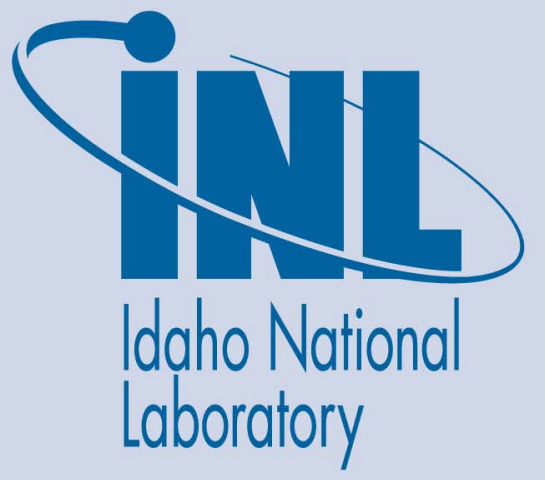

The INL is a U.S. Department of Energy National Laboratory operated by Battelle Energy Alliance 
INL/EXT-06-11464

\title{
Critical Infrastructure Interdependency Modeling: A Survey of U.S. and International Research
}

\author{
P. Pederson ${ }^{a}$ \\ D. Dudenhoeffer ${ }^{\text {b }}$ \\ S. Hartley \\ M. Permann ${ }^{\text {b }}$ \\ ${ }^{a}$ Technical Support Working Group, Washington D.C. \\ bIdaho National Laboratory
}

August 2006

Idaho National Laboratory Idaho Falls, Idaho 83415

Prepared for the

Technical Support Working Group Under

Work for Others Agreement 05734

Under DOE Idaho Operations Office

Contract DE-AC07-05ID14517 


\section{ABSTRACT}

"The Nation's health, wealth, and security rely on the production and distribution of certain goods and services. The array of physical assets, processes, and organizations across which these goods and services move are called critical infrastructures." This statement is as true in the U.S. as in any country in the world. Recent world events such as the 9-11 terrorist attacks, London bombings, and gulf coast hurricanes have highlighted the importance of stable electric, gas and oil, water, transportation, banking and finance, and control and communication infrastructure systems.

Be it through direct connectivity, policies and procedures, or geospatial proximity, most critical infrastructure systems interact. These interactions often create complex relationships, dependencies, and interdependencies that cross infrastructure boundaries. The modeling and analysis of interdependencies between critical infrastructure elements is a relatively new and very important field of study.

The U.S. Technical Support Working Group (TSWG) has sponsored this survey to identify and describe this current area of research including the current activities in this field being conducted both in the U.S. and internationally. The main objective of this study is to develop a single source reference of critical infrastructure interdependency modeling tools (CIIMT) that could be applied to allow users to objectively assess the capabilities of CIIMT. This information will provide guidance for directing research and development to address the gaps in development. The results will inform researchers of the TSWG Infrastructure Protection Subgroup of research and development efforts and allow a more focused approach to addressing the needs of CIIMT end-user needs.

This report first presents the field of infrastructure interdependency analysis, describes the survey methodology, and presents the leading research efforts in both a cumulative table and through individual datasheets. Data was collected from open source material and when possible through direct contact with the individuals leading the research. 


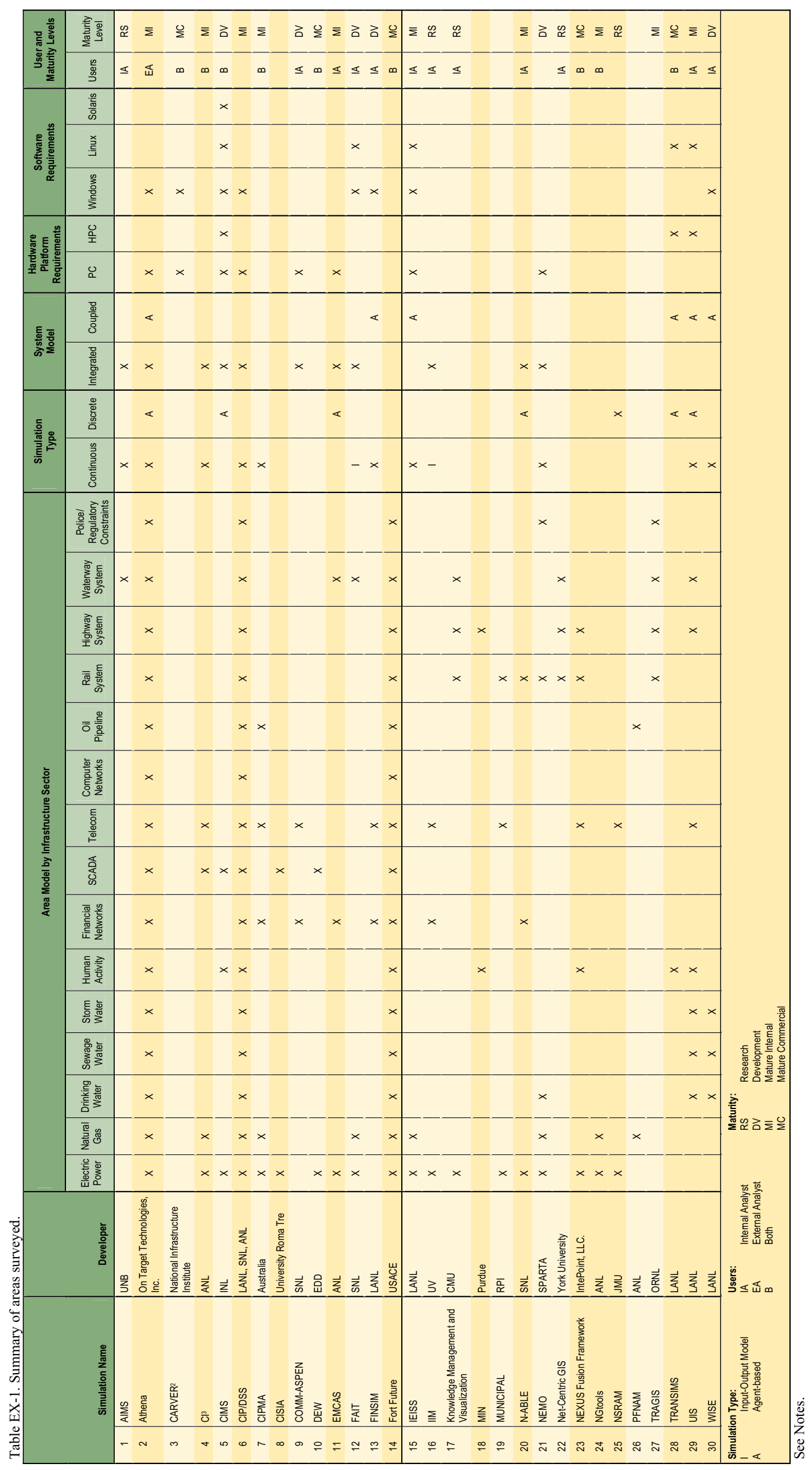




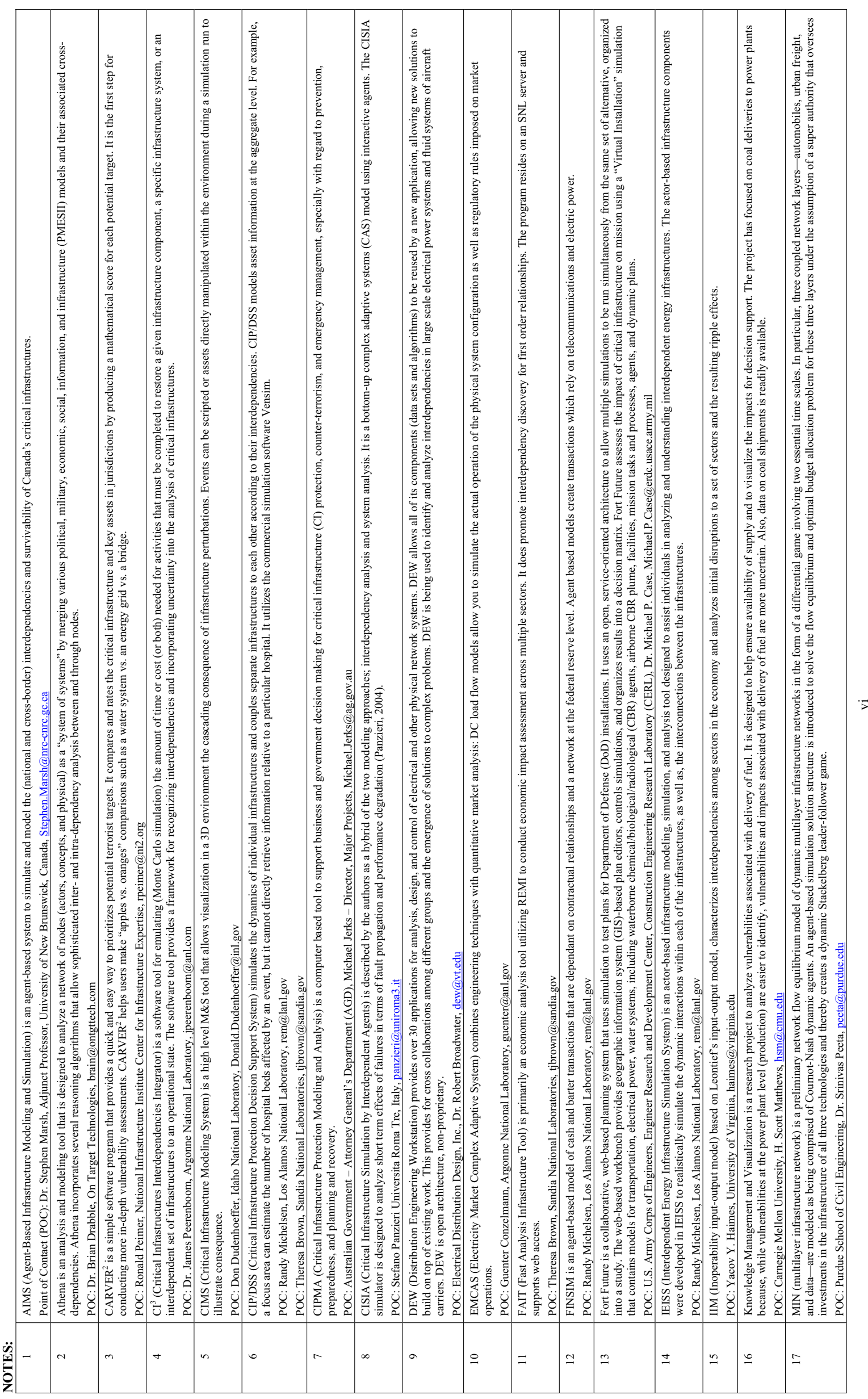




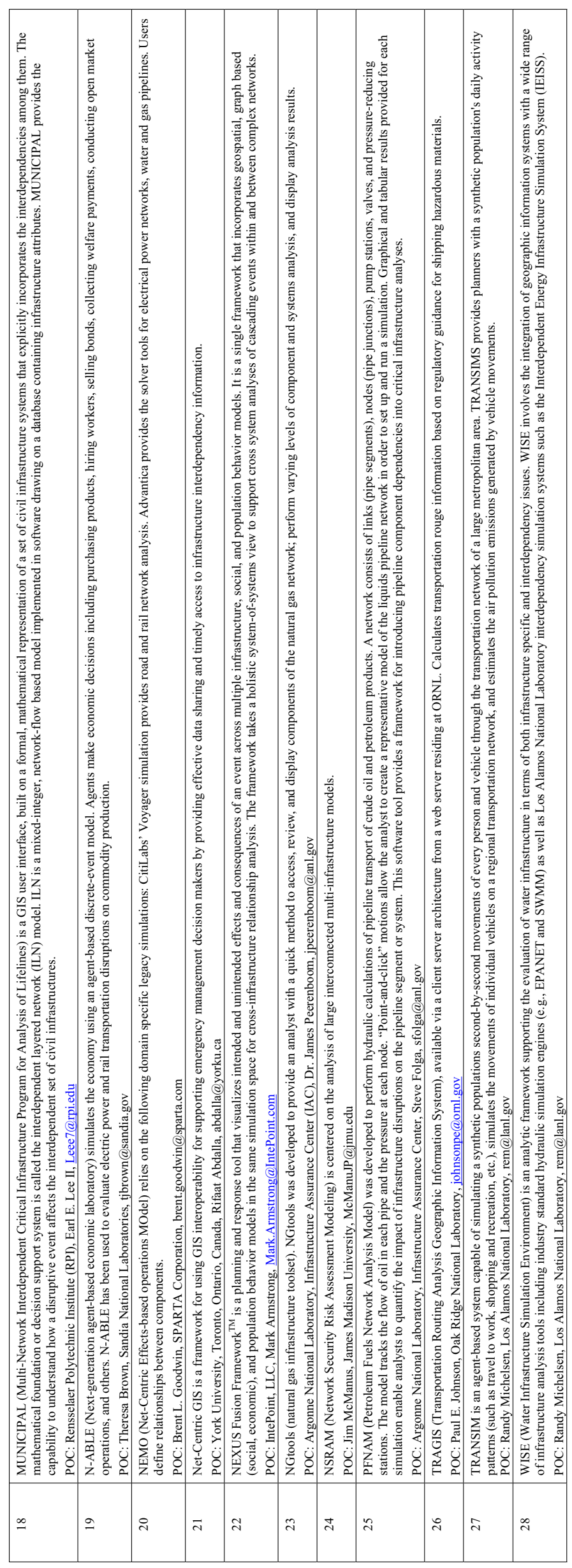




\section{CONTENTS}

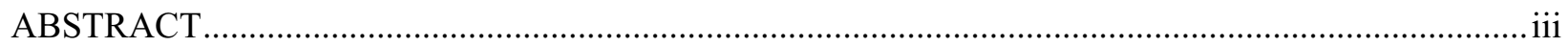

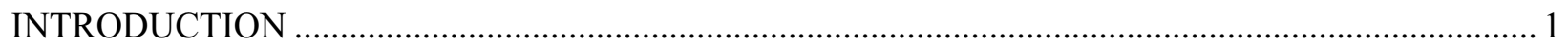

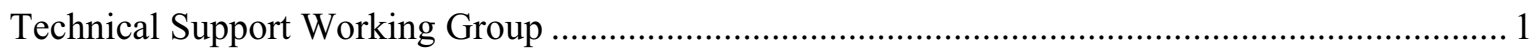

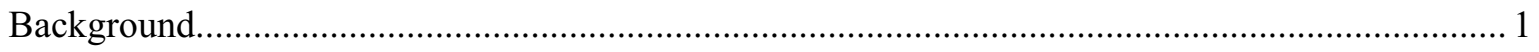

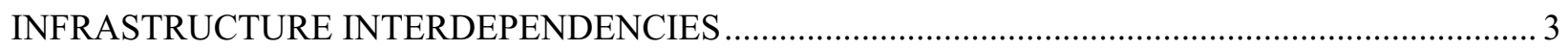

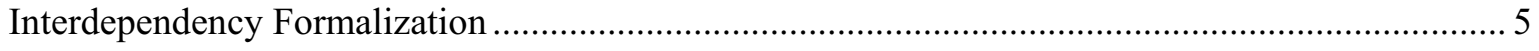

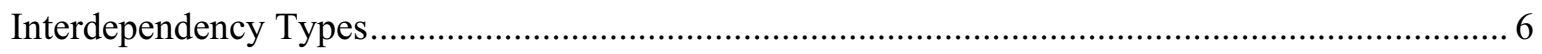

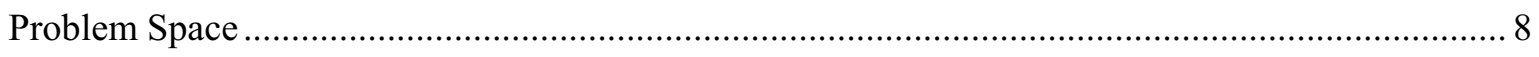

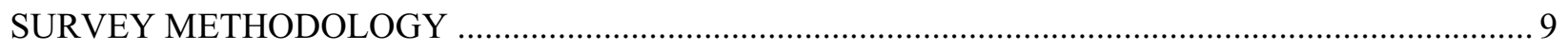

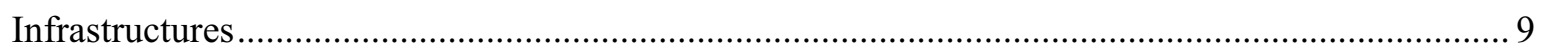

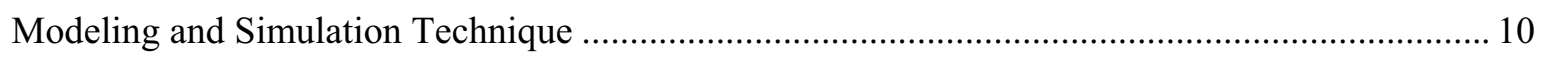

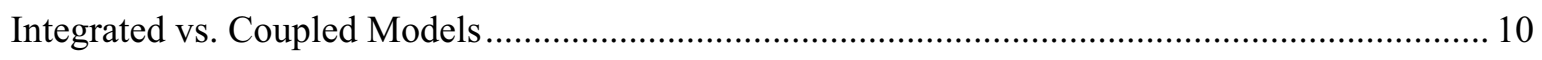

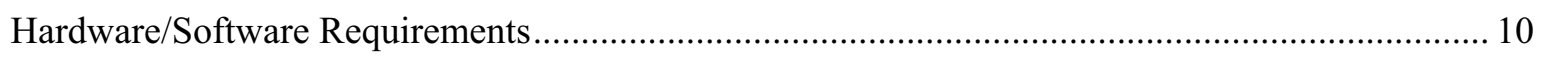

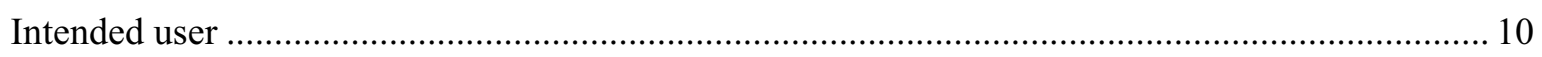

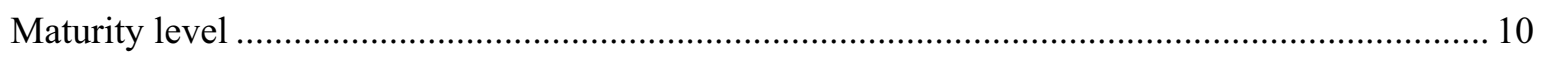

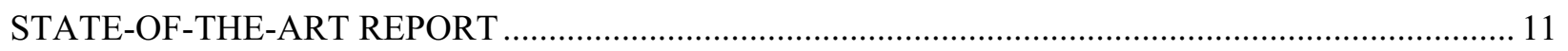

POLITICAL, MILITARY, ECONOMIC, SOCIAL, INFORMATION, AND INFRASTRUCTURE

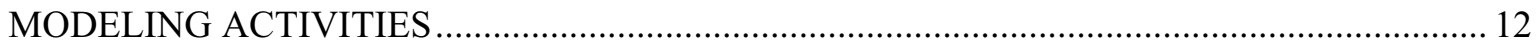

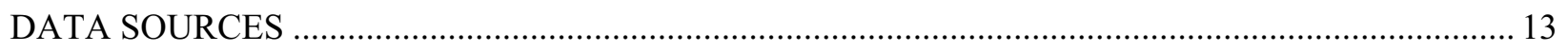

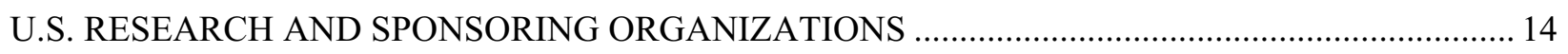

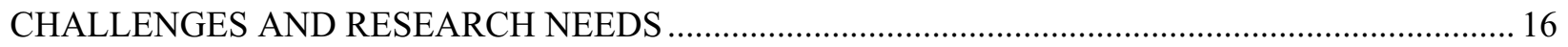

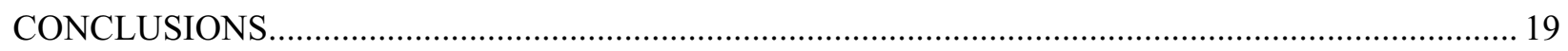

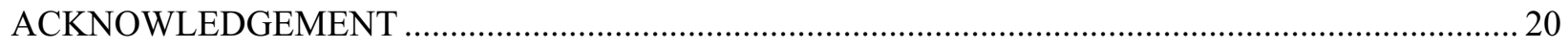

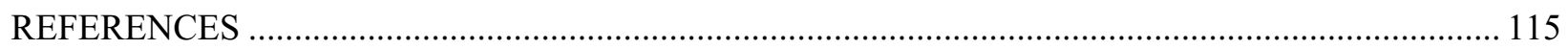




\section{FIGURES}

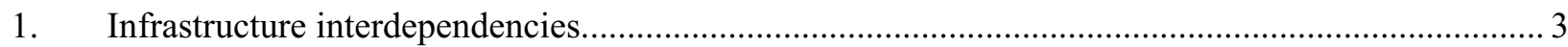

2. Thick, black smoke billows out of the railroad tunnel near Oriole Park at Camden Yards. Interstate 395 and the baseball park were closed, along with the Inner Harbor (see Reference 9)

3. An official surveys the gaping hole and broken 40-in. water main at Howard and Lombard streets (see Reference 10)

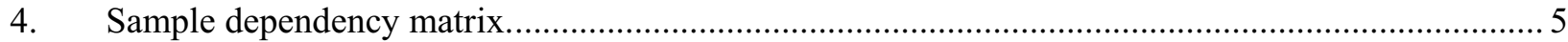

5. Cascading consequence example (see Reference 13) ............................................................. 7

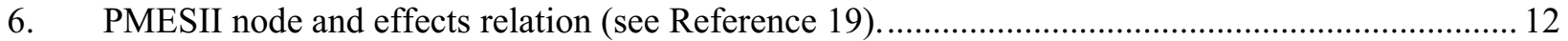

\section{TABLES}

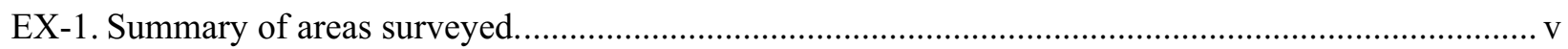

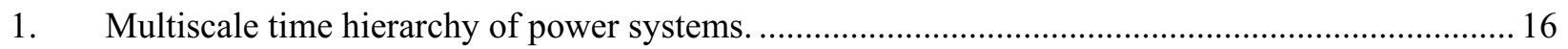

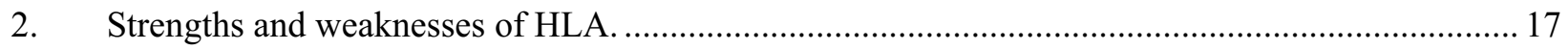

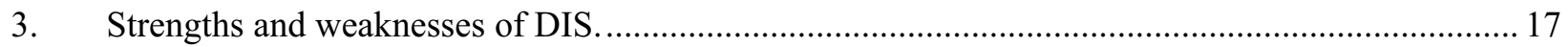




\section{Critical Infrastructure Interdependency Modeling: A Survey of U.S. and International Research}

\section{INTRODUCTION}

“The Nation's health, wealth, and security rely on the production and distribution of certain goods and services. The array of physical assets, processes, and organizations across which these goods and services move are called critical infrastructures." "2 This statement is as true in the U.S. as in any country in the world. Recent world events such as the 9-11 terrorist attacks, London bombings, and gulf coast hurricanes have highlighted the importance of stable electric, gas and oil, water, transportation, banking and finance, and control and communication infrastructure systems.

Be it through direct connectivity, policies and procedures, or geospatial proximity, most critical infrastructure systems interact. These interactions often create complex relationships, dependencies, and interdependencies that cross infrastructure boundaries. The modeling and analysis of interdependencies between critical infrastructure elements is a relatively new and very important field of study.

Much effort is currently being spent to develop models that accurately simulate critical infrastructure behavior and identify interdependencies and vulnerabilities. The results of these simulations are used by private companies, government agencies, military, and communities to plan for expansion, reduce costs, enhance redundancy, improve traffic flow, and to prepare for and respond to emergencies.

Modelers have developed various innovative modeling approaches including agent based modeling, effects-based operations (EBO) models, input-output models, models based on game theory, mathematical models, and models based on risk. These have been applied to infrastructure of shipboard systems, University campuses, large power grids, and waterways to name a few. Modeling is complicated by the quality and availability of data, intricacy of systems, complexity of interactions between infrastructure sectors, and implications and sensitivity of results.

This survey identifies and catalogs much of the state-of-the-art research being conducted in the area of infrastructure interdependency modeling and analysis.

\section{Technical Support Working Group}

The U.S. Technical Support Working Group (TSWG) is the sponsor for this effort. ${ }^{3}$ TSWG is a national forum to identify, prioritize, and coordinate interagency and international research and development $(\mathrm{R} \& \mathrm{D})$ requirements for combating terrorism. The aim of TSWG is to support rapidly developed technologies and product development to provide tools for combating terrorism. It supports multiple U.S. government agencies as well as major allies.

The main objective of this study is to develop a single source reference of critical infrastructure interdependency modeling tools (CIIMT) that could be applied to allow users to objectively assess the capabilities of CIIMT. This information will provide guidance for directing $\mathrm{R} \& \mathrm{D}$ to address the gaps in development. The results will inform the R\&D efforts of the TSWG Infrastructure Protection Subgroup of R\&D efforts and allow a more focused approach to addressing the needs of CIIMT end-user needs.

\section{Background}

The study and analysis of infrastructure interdependencies is relatively new. The interdependencies between critical infrastructures received little attention in the early 1990s.

However, in the mid 1990s events such as the Oklahoma City bombing in 1995 and the report from the Defense Science Board Task Force on Information Warfare in 1996, and the increased reliance on information and computerized control systems brought the increasing importance of 
infrastructure interdependencies into focus. Also in 1996, President Clinton established the President's Commission on Critical Infrastructure Protection (PCCIP). ${ }^{4}$

The PCCIP report was released in 1997 and though it identified no immediate critical threats to national infrastructures, it did highlight the importance of interdependencies including those between power, transportation, emergency response, vital human services, banking and finance, and telecommunications, especially through digital means. A general recommendation of the commission was that since the lion's share (approximately 85\%) of the nation's critical infrastructure is in private hands, there needs to be good cooperation and information sharing between government and private sector.

In May of 1998, Presidential Decision Directive (PDD) no. 63 was released. That directive set a national goal to protect the nation's critical infrastructure from deliberate attacks by 2003. PDD-63 was followed by executive orders (E.O.s) by both Presidents Clinton (E.O. $13130^{5}$ in July 1999) and Bush (E.O. $13231^{6}$ in 2001) establishing Information Sharing and Analysis Centers that were largely private-sector run and a National Infrastructure Advisory Council (NIAC). While there were some changes in the wording of the E.O.s, the functions of NIAC remained largely the same.

We have since seen the establishment of the U.S. Department of Homeland Security (DHS) in November of 2002 and the National Infrastructure Simulation and Analysis Center (NISAC) in fall of 2001. NISAC is a partnership between Sandia National Laboratory (SNL) and Los Alamos National Laboratory (LANL) established to develop advanced infrastructure modeling and simulation techniques that identify vulnerabilities and interdependencies.

This increased attention has been followed by increases in funding to universities, national laboratories, and private companies involved in modeling and simulation of critical interdependencies. Funding has come from national organizations, private investments, the Department of Defense (DoD), U.S. government agencies (DHS, U.S. Department of Energy [DOE], Department of Commerce, and others), and other governments and agencies.

The increased funding and level of efforts has led to much innovative work in this area. Thus, while efforts focusing on modeling of critical infrastructure interdependencies have only begun recently, much valuable work has already been done. 


\section{INFRASTRUCTURE INTERDEPENDENCIES}

"One of the most frequently identified shortfalls in knowledge related to enhancing critical infrastructure protection capabilities is the incomplete understanding of interdependencies between infrastructures. Because these interdependencies are complex, modeling efforts are commonly seen as a first step to answering persistent questions about the "real" vulnerability of infrastructures."7

The importance of "What are infrastructure inter-dependencies, and how are they modeled?" is addressed in this section. References to interdependent relationships in this paper are actually referring to as dependent relationships or influences between infrastructures. Figure 1 illustrates common representations of infrastructure based on the scenario of a flooding event and the subsequent response. Parallels to this scenario with the events in New Orleans during Hurricane Katrina can easily be drawn. Within the figure, individual infrastructure networks are represented on a single plane. The parallel lines represent individual sectors or subsets within that particular infrastructure. The spheres or nodes represent key infrastructure components within that sector from the events in New Orleans

The energy sector infrastructure, for example, during Hurricane Katrina contains the sectors of electrical generation and distribution, natural gas production and distribution, etc. Ties and dependencies exist within each infrastructure and between the different sectors. The solid lines in Figure 1, crossing sectors and connecting nodes, represent internal dependencies, while the dashed lines represent dependencies that also exist between different infrastructures (infrastructure interdependencies).

The example in Figure 1 is a simple attempt to portray the complexity of dependencies that may exist between components. In chaotic environments such as emergency response to catastrophic events, decision makers should

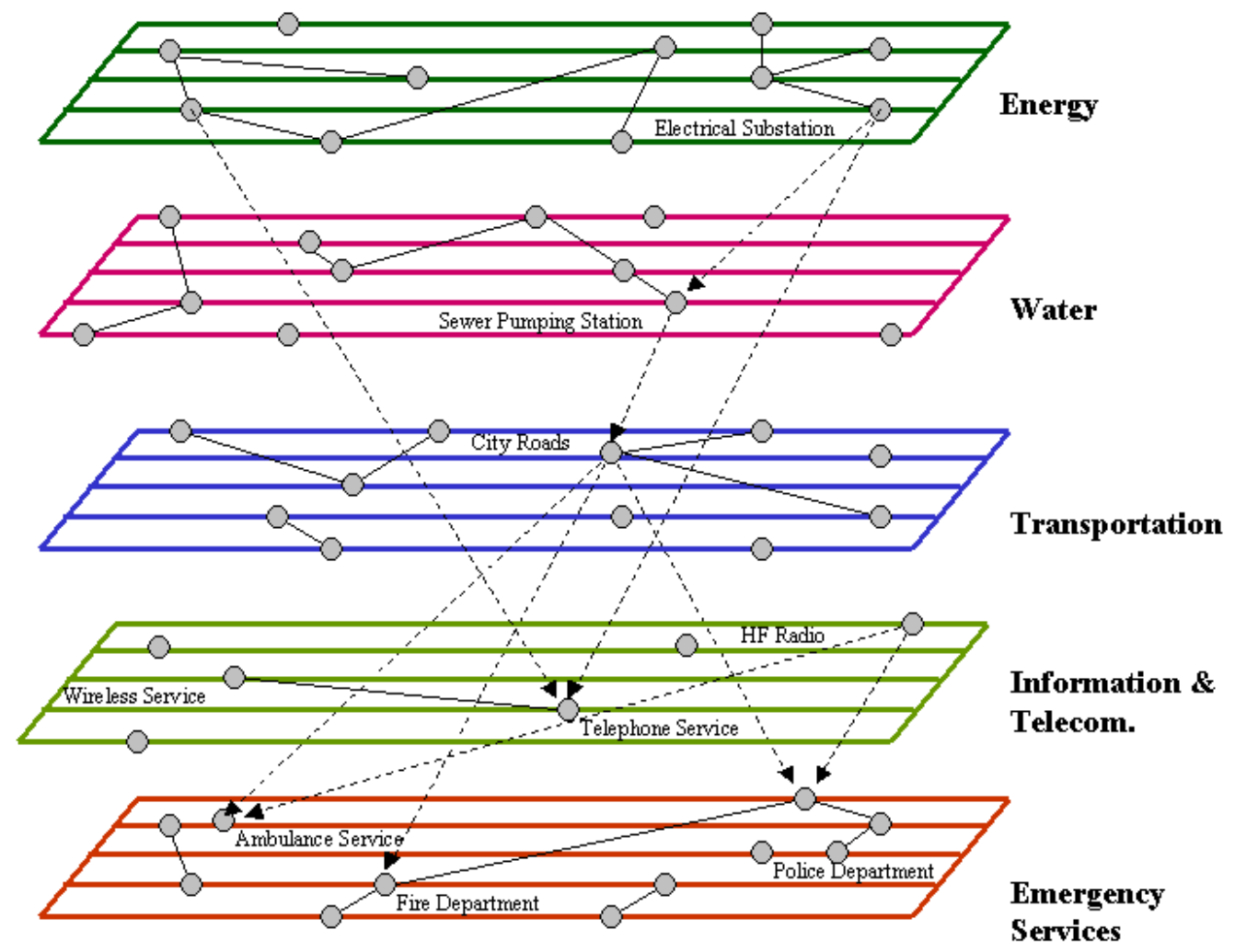

Figure 1. Infrastructure interdependencies. 
understand the dynamics underlying the infrastructures. Failure to understand those dynamics will result in ineffective response and poor coordination between decision makers and agencies responsible for rescue, recovery, and restoration. It could also cause the mismanagement of resources, including supplies, rescue personnel, and security teams. At best, emergency responders will lose public trust, at worst, human life.

This interrelationship among infrastructures and its potential for cascading effects was never more evident than on July 19, 2001 when a 62-car freight train carrying hazardous chemicals derailed in Baltimore's Howard Street Tunnel, Figure 2.

This disaster, in addition to its expected effect on rail system traffic, automobile traffic, and emergency services, caused a cascading degradation of infrastructure components not previously anticipated. For example, the tunnel fire caused a water main to break above the tunnel shooting geysers $20 \mathrm{ft}$ into the air, Figure 3 . The break caused localized flooding which exceeded a depth of three feet in some areas.

Additionally, the flooding knocked out electricity to about 1,200 downtown Baltimore residences. ${ }^{8}$ Fiber optical cables running through the tunnel were also destroyed. This resulted in major disruptions to phone and cell phone service, email service, web services, and data services to major corporations including WorldCom Inc., Verizon Communications Inc., the Hearst Corp. in New York City, Nextel Communications Inc., and the Baltimore Sun newspaper. ${ }^{9}$ Disruption to rail services and its effects on the Middle Atlantic states were significant also. ${ }^{10}$ These effects included delays in coal delivery and also limestone delivery for steel.

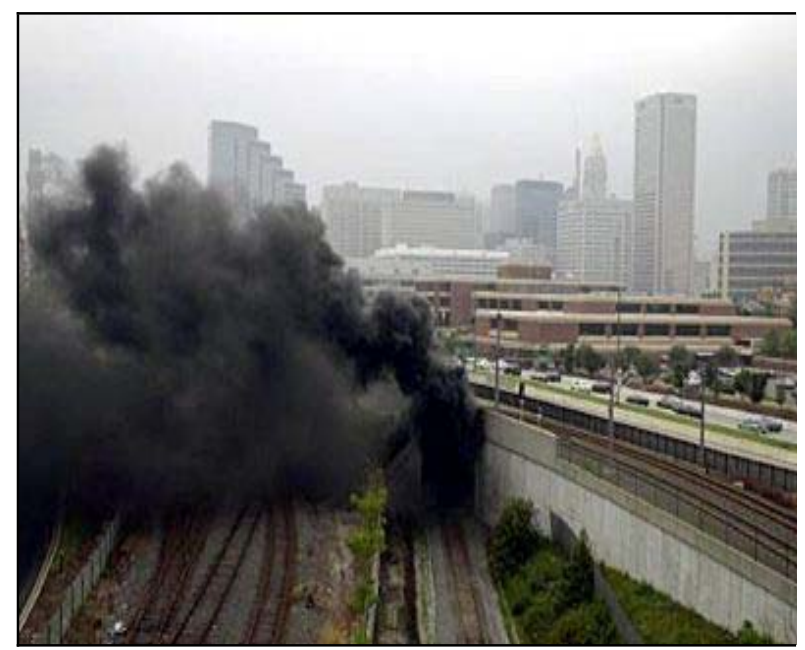

Figure 2. Thick, black smoke billows out of the railroad tunnel near Oriole Park at Camden Yards. Interstate 395 and the baseball park were closed, along with the Inner Harbor (see Reference 9).

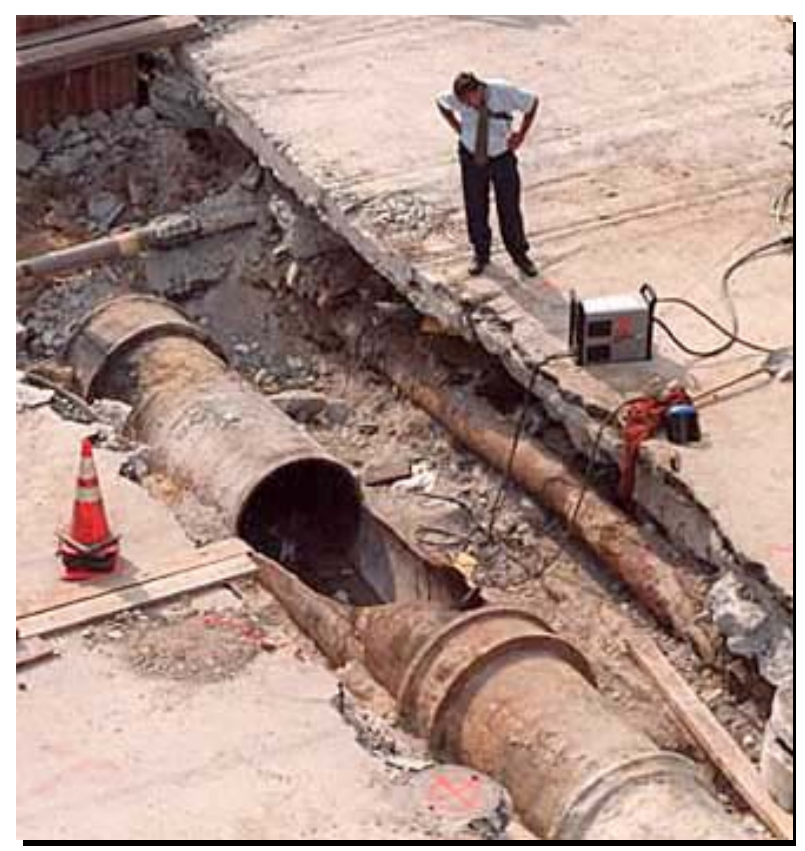

Figure 3. An official surveys the gaping hole and broken 40-in. water main at Howard and Lombard streets (see Reference 10). 
A dependency matrix is another way to represent interdependencies between infrastructure networks and their relative impact. The Critical Infrastructure Protection Task Force of Canada used a dependency matrix (see Figure 4) to relate the interdependency among six sectors identified as crucial: Government, Energy and Utilities, Services, Transportation, Safety, and Communications. ${ }^{11}$ The matrix is their attempt to better understand the level of dependency and the potential impact among sectors.

Infrastructure owners historically concerned with the operation of their own, often well defined domains must now contend with unbounded networks brought about by greater information technology connectivity. There is a growing need to analyze and better understand the chains of influence that cross multiple sectors that can induce potentially unforeseen secondary effects. This survey addresses a growing concern dealing with the influence or impact, that one infrastructure can have, either directly or indirectly, upon another. The cross infrastructure effects continue to grow as information technology pushes interconnectivity between all aspects of business.

Infrastructure interdependencies therefore refer to relationships or influences that an element in one infrastructure imparts upon another infrastructure.

\section{Interdependency Formalization}

Precisely how is an infrastructure interdependency relationship defined? Dudenhoeffer, Permann and Manic ${ }^{12}$ model the levels of infrastructure as a large graph in which nodes represent infrastructure components, and edges the relations between nodes.

\begin{tabular}{|c|c|c|c|c|c|c|c|c|c|}
\hline \multirow[t]{2}{*}{ Sector } & & \multicolumn{5}{|c|}{ Energy \& Utilities } & \multicolumn{3}{|c|}{ Services } \\
\hline & Element & 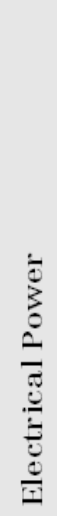 & 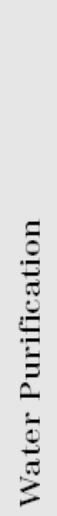 & 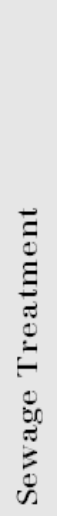 & 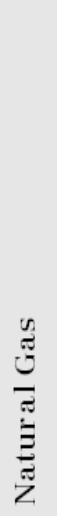 & 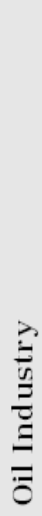 & 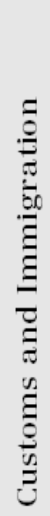 & 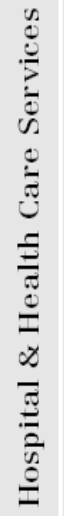 & 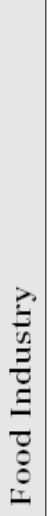 \\
\hline \multirow[t]{5}{*}{ Energy \& Utilities } & Electrical Power & & L & & & $\mathbf{M}$ & & & \\
\hline & Water Purification & H & & & & $\bar{M}$ & & & \\
\hline & Sewage Treatment & M & H & & & H & & & \\
\hline & Natural Gas & L & & & & $\mathbf{L}$ & & & \\
\hline & Oil Industry & H & L & & & & & & \\
\hline \multirow[t]{4}{*}{ Services } & Customs \& Immigration & H & $\mathbf{L}$ & $\mathbf{L}$ & $\mathbf{L}$ & L & & $\mathbf{L}$ & \\
\hline & Hospital \& Health Care Services & H & H & $\mathbf{L}$ & H & H & M & & H \\
\hline & Food Industry & H & H & H & $\mathbf{L}$ & M & M & $\mathbf{L}$ & \\
\hline & $\mathrm{Ke}$ & H & High & $\bar{M}$ & & & $\mathbf{L}$ & Low & \\
\hline
\end{tabular}

Figure 4. Sample dependency matrix. 
A formal model of this infrastructure and the interrelationships is presented in the following definitions:

1. An infrastructure network, $I$, is a set of nodes related to each other by a common function.

The network may be connected or disjoint. It may be directional, bi-directional or have elements of both. Internal

relationships/dependencies within the infrastructure I are represented by edge $(a, b)$ with $a, b \in I$.

2. Given $I_{i}$ and $I_{j}$ are infrastructure networks, $i \neq$ $j, a \in I_{i}$ and $b \in I_{j}$, an interdependency is defined as a relationship between infrastructures and represented as the edge $(a, b)$ which implies that node $b$ is dependent upon node a. Depending on the nature or type of the relationship, this relationship may be reflexive in that $(a, b) \rightarrow(b, a)$.

\section{Interdependency Types}

Interdependencies can be of different types. Several taxonomies have been presented ${ }^{3}$ to categorize the types of interdependencies.

Rinaldi, Peerenboom, and Kelly ${ }^{13}$ describe dependencies in terms of four general categories:

- Physical - a physical reliance on material flow from one infrastructure to another

- Cyber - a reliance on information transfer between infrastructure

- Geographic - a local environmental event affects components across multiple infrastructures due to physical proximity

- Logical - a dependency that exists between infrastructures that does not fall into one of the above categories.

This study used a slightly expanded taxonomy developed by Dudenhoeffer and Permann. ${ }^{4}$ The categorization classifies the following types of relationships:

- Physical. A requirement, often engineering reliance between components. For example: a tree falls on a power line during a thunderstorm resulting in a loss of power to an office building and all the computers inside.

- Informational Interdependency. An informational or control requirement between components. For example: a supervisory control and data acquisition (SCADA) system that monitors and controls elements on the electrical power grid. A loss of the SCADA system will not by itself shut down the grid, but the ability to remotely monitor and operate the breakers is lost. Likewise, this relationship may represent a piece of information or intelligence flowing from a node that supports a decision process elsewhere. An example is the dispatch of emergency services. While the responders may be fully capable of responding, an informational requirement exists as to answering where, what, and when to initiate response.

- Geospatial Interdependency. A relationship that exists entirely because of the proximity of components. For example: flooding or a fire may affect all the assets located in one building or area.

- Policy/Procedural Interdependency. An interdependency that exists due to policy or procedure that relates a state or event change in one infrastructure sector component to a subsequent effect on another component. Note that the impact of this event may still exist given the recovery of an asset. For example: after aircraft were flown into the World Trade Towers "all U.S. air transportation was halted for more than 24 hours, and commercial flights did not resume for three to four days."14

- Societal Interdependency. The interdependencies or influences that an infrastructure component event may have on societal factors such as public opinion, public confidence, fear, and cultural issues. Even if no physical linkage or relationship exists, consequences from events in one infrastructure may impact other infrastructures. This influence may also be time sensitive and decay over time from the original event grows. For example: air traffic following the 9-11 attack dropped significantly while the public evaluated the safety of travel. This resulted in layoffs within 
the airline industry and bankruptcy filings by some of the smaller airlines (see Reference 12).

Again, while the dependencies within an individual infrastructure network are often well understood, the region of interest in interdependency and effects modeling is the influence or impact that one infrastructure can impart upon another. Therefore, the key effects to model and gain understanding of are the chains of influence that cross multiple sectors and induce potentially unforeseen n-ary effects. These chains, potentially composed of multiple interdependency types, compose the paths or arcs between infrastructure components or nodes denoted as $\{(a, b),(b, c),(c, d), \ldots(y, z)\}$. This particular path represents the cascading consequence of an event or the derived dependency of node $z$ on node $a$, further denoted $(a D z)$. Likewise the genesis of the chain may not be singular in that the end effect is the influence of multiple nodes, denoted by $(a b c . . D z)$.

These paths may not be unique in terms of effect, they may change over time, and their behavior may be cumulative in nature, i.e., the end effect may be the culmination of multiple predicated events. The intertwining of networks in this fashion represents a complex system where emergent behaviors are rarely fully understood. Rinaldi, Peerenboom and Kelly (see Reference 13) provide a nice visual representation of this intertwining and the potential cascading effects. This is shown in Figure 5.

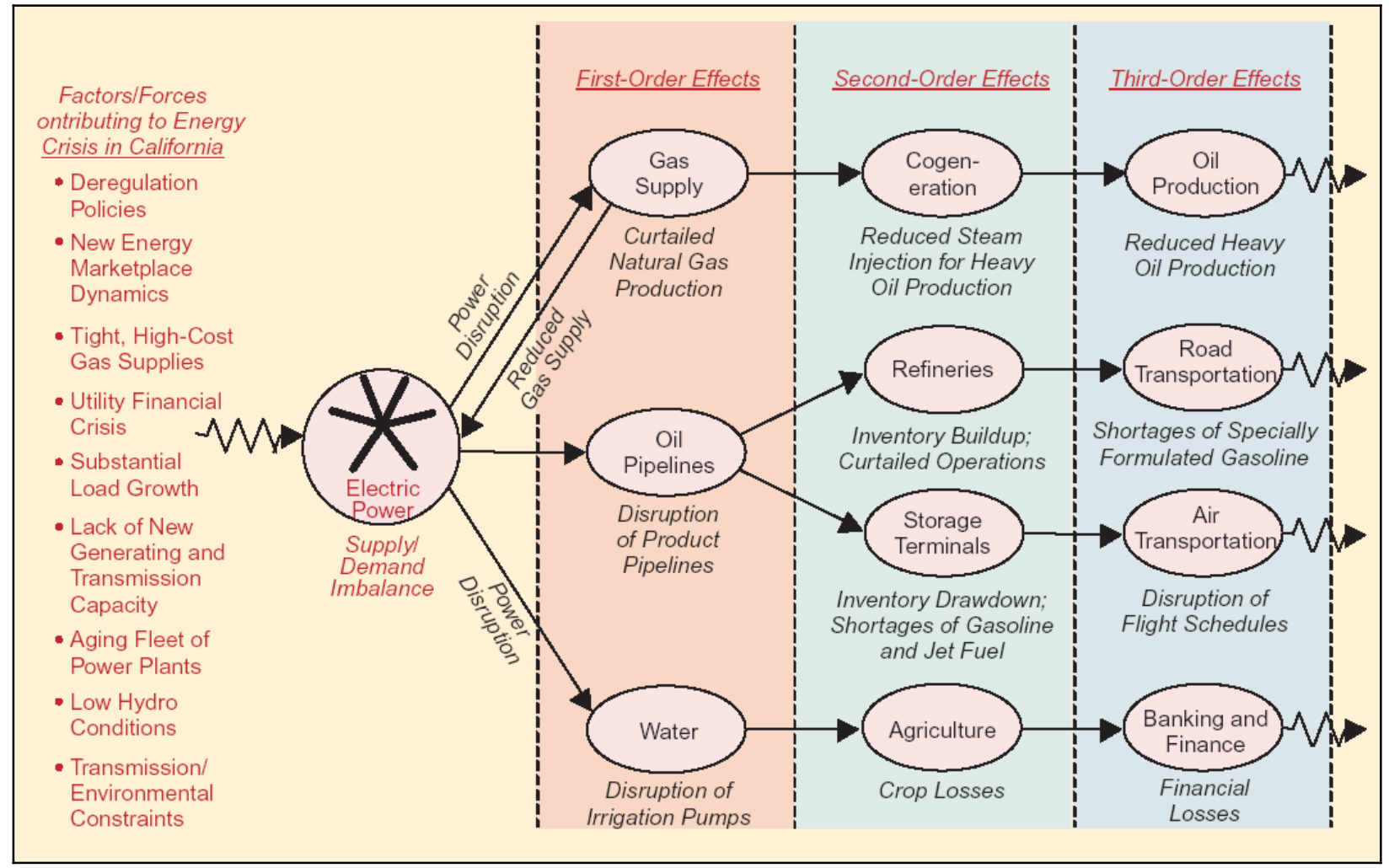

Figure 5. Cascading consequence example (see Reference 13). 


\section{Problem Space}

Thus given the realm of interdependency analysis, what are the goals for modeling and simulation efforts? In the analysis of infrastructure interdependencies and the subsequent emergent system behaviors, some of the major problem areas being examined include:

1. Given a set of initiating events $\{E(a), E(b), \ldots\}$ what is the cascading impact on a subset of nodes $\{x, y, z, \ldots\}$ ?

2. Given a set of nodes $\{x, y, z, \ldots\}$ and a desired end state, what is a set of events $\{E(a), E(b)$, ...\} that would cause this effect?
3. Given a set of events $\{E(a), E(b), \ldots\}$ and a set of observed outcomes of on nodes $\{x, y, z, \ldots\}$, is it possible to determine the derived interdependence ( $a b D x y z)$ ?

4. Given a set of infrastructure networks and a critical function, what is the subset of critical nodes $\{x, y, z, \ldots\}$ across all networks that will adversely impact a specific mission functionality due to direct or derived dependency? 


\section{SURVEY METHODOLOGY}

The areas included in this survey were selected because they focus on modeling and simulation across multiple infrastructure layers. Systems such as geographical information systems (GIS), which may provide geospatial relationships, are not included unless they possess additional analytical capabilities.

Each model examined in the survey offers unique capabilities and provides specific insights into various aspects of the problem domain. The modeling approaches and the objectives of the efforts varied greatly. Specific parameters in the survey were of interest for comparison. One of the goals of the survey was to identify potential resources for a wide range of customers and domains.

Six major categories were considered in the survey:

- Infrastructures

- Modeling and simulation technique

- Integrated vs. coupled models

- Hardware/software requirements

- Intended user

- Maturity level. below.

Each of these categories is briefly discussed

\section{Infrastructures}

The U.S. Patriot Act defines critical infrastructure as "systems and assets, whether physical or virtual, so vital to the U.S. that the incapacity or destruction of such systems and assets would have a debilitating impact on security, national economic security, national public health or safety, or any combination of those matters." 15

Further, congress set forth the following findings in Section 1016 of the U.S. Patriot Act:

- The information revolution has transformed the conduct of business and the operations of government as well as the infrastructure relied upon for the defense and national security of the U.S.

- Private business, government, and the national security apparatus increasingly depend on an interdependent network of critical physical and information infrastructures, including telecommunications, energy, financial services, water, and transportation sectors.

- A continuous national effort is required to ensure the reliable provision of cyber and physical infrastructure services critical to maintaining the national defense, continuity of government, economic prosperity, and quality of life in the U.S..

- This national effort requires extensive modeling and analytic capabilities for purposes of evaluating appropriate mechanisms to ensure the stability of these complex and interdependent systems, and to underpin policy recommendations, so as to achieve the continuous viability and adequate protection of the critical infrastructure of the Nation. ${ }^{16}$

Although countries tend to have slightly different lists detailing their "critical sectors," most contain elements of the following:

- Agriculture and food

- Water

- Public health and safety

- Emergency services

- Government

- Defense industrial base

- Information and telecommunications

- Energy

- Transportation

- Banking and finance

- Industry/manufacturing

- Postal and shipping.

These sectors in turn contain individual infrastructures such as highways, rail systems, electric power generation and distribution, etc. 
Some of these systems are managed by government agencies, but the majority resides with industry.

This survey attempts to capture and describe the infrastructures/infrastructure sectors each program models. This report seeks to reflect only those infrastructures that have been actually modeled and not those presumed to be capable of being modeled.

\section{Modeling and Simulation Technique}

This category attempts to capture the modeling and simulation method used for the infrastructure and interdependencies. It has multiple dimensions that include those of time (continuous vs. discrete time step) and modeling technique (Markov chains, Petri Nets, dynamic simulation, agent-based, physics based, ordinary differential equations, input-output model, etc.).

\section{Integrated vs. Coupled Models}

During the course of the survey it became apparent that two different approaches were often used to conduct cross infrastructure analysis. One approach was to create an integrated system model that attempted to model multiple infrastructures and their interdependencies within one framework. The other approach coupled a series of individual infrastructure simulations together, which then illustrated the cascading influence between them. An example of this approach would be an electric grid simulation that determines an outage area for a specific event. The electrical outage area is then fed to a telecommunication model used to determine the subsequent impact on message routing. This impact is fed to a financial simulation that determines the loss of telecommunication impact on commerce and financial transactions. As one might expect, integrated models tend to model at a much higher level than coupled models.

\section{Hardware/Software Requirements}

In an effort to identify possible tool sets, the survey captures the portability and exportability of programs and data.

\section{Intended user}

The survey categorizes products as internal analytical tools intended for internal use only or external analytical tools available for use outside the developing organization. This decision relates to the level of expertise required to use the product, the application requirements, and the analytical output of the product. The requirement is sometimes driven by the size, complexity, or proprietary nature underlying the data

\section{Maturity level}

The following four categories were used to identify the product's level of maturity:

- Research - the product is still highly conceptual without vetted application in real-world domains.

- Development - the product has been applied and validated against real-world infrastructure. Beyond conceptual, the product has been used by internal or external customers, but is still undergoing substantial development.

- Mature analytic - the product has reached a high level of code stability and is part of a vested internal analytical process. The results of analysis may be an external report, but the tool usage is strictly internal to the organization.

- Mature commercial - the tool is a commercially licensed product. 


\section{STATE-OF-THE-ART REPORT}

Appendix A contains data on U.S. and international efforts and interdependency modeling tools. The information is presented at a high level with POC information for those desiring greater detail. 


\section{POLITICAL, MILITARY, ECONOMIC, SOCIAL, INFORMATION, AND INFRASTRUCTURE MODELING ACTIVITIES}

A modeling area that closely follows infrastructure interdependency modeling is EBO modeling and analysis. War and conflict are rarely confined to only the battlefield and force-on-force engagement. Potential U.S. adversaries comprise a complex and interdependent system of systems, all of which contribute, to some degree, toward their societal coherence, will, and capability to pursue a course of action contrary to U.S. interests. ${ }^{17}$ Conflict, war, and reconstruction represent a complex set of influences, competing goals, and resources. The battle environment, and thus the means of victory, are often shaped by the intricate interactions between them.

Many point to the emergence of a new generation of warfare termed fourth generation warfare (4GW). Retired Colonel Thomas Hammes, U.S. Military Complex, describes this concept:

"4GW uses all available networks - political, economic, social, and military - to convince the enemy's political decision makers that their strategic goals are either unachievable or too costly for the perceived benefit. It is an evolved form of insurgency. Still rooted in the fundamental precept that superior political will, when properly employed, can defeat greater economic and military power, $4 \mathrm{GW}$ makes use of a society's networks to carry on its fight. Unlike previous generations of warfare, it does not attempt to win by defeating the enemy's military forces. Instead, via the networks, it directly attacks the minds of enemy decision makers to destroy the enemy's political will."18

Operational Net Assessment (ONA) is the integration of people, processes, and tools that use multiple information sources and collaborative analysis to build shared knowledge of the adversary, the environment, and ourselves in understanding and effectively employing EBO. ONA analytical products are based on a system-of-systems analysis and the understanding of key relationships, dependencies, strengths, and vulnerabilities within and between the adversary's political, military, economic, social, information, and infrastructure (PMESII) elements. These products identify leverage points, key nodes, and links that we can act upon to decisively influence the adversary's behavior, capabilities, perceptions, and decisions. ${ }^{19}$

Within this operating environment, EBOs are actions that change the state of a system to achieve directed policy aims using the integrated application of the diplomatic, informational, military, and economic instruments of national power. In order to achieve EBO, however, it is imperative to understand the relationships and influences of the PMESII dimensions that shape the actions of the adversary, of allies, and of your organization. Figure 6 illustrates this concept showing a representation of the connectivity and interdependencies between these dimensions as both a strength and potential weakness.

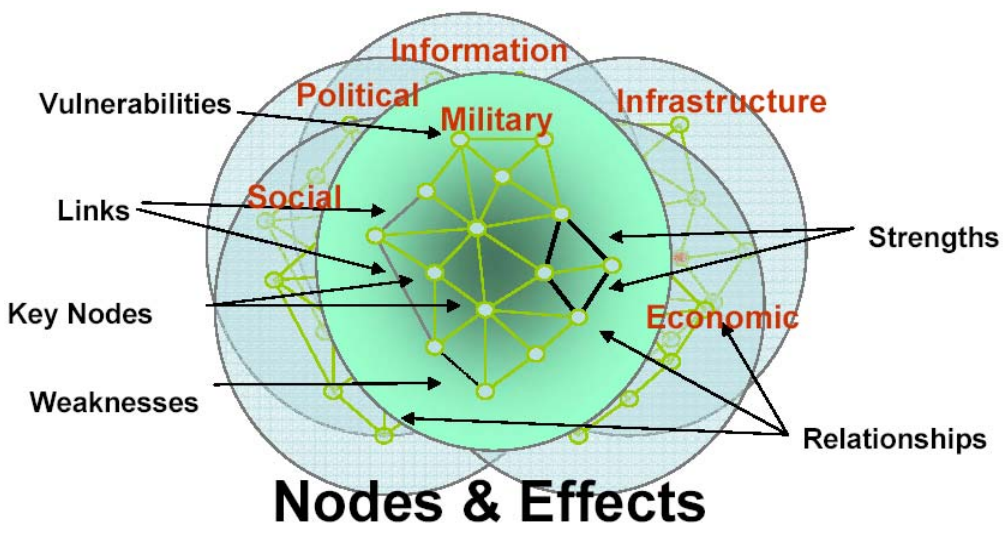

Figure 6. PMESII node and effects relation (see Reference 19). 


\section{DATA SOURCES}

The paradigm of modeling and simulation is "garbage in, garbage out." Having credible and traceable data available to use is key to infrastructure and interdependency modeling. Gathering information on a particular infrastructure is possibly the most significant challenge. Interdependency modeling also requires that gathered information (assets) be linked across multiple infrastructures. Supporting data for these analyses often spread across multiple data sets. The fact that most infrastructures data is held by private industry and, to a large extent, considered proprietary in nature complicates the situation further. The data is often accompanied by the analytical requirement for a certain level of domain expertise in identifying and validating cross infrastructure influences.

The scale of the model also determines the possible sources of information. Consider, for example, the electrical power grid. If the goal is to model assets on a national scale, data equivalent to transmission level information may suffice with broad asset effects drawn from course outage area determination. If the goal is to evaluate a particular city, compound, or facility, distribution level information is required reflecting a far greater level of granularity.

Commercial geospatial data sets such as those provided by ESRI, Platts, etc., provide coarse level data that may suffice for initial model development, but they lack the detail needed to construct a more precise model. Public census provides a good data source for an initial data set. Recall however, that the census data reflects nighttime residential demographics in terms of grid-wise statistics, which may not be adequate in terms of population mobility and granularity.

To mitigate the shortcomings of data, several efforts have been made to compose and validate detail infrastructure and demographic data sources. Two of the data sets used by those surveyed are LandScan and National Asset Database:
- LandScan - The LandScan series of data sets have been developed and are maintained by Oak Ridge National Laboratory. They are a population distribution model, database, and tool developed from census data that incorporates other spatial information for greater accuracy and granularity. The LandScan series consist of LandScan Global representing data in 30 arc second grid cells for $\sim 1 \mathrm{~km}$ resolution, LandScan Interim, which has a 15 -arc ( 450 m) second resolution, and LandScan USA with 3 -arc-second resolution for $\sim 90 \mathrm{~m}$ resolution with both day and night time population distributions and demographic and socioeconomic characteristics data. ${ }^{20}$

- National Asset Database - In July 2004, the Office of Infrastructure Protection (DHS/IP) initiated a data call to states and territories requesting a listing of assets deemed of national or local importance. The collection, named the National Asset Database, contains basic asset and facility information, including data associated with location, POC, and risk attributes.

In addition to these specialized data sets, several DOE national laboratories maintain system expertise that includes detailed infrastructure data. These information sets are, to a large degree, the result of industry nondisclosure agreements and therefore are not generally releasable for public use.

- LANL - National electrical generation and transmission data

- Argonne National Laboratory (ANL) - Natural gas and oil pipeline data

- Oak Ridge National Laboratory (ORNL) National transportation sector information including rail systems, highway, and waterway data and models

- Idaho National Laboratory (INL) - National electrical power SCADA system information. 


\section{U.S. RESEARCH AND SPONSORING ORGANIZATIONS}

The modeling and simulation of infrastructure interdependencies is a substantial effort in terms of development resources such as infrastructure expertise, modeling and simulation, data accessibility, and so on. For this reason, U.S. government agencies are currently doing most of the research in this area. In order to understand the current focus on ongoing research, it is important to understand the thrust of these organizations. A brief description of the more prominent supporting agencies and their programs are described as follows:

- Department of Homeland Security (DHS) - The NISAC provides advanced modeling and simulation capabilities for the analysis of critical infrastructures, their interdependencies, vulnerabilities, and complexities. These capabilities help improve the robustness of our nation's critical infrastructures by aiding decision makers in the areas of policy analysis, investment and mitigation planning, education and training, and near real-time assistance to crisis response organizations. The NISAC program is sponsored by the DHS Information Analysis and Infrastructure Protection Directorate. NISAC is a core partnership of Los Alamos and Sandia National Laboratories. NISAC integrates the modeling and simulation expertise of both laboratories to address the nation's potential vulnerabilities and the consequence of disruption among our critical infrastructures. ${ }^{21}$

- Department of Energy (DOE) - The Visualization and Modeling Working Group (VMWG) sponsored by DOE's Office of Electricity Delivery and Energy Reliability activates in response to national energy emergencies to provide data, analyses, and visualization tools as was done for Hurricanes Katrina and Rita. The VMWG was formed in September 2003 to improve the ability of DOE to perform quick turn-around analyses during energy emergencies. It is comprised of energy experts from several DOE offices and energy infrastructure and modeling experts from various DOE national laboratories. Their technical expertise is combined with modeling, GIS, data libraries on past energy disruptions, and other tools to conduct in-depth analysis. DOE national laboratories provide the bulk of this modeling and analysis. ${ }^{22}$

- $\quad$ Technical Support Working Group (TSWG) TSWG is an inter-agency organization tasked with providing technologies to a variety of government organizations. Their development and product deployment goals focus on identifying and answering specific programmatic needs versus sponsoring national infrastructure modeling and simulation initiatives. This study attempts to identify available and developing resources that may be utilized to address those needs. ${ }^{23}$

- Defense Advanced Research Projects Agency (DARPA) - DARPA is a central research and development organization for DoD. It manages and directs selected basic and applied research and development projects for $\mathrm{DoD}$, and pursues research and technology where risk and payoff are both very high and where success may provide dramatic advances for traditional military roles and missions. DARPA also has a research program in the area of crossdimensional infrastructure influence modeling. By focusing on PMESII dimension interactions, DARPA is leading the Integrated Battle Command. The objective of this program is the development of decision aids to support the commander in conducting a future, complex, multidimensional, coalition, and effects-based campaign. The decision aids will assist the commander and staff in generating, assessing, and visualizing the consequences of employing diplomatic, military, information operations and economic actions, singularly or in combinations, to achieve effects against the adversary's PMESII systems. The decision aids will also assist the commander and staff in constructing, visualizing, and evaluating campaign plans that exploit the impact of multidimensional effects and the interaction among effects. http://www.darpa.mil/ato/solicit/IBC/index.htm.

- Department of the Air Force, Air Force Materiel Command, (AFRL) - Similar to DARPA, AFRL is leading multiple research efforts in developing PMSEII analytical models. One effort is the Commander's Predictive Environment program, whose objective is to provide a decision support environment that 
enables the joint force commander to anticipate and shape the future battlespace. Similar in view to the DARPA effort, the battlespace is seen as a complex and interrelated system of PMESII dimensions. A full understanding of the battlespace requires comprehension of how these interrelated factors affect not only the adversary, but also friendly forces. The focus of this research program is to (1) model and analyze adversaries, self, and neutrals as a complex adaptive system; (2) understand key relationships, dependencies, and vulnerabilities of adversary/self/neutrals; and (3) identify leverage points that represent opportunities to influence capabilities, perceptions, decision making, and behavior. ${ }^{24}$ 


\section{CHALLENGES AND RESEARCH NEEDS}

Critical infrastructure interdependency modeling has many of the same challenges that one can expect with any modeling and simulation domain: data accessibility, model development, and model validation. Interdependency modeling is further complicated by the extremely large and disparate cross sector analysis required. Many extremely detailed single sector models have been developed. One driving research question asks: "How do we leverage these existing models into a common operating picture?" Such a question is further exasperated by the granularity and the time factors associated with the models. For example, Table 1 illustrates the multiple time scales that exist within the electrical power sector.

While currently no standards exists that directly address infrastructure and specifically cross sector modeling, standards do exists for exchanging information between distributed simulations. The two most common methods are the High Level Architecture (HLA) and the Distributed Interactive Simulation (DIS) frameworks.

HLA, developed under the leadership of the Defense Modeling and Simulation Office is a general purpose high-level simulation architecture/framework to facilitate the interoperability of multiple types of models and simulations. The purpose of its development is to support reuse and interoperability across the large numbers of different types of simulations developed and maintained by DoD. Within HLA, simulation objects exist as federates in a larger simulation federation. HLA was approved as an open standard through the Institute of Electrical and Electronic Engineers (IEEE) - IEEE Standard 1516 - in September 2000.
Table 1. Multiscale time hierarchy of power systems. $^{25}$

\begin{tabular}{|l|l|}
\multicolumn{1}{|c|}{ Action/Operation } & \multicolumn{1}{|c|}{ Time frame } \\
\hline Wave effects (fast dynamics, & Microseconds \\
to milliseconds \\
Switching over voltages & Milliseconds \\
Fault protection & 100 \\
milliseconds or \\
Electromagnetic effects in machine \\
windings & $\begin{array}{l}\text { Milliseconds to } \\
\text { seconds }\end{array}$ \\
Stability & 60 cycles or 1 \\
Second \\
Stability augmentation & Seconds \\
Electromechanical effects of & Milliseconds to \\
oscillations in motors \& generators & minutes \\
Tie line load frequency control & 1 to 10 \\
seconds; \\
ongoing \\
Economic load dispatch & 10 seconds to 1 \\
hour; ongoing \\
Seconds to \\
hours \\
Thermodynamic changes from \\
boiler control action (slow \\
dynamics)
\end{tabular}


Table 2 provides a listing of HLA strengths and weaknesses as detailed by Schmitz and Neubecker. ${ }^{26}$ Additional information on HLA can be found by contactinghla@dmso.mil or via the website https://www.dmso.mil/public/transition/hla/.

Table 2. Strengths and weaknesses of HLA.

\begin{tabular}{|c|c|}
\hline HLA Strengths & HLA Weaknesses \\
\hline $\begin{array}{l}\text { HLA is an open standard } \\
\text { that will be supported } \\
\text { beyond } 2006 \text { (ref. IEEE } \\
\text { 1516). }\end{array}$ & $\begin{array}{l}\text { HLA developments may } \\
\text { be subject to significant } \\
\text { changes in order to meet } \\
\text { future needs. }\end{array}$ \\
\hline $\begin{array}{l}\text { The architecture can be } \\
\text { implemented across } \\
\text { different computing } \\
\text { environments. }\end{array}$ & $\begin{array}{l}\text { Changes to future HLA } \\
\text { standards may have } \\
\text { significant impact on } \\
\text { local implementations. }\end{array}$ \\
\hline $\begin{array}{l}\text { Provides a documented } \\
\text { process for developing } \\
\text { distributed simulation } \\
\text { systems, e.g., the } \\
\text { federation development } \\
\text { execution process. }\end{array}$ & $\begin{array}{l}\text { U.S. will continue to } \\
\text { lead HLA development } \\
\text { and thus there may be } \\
\text { dependence on U.S. } \\
\text { support for software } \\
\text { implementations. }\end{array}$ \\
\hline $\begin{array}{l}\text { More "bandwidth" } \\
\text { friendly. } \\
\text { Supports real-time, faster } \\
\text { than real-time, and event- } \\
\text { driven time domains. } \\
\text { Availability of }\end{array}$ & $\begin{array}{l}\text { The resources and time } \\
\text { required to implement an } \\
\text { HLA federation can be } \\
\text { significant — up to } \\
\text { double that required for } \\
\text { noncompliant } \\
\text { implementations. }\end{array}$ \\
\hline $\begin{array}{l}\text { commercial off the shelf } \\
\text { (COTS) software support } \\
\text { tools, e.g., data } \\
\text { capture/replay, simulation } \\
\text { (federation) exercise } \\
\text { management (reduces the }\end{array}$ & $\begin{array}{l}\text { HLA does not ensure } \\
\text { plug-and-play } \\
\text { interoperability, it } \\
\text { facilitates } \\
\text { communication. }\end{array}$ \\
\hline $\begin{array}{l}\text { requirements for bespoke } \\
\text { developments). }\end{array}$ & $\begin{array}{l}\text { HLA compliance cannot } \\
\text { be established in } \\
\text { abstract, but only by } \\
\text { reference to a defined } \\
\text { federation. }\end{array}$ \\
\hline
\end{tabular}

DIS is another framework for linking real-time and potentially distributed simulations. Defined under IEEE Standard 1278, the chief objective of DIS was to create real-time, synthetic, virtual representations of the warfare environment. This environment is created by interconnecting separate, distributed computers/simulators, called component simulator nodes. These nodes typically represent entities on the order of a military unit. DIS has its roots in the DARPA simulation networking program. Table 3 provides an assessment of the strengths and weakens of DIS by the IAPG. Further information on DIS can be found at http://www.sei.cmu.edu/architecture/Architectures for_DIS.html\#291.

Table 3. Strengths and weaknesses of DIS.

\begin{tabular}{|c|c|}
\hline DIS S & DIS We \\
\hline $\begin{array}{l}\text { DIS is an open standard } \\
\text { (ref: IEEE 1278.x). } \\
\text { The architecture can be } \\
\text { implemented across } \\
\text { different computing } \\
\text { environments. } \\
\text { Provides a set of well } \\
\text { defined data protocols to } \\
\text { support the interaction of } \\
\text { real-time simulation } \\
\text { systems. } \\
\text { Availability of COTS } \\
\text { software support tools } \\
\text { (e.g., DIS Stealth } \\
\text { Viewers, DIS Data } \\
\text { Loggers) reduces the } \\
\text { requirements for bespoke } \\
\text { developments. } \\
\text { DIS is a stable "product." }\end{array}$ & $\begin{array}{l}\text { scale up to very large } \\
\text { exercises, e.g., }>500 \\
\text { simulation entities. } \\
\text { Efficiency - rigid } \\
\text { structure of data } \\
\text { protocols (PDUs) leads } \\
\text { to inefficiency of } \\
\text { network resources, e.g., } \\
\text { wide area network } \\
\text { (WAN) bandwidth. } \\
\text { IEEE standards will not } \\
\text { be developed to meet } \\
\text { future simulation } \\
\text { requirements. } \\
\text { DIS only supports real- } \\
\text { time simulations, it does } \\
\text { not support event driven, } \\
\text { faster than real-time } \\
\text { applications. } \\
\text { Limited number of } \\
\text { PDUs. }\end{array}$ \\
\hline
\end{tabular}

HLA and DIS are examples of frameworks that integrate "real-time" simulation models. Information is passed actively between models and timing between models is synchronized. This method may support some aspects of infrastructure model integration. The issue may arise however when the computational time for processing a model makes this type of integration unrealistic, i.e., the computational requirements greatly exceed real-time.

One potential method to address this issue and also to provide a more rapid response capability is to develop scenario libraries consisting of preprocessed scenarios with run profiles available for immediate access. Los Alamos National Laboratory utilizes this approach with their Scenario Library Visualizer.

Another method of model integration consists of devising a common architecture to distribute 
information between models. This method is currently used by Los Alamos National Laboratory and NISAC to relate impacts across different infrastructure models. In a broad sense, a damage profile based on expected physical damage is constructed first. An example of this is determining power outages based on projected high wind profiles, surge, and flooding models associated with hurricanes. The physical impact of the event is transformed into impact on the power grid in terms of outage areas. This information is then passed to other models (water, financial, transportation, etc.) such that the corresponding impact in the electrical power sector integrates into other sectors. In this way, impact cascades across infrastructure boundaries and presents potential effects via infrastructure interdependencies. This type of model integration works well when the timing between infrastructures precludes a true federation of simulations.

Interdependency discovery and validation is another challenging area of research. Although physical interdependencies can be derived by subject matter experts, doing so on a large scale is a resource challenge. Discovery methods and tools, including automated mapping, are essential for highfidelity models. Fast Analysis Infrastructure Tool (FAIT) by Sandia National Laboratory conducts rough first order interdependency mapping based on simple rule sets. The IEISS model and Los Alamos National Laboratory suite of models use outage areas to identify geospatial and gross order dependencies. The Critical Infrastructure Modeling System (CIMS) developed by Idaho National Laboratory likewise supports geospatial dependencies, but requires manual direct association for other dependencies.

Identifying and mapping societal interdependencies is perhaps the most challenging aspect in terms of discovery, mapping, and validation. Identifying a multicultural response and the duration of impacts on a society is challenging. The impact of "like" events can be speculated, but drawing inferences to unforeseen and rare events relative to the other infrastructure sectors is a challenging area of active research. This is one of the main focuses of PMESII research that is underway. 


\section{CONCLUSIONS}

Infrastructure interdependency modeling is a relatively new area of research and analysis, but recent events of both natural disasters and malicious acts have shown that the impact of these cross infrastructure relationships can be measured. Significant research efforts are underway in the U.S. and abroad.

One observation resulting from this effort is that no cross program working group or forum is specifically dedicated to this critical area of research. Most research exchange occurs within specific programs. Consequently, a limited exchange of ideas has occurred across the sponsoring agencies in this area. The strongest collaboration exists between DHS and DOE, mainly due to the fact that the same research teams are sponsored by both organizations. One suggestion from our study is the development, whether formally or informally, of a national or international working group with a central focus of infrastructure interdependency analysis. It is hoped that this state-of-the-art report will serve to not only report on current activities, but will also act as a catalysts for information exchange for such activities. 


\section{ACKNOWLEDGEMENT}

We appreciate the many contributors to this report. Our preferred method has been to directly interact with the project leaders in collecting this information. All that have participated have been extremely supportive. Again, this is an ongoing project and we apologize to those efforts which were not recognized in this first report.
Please forward comments on material contained within this document and also points of contacts for those efforts not covered in this initial document to Donald.Dudenhoeffer@inl.gov.

Finally, we would like to express our gratitude to Dr. Steve Fernandez of Los Alamos Laboratory who acted as a constant guide and source of data for this report. 
Appendix A 
Table Abbreviations:

\begin{tabular}{ll}
\multicolumn{2}{l}{ Infrastructure Sectors } \\
EP & Electric Power \\
NG & Natural Gas \\
DW & Drinking Water \\
SW & Sewage Water \\
ST & Storm Water \\
HA & Human Activity \\
FN & Financial Networks \\
SCADA & Supervisory Control and Data Acquisition \\
TC & Telecom \\
CN & Computer Networks \\
OL & Oil Pipeline \\
RL & Rail System \\
HW & Highway System \\
WW & Waterway System \\
POL & Policy/Regulatory constraints \\
\hline
\end{tabular}

\section{Simulation Type}

I Input-Output Model

A Agent-based

\section{Intended Users Types}

IA Internal Analyst

EA External Analyst

B Both

\section{Maturity Level}

RS Research

DV Development

MI Mature Internal

MC Mature Commercial 


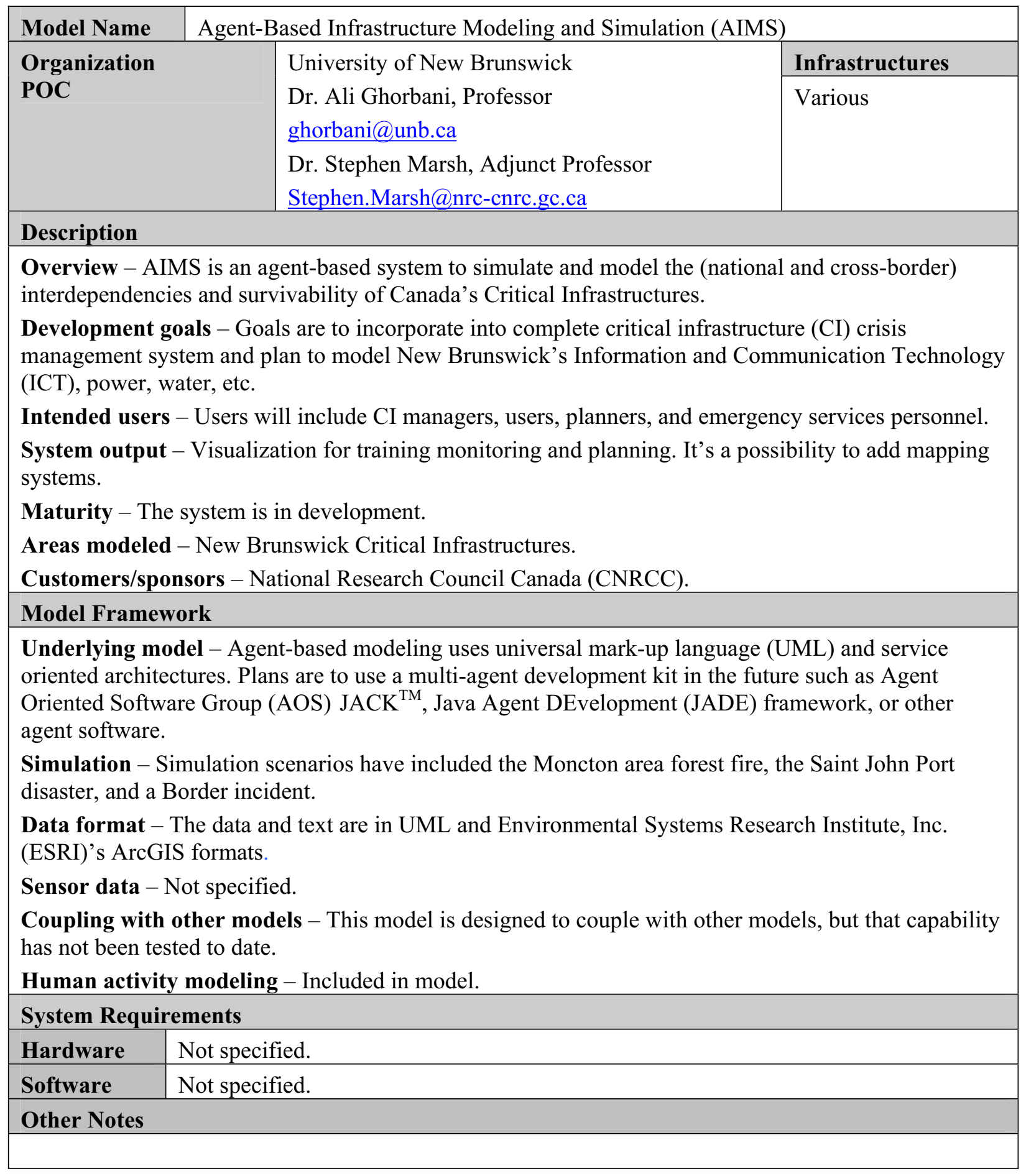

\section{References}

Stephen Marsh, Critical Infrastructure Interdependencies, http://iit-iti.nrc-cnrc.gc.ca/colloq/0405/0411-04 e.html, November 4, 2004, Webpage visited July 10, 2006. 


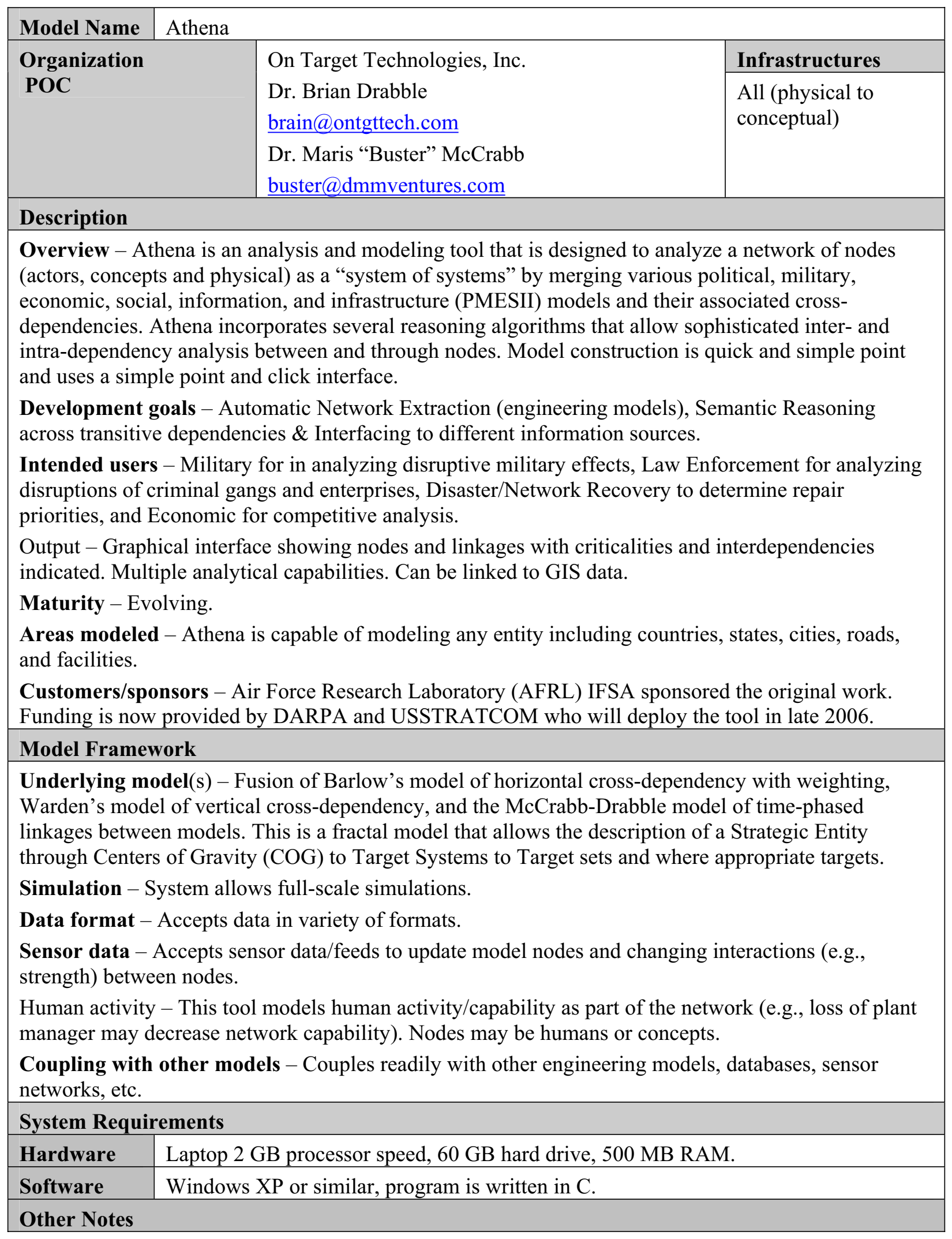



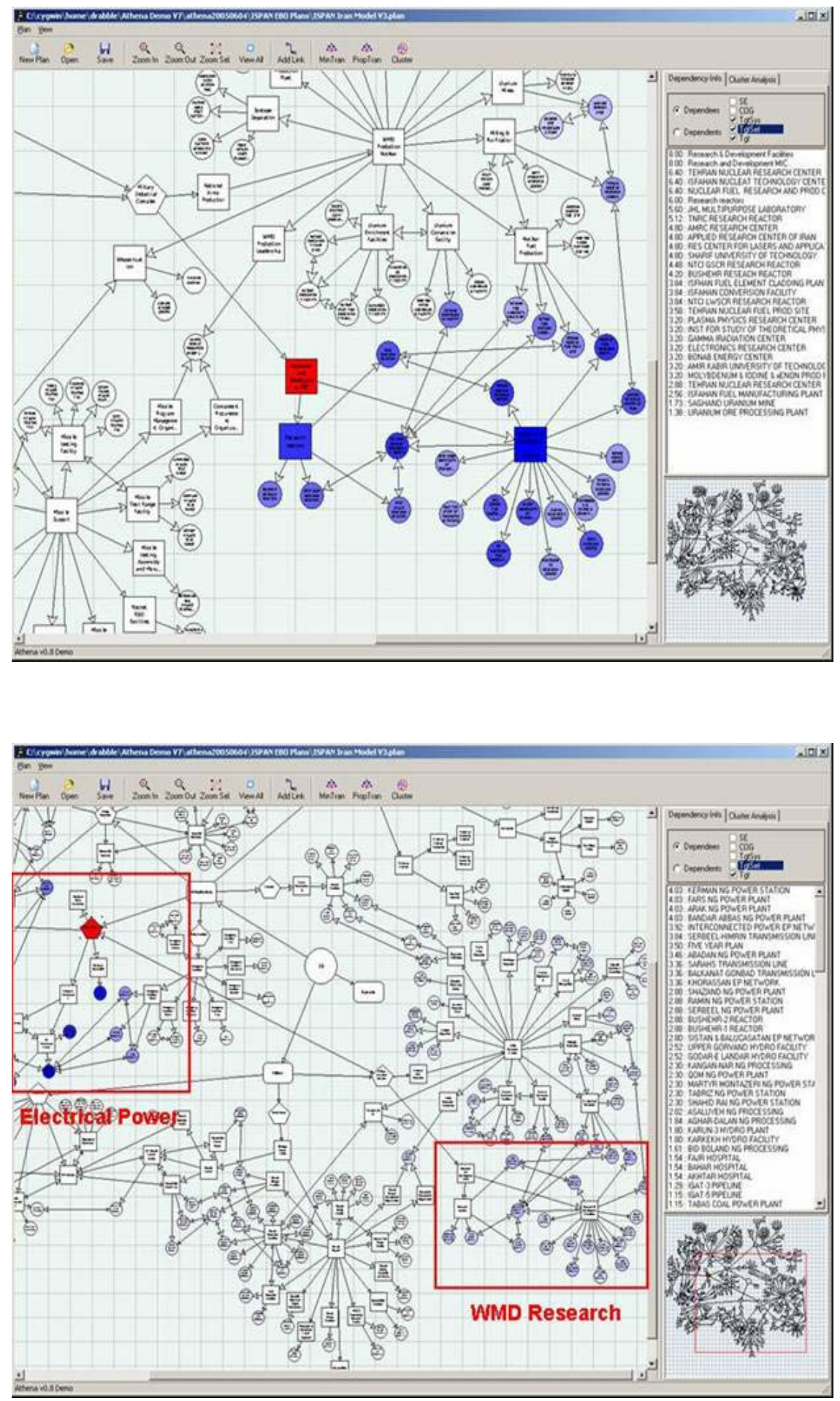

\section{References}

Athena: Effects-based Cross-Dependency Modeling for Target Systems Analysis Final Report. (Limited distribution) Final Athena Demonstration (Microsoft PowerPoint presentation). 


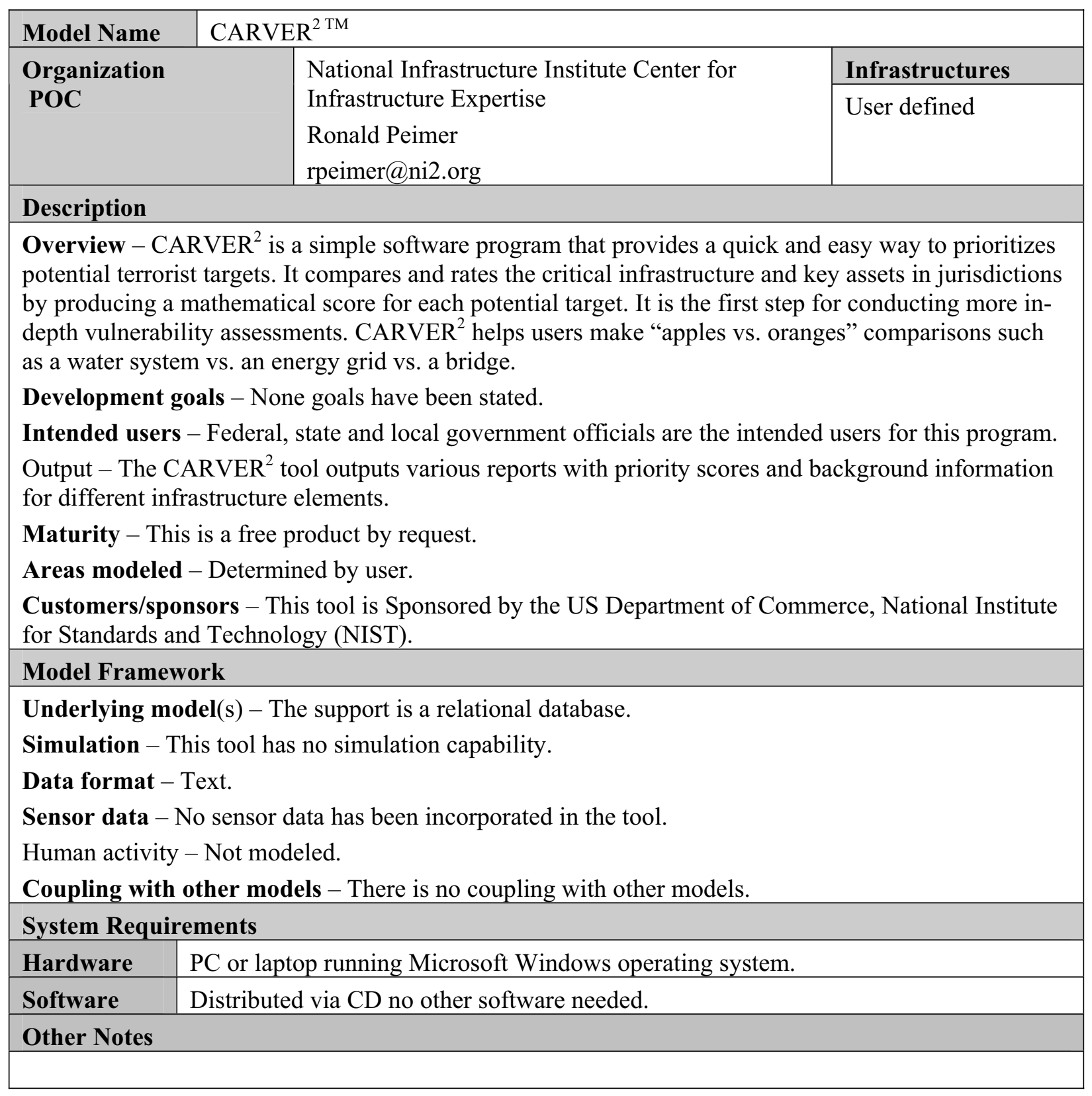




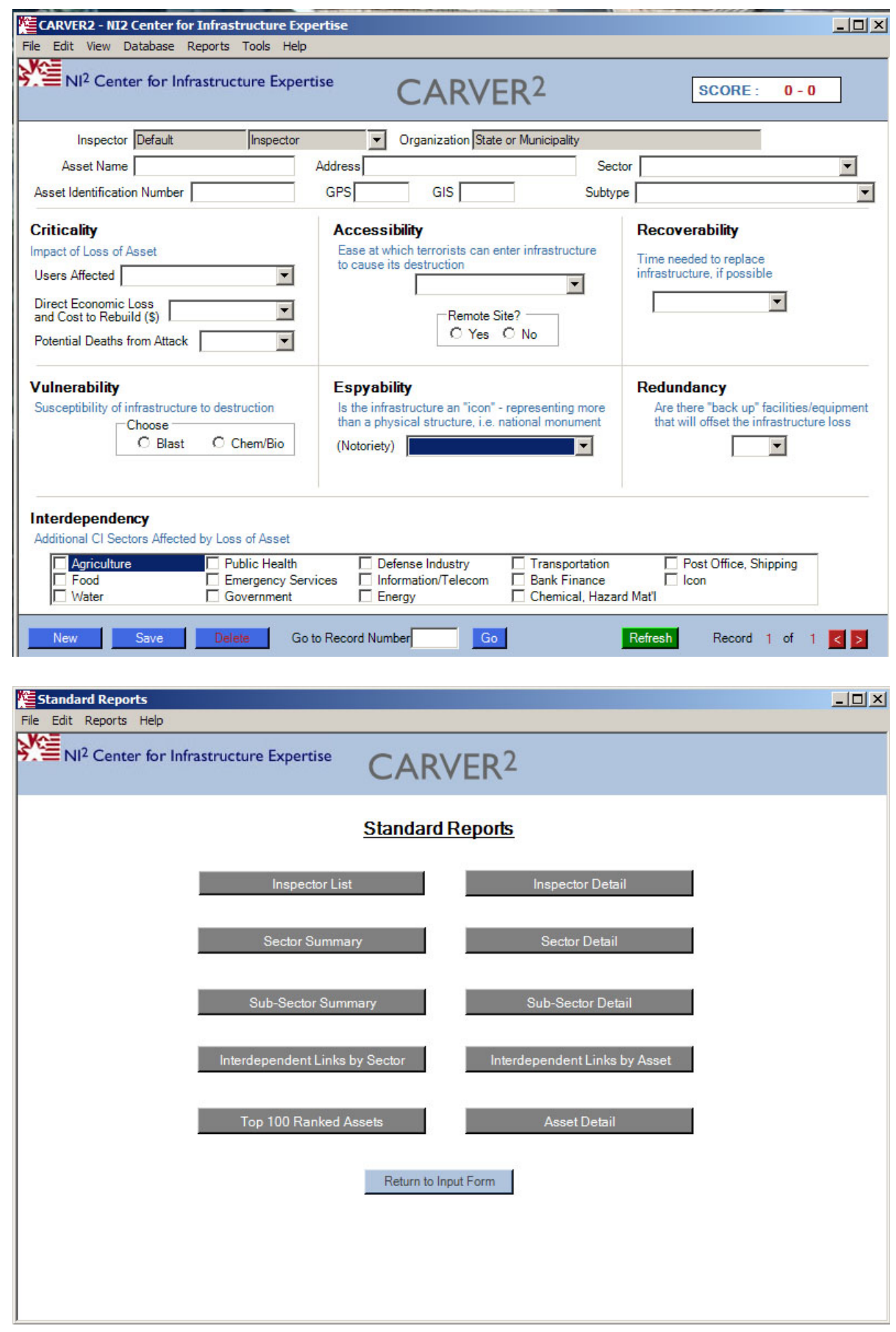

\section{References}

NI2 Center for Infrastructure Expertise Critical Infrastructure Library, http://www.ni2ciel.org/,Webpage visited July 3, 2006.

National Infrastructure Institute home page, http://www.ni2.org/default.asp, Webpage visited July 3, 2006

CARVER2 Project Page, http://www.ni2cie.org/CARVER2.asp, Webpage visited July 3, 2006. 


\begin{tabular}{|c|c|c|}
\hline Model Name & \multicolumn{2}{|l|}{ COMM-ASPEN } \\
\hline \multirow{2}{*}{$\begin{array}{l}\text { Organization } \\
\text { POC }\end{array}$} & \multirow[t]{2}{*}{ Sandia National Laboratory } & Infrastructures \\
\hline & & $\mathrm{FN}$, \\
\hline \multicolumn{3}{|l|}{ Description } \\
\hline \multicolumn{3}{|c|}{$\begin{array}{l}\text { Overview - CommAspen is a new agent-based model for simulating the interdependent effects of } \\
\text { market decisions and disruptions in the telecommunications infrastructure on other critical } \\
\text { infrastructures in the U.S. economy such as banking and finance, and electric power. CommAspen } \\
\text { extends and modifies the capabilities of Aspen-EE, an agent-based model previously developed by } \\
\text { Sandia National Laboratories to analyze the interdependencies between the electric power system and } \\
\text { other critical infrastructures. CommAspen has been tested on a series of scenarios in which the } \\
\text { communications network has been disrupted, due to congestion and outages. Analysis of the scenario } \\
\text { results indicates that communications networks simulated by the model behave as their counterparts do } \\
\text { in the real world. Results also show that the model could be used to analyze the economic impact of } \\
\text { communications congestion and outages. }\end{array}$} \\
\hline \multicolumn{3}{|c|}{$\begin{array}{l}\text { Development goals - To analyze interdependent infrastructure systems in a more holistic way, Sandia } \\
\text { and other research institutions have developed models of critical infrastructure systems using agent- } \\
\text { based approaches. Sandia's first agent-based model of the U.S. economy, developed in the mid-1990s, } \\
\text { is called Aspen. This model is a Monte Carlo simulation that uses agents to represent various decision- } \\
\text { making segments in the economy, such as banks, households, industries, and the Federal Reserve. An } \\
\text { agent is a computational entity that receives information and acts on its environment in an autonomous } \\
\text { way; that is, an agent's behavior depends at least partially on its own experience. Through the use of } \\
\text { evolutionary learning techniques, Aspen allows us to examine the interactive behavior of these agents } \\
\text { as they make real-life decisions in an environment where agents communicate with each other and } \\
\text { adapt their behaviors to changing economic conditions, all the while learning from their past } \\
\text { experience. In 2000, Sandia developed a new model of infrastructure interdependency called Aspen- } \\
\text { EE. This model extended the capabilities of Aspen to include the impact of market structures and } \\
\text { power outages in the electric power system, a critical infrastructure, on other infrastructures in the } \\
\text { economy. }\end{array}$} \\
\hline \multicolumn{3}{|c|}{$\begin{array}{l}\text { One of the limitations of agent-based models in current development at Sandia and other research } \\
\text { institutions is that communication is treated simply as a message passing between agents. Effectively, } \\
\text { the telecommunications infrastructure is not specifically represented. None of the models simulates the } \\
\text { differences in communication over telephone, computer, wireless, or other networks and therefore } \\
\text { cannot model the impact of specific communication failures on the whole system. Nor can current } \\
\text { models simulate the impact of other infrastructure failures on telecommunications. }\end{array}$} \\
\hline \multicolumn{3}{|c|}{$\begin{array}{l}\text { To address the communications deficiencies described above, Sandia revised and restructured the } \\
\text { Aspen-EE model to include a more realistic representation of the telecommunications infrastructure. } \\
\text { This new model of infrastructure interdependency is called CommAspen. In CommAspen, } \\
\text { communication is treated as an integrated agent system capable of creating, transforming, sending, } \\
\text { receiving, and storing information and messages over time and across distance. With CommAspen, we } \\
\text { can model communication networks or medium-specific vulnerabilities to failures and their } \\
\text { dependence on supporting infrastructures like power. }\end{array}$} \\
\hline \multicolumn{3}{|c|}{ Intended users - Internal analyst. } \\
\hline \multicolumn{3}{|c|}{ System output - Not specified. } \\
\hline \multicolumn{3}{|c|}{ Maturity - Development. } \\
\hline \multicolumn{3}{|c|}{ Areas modeled - Not specified. } \\
\hline \multicolumn{3}{|c|}{ Customers/sponsors - Not specified. } \\
\hline
\end{tabular}




\section{Model Framework}

Underlying model - There are several ways that we can implement the notion of infrastructures in CommAspen. One method of representing certain types of infrastructures in CommAspen is through the use of spigots and sinks. Such infrastructures are for commodities that run continuously, like water from a municipality and electricity from a local utility. A sink is where a producer puts product into an infrastructure. For example, a power company may have a natural gas-fired electric generating plant producing power. It would put power on the transmission lines by passing the power into the associated sink. A spigot is where a consumer gets the product, such as turning on the lights in a residence or getting water from a faucet.

Simulation - Agent Based Model.

Data format - Not specified.

Sensor data - None.

Coupling with other models - No.

Human activity modeling - Not Known.

\section{System Requirements}

\begin{tabular}{|l|l|}
\hline Hardware & Not specified. \\
\hline Software & Not specified. \\
\hline
\end{tabular}

Other Notes

Images: None.

\section{References}

Barton, Dianne C., Eric D. Edison, David A. Schoenwald, Roger G. Cox, and Rhonda K.

Reinert, "Simulating Economic Effects of Disruptions in the Telecommunications Infrastructure", SAND REPORT, SAND2004-0101, Printed January 2004. 


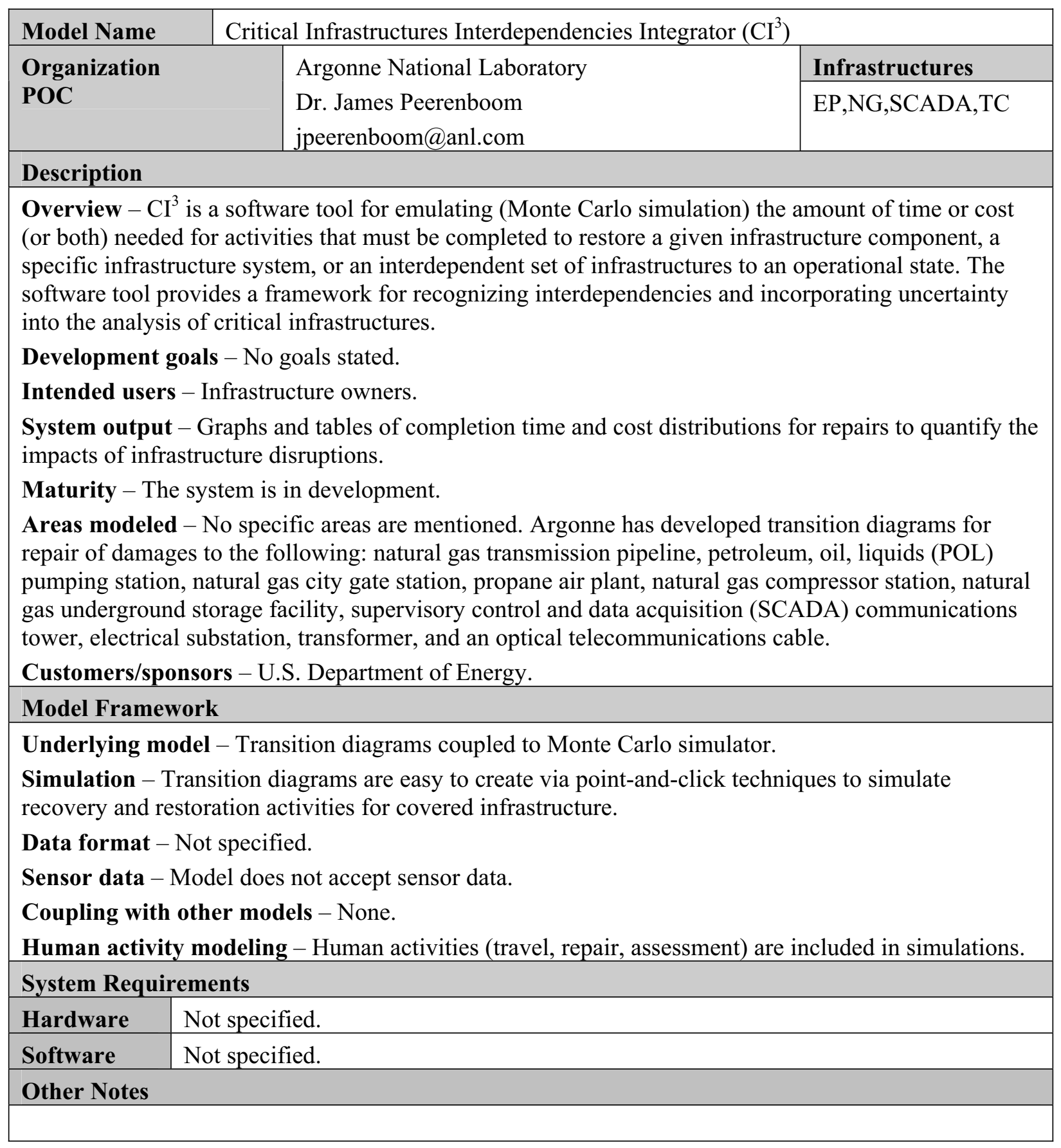




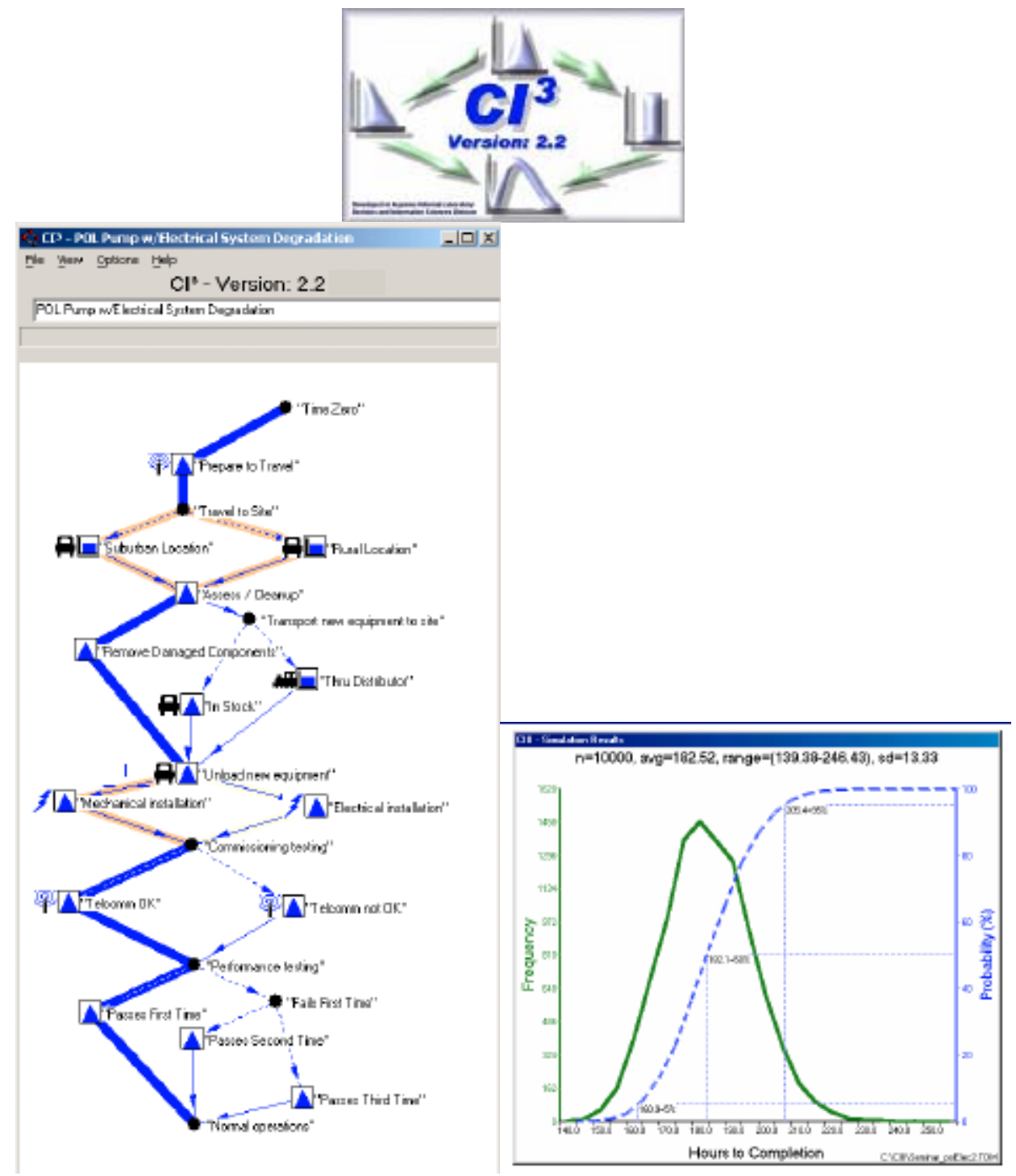

References 


\begin{tabular}{|c|c|c|}
\hline Model Name & \multicolumn{2}{|l|}{ Critical Infrastructure Modeling System $\left(\mathrm{CIMS}^{\odot}\right)$} \\
\hline \multirow{2}{*}{$\begin{array}{l}\text { Organization } \\
\text { POC }\end{array}$} & Idaho National Laboratory (INL) & Infrastructures \\
\hline & $\begin{array}{l}\text { Donald Dudenhoeffer } \\
\text { Donald.Dudenhoeffer@inl.gov }\end{array}$ & $\begin{array}{l}\text { EP, SCADA, HW, } \\
\text { HA, POL, PMESII }\end{array}$ \\
\hline \multicolumn{3}{|l|}{ Description } \\
\hline \multicolumn{3}{|c|}{$\begin{array}{l}\text { Overview - A modeling and simulation framework that combines geospatial information and a four } \\
\text { dimensional (4D) environment (time-based) to support 'what if' analysis. }\end{array}$} \\
\hline \multicolumn{3}{|c|}{$\begin{array}{l}\text { Development goals - Provide decision makers with a highly adaptable and easily constructed } \\
\text { 'wargaming' tool to assess infrastructure vulnerabilities including policy and response plans. Operating } \\
\text { at a high level of simulation, it supports rapid 'point and click' model development to allow the } \\
\text { adaptation of models to rapidly changing environments. }\end{array}$} \\
\hline \multicolumn{3}{|c|}{ Intended users - Emergency planners and responders. } \\
\hline \multicolumn{3}{|c|}{$\begin{array}{l}\text { System output - Four dimensional geospatial visualization in a VTK framework along with report } \\
\text { generation. }\end{array}$} \\
\hline \multicolumn{3}{|c|}{ Maturity - Development - in the process of commercial licensing. } \\
\hline \multicolumn{3}{|c|}{ Areas modeled - Idaho National Laboratory, New Orleans Louisiana. } \\
\hline \multicolumn{3}{|c|}{$\begin{array}{l}\text { Customers/sponsors - Research has been ongoing for the past } 4 \text { years under the INL National } \\
\text { Security Divisions. Sponsors have included the INL's internal research program, the Department of } \\
\text { Energy, the U.S. Air Force Research Laboratory (AFRL), and negotiations are underway with the State } \\
\text { of Louisiana. }\end{array}$} \\
\hline \multicolumn{3}{|c|}{ Model Framework } \\
\hline \multicolumn{3}{|c|}{$\begin{array}{l}\text { Underlying model - The underlying model is a network representation of infrastructure utilizing } \\
\text { nodes and edges for assets and relationships. Graphical objects such as aerial images, 3DS images, or } \\
\text { VRML models can be tied to the assets. Additionally, information can be embedded within nodes such } \\
\text { as documents, web site hyperlinks, web cams, avis, etc }\end{array}$} \\
\hline \multicolumn{3}{|c|}{ Simulation - Agent-based discrete event simulation. } \\
\hline \multicolumn{3}{|c|}{$\begin{array}{l}\text { Data format - Flat files are used as direct feeds to the simulations. These files can be fed by a } \\
\text { multitude of different databases including Access, GIS, etc }\end{array}$} \\
\hline \multicolumn{3}{|c|}{$\begin{array}{l}\text { Sensor data - Agent objects(nodes) can have autonomous behaviors or they can be fed by external } \\
\text { sensor input. }\end{array}$} \\
\hline \multicolumn{3}{|c|}{ Coupling with other models - Yes. } \\
\hline \multicolumn{3}{|c|}{$\begin{array}{l}\text { Human activity modeling - Human activity can be modeled directly or as the result of } \\
\text { policy/procedure enactment. }\end{array}$} \\
\hline \multicolumn{3}{|c|}{ System Requirements } \\
\hline Hardware & $\begin{array}{l}\text { Cross platform compatibility - Windows, Ul } \\
\text { connectivity required to access embedded lir }\end{array}$ & aris. Internet \\
\hline Software & No external software to CIMS $\sim$ requires $<5$ & \\
\hline
\end{tabular}




\section{Other Notes}

The objective of CIMS was to create a rapid modeling and analysis capability that did not require extensive data collection or proprietary GIS software. As such, CIMS allows the ability to create models and infrastructure simulations on the fly embedding new intelligence as it becomes available. Model development can start with an aerial image or a scanned/sketched chart/map image. All information is georeferenced.

Models construction can occur via one of three methods.

- Direct manipulation of the network descriptor flat files

- Conversion from a database to the flat file format

- Point and click network construction via the Model Builder Application.

User interactivity with the Model. The models were developed with a wargaming approach to allow maximum user interaction with the simulation. Thus the user has several different ways to interact with the data:

- An event script can be created to initiate specific events at a designated time

- The user can select and directly manipulate the state of individual nodes and edges, i.e., shutting down an electrical substation or making a bridge impassible

- The user can inject events during runtime, i.e., placing and detonating a bomb to observe cascading impacts. 

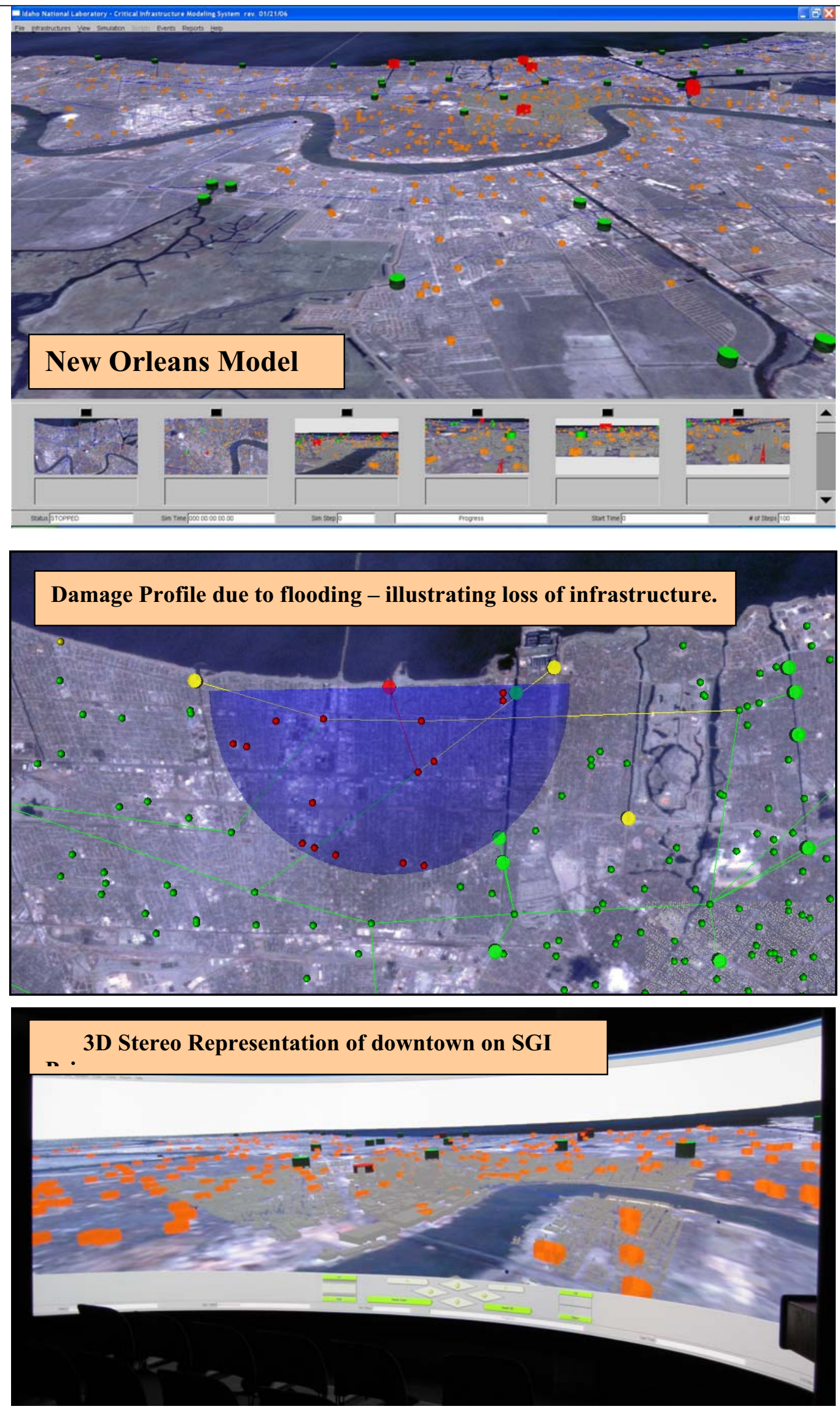

Images 

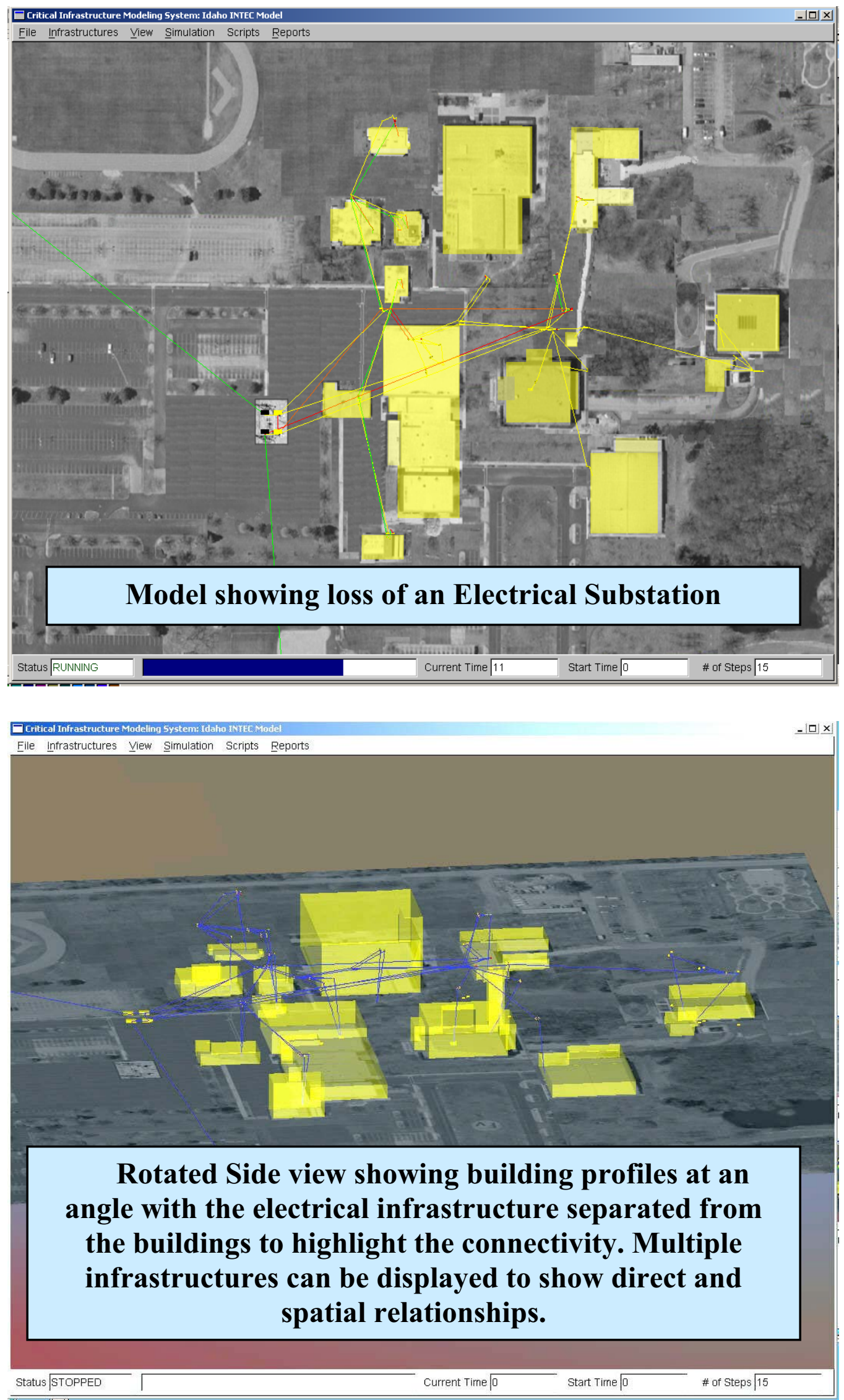


\section{References}

Dudenhoeffer, D.D, M. R. Permann, and M. Manic, "CIMS: A Framework For Infrastructure Interdependency Modeling And Analysis." Submitted to Proceedings of the 2006 Winter Simulation Conference, ed L. F. Perrone, F. P. Wieland, J. Liu, B. G. Lawson, D. M. Nicol, and R. M. Fujimoto. Piscataway, New Jersey: Institute of Electrical and Electronics Engineers, 2006.

Dudenhoeffer, D. D., M. R. Permann, and R. L. Boring, 2006. Decision consequence in complex environments: Visualizing decision impact. In Proceeding of Sharing Solutions for Emergencies and Hazardous Environments. American Nuclear Society Joint Topical Meeting: 9th Emergency Preparedness and Response/11th Robotics and Remote Systems for Hazardous Environments.

Dudenhoeffer, D. D., M. R. Permann, and E.M. Sussman. 2002. A Parallel Simulation Framework For Infrastructure Modeling And Analysis. In Proceedings of the 2002 Winter Simulation Conference, ed E. Yücesan, C. H. Chen, J. L. Snowdon, and J. M. Charnes, 1971-1977. Piscataway, New Jersey: Institute of Electrical and Electronics Engineers.

Critical Infrastructure Modeling System Fact Sheet $<$ http://www.inl.gov/nationalsecurity/factsheets/docs/cims.pdf $>$ 


\begin{tabular}{|c|c|c|}
\hline Model Name & \multicolumn{2}{|c|}{ The Critical Infrastructure Protection Decision Support System (CIP/DSS) } \\
\hline \multirow{2}{*}{$\begin{array}{l}\text { Organization } \\
\text { POC }\end{array}$} & Los Alamos National Laboratory & Infrastructures \\
\hline & $\begin{array}{l}\text { Randy Michelsen } \\
\text { rem@lanl.gov } \\
\text { Sandia National Laboratories } \\
\text { Theresa Brown } \\
\text { tjbrown@sandia.gov }\end{array}$ & ALL \\
\hline \multicolumn{3}{|l|}{ Description } \\
\hline \multirow{3}{*}{\multicolumn{3}{|c|}{$\begin{array}{l}\text { Overview - The Critical Infrastructure Protection Decision Support System (CIP/DSS) } \\
\text { simulates the dynamics of individual infrastructures and couples separate infrastructures to } \\
\text { each other according to their interdependencies. For example, repairing damage to the electric } \\
\text { power grid in a city requires transportation to failure sites and delivery of parts, fuel for repair } \\
\text { vehicles telecommunications for problem diagnosis and coordination of repairs, and the } \\
\text { availability of labor crews. The repair itself involves diagnosis, ordering parts, dispatching } \\
\text { crews, and performing work. The electric power grid responds to the initial damage and to the } \\
\text { completion of repairs with changes in its operating characteristics. Dynamic processes like } \\
\text { these are represented in the CIP/DSS infrastructure sector simulations by differential } \\
\text { equations, discrete events, and codified rules of operation. Many of these variables are output } \\
\text { metrics estimating the human health, economic, or environmental effects of disturbances to the } \\
\text { infrastructures. } \\
\text { CIP/DSS will assist decision makers in making informed choices by: } \\
\text { - Functionally representing all } 14 \text { critical infrastructures with their interdependencies } \\
\text { - Computing human health and safety, economic, public confidence, national security, and } \\
\text { environmental impacts } \\
\text { Synthesizing a methodology that is technically sound, defensible, and extendable. } \\
\text { Development goals - Charter is to model all infrastructures and key assets. Used for quick response on } \\
\text { areas Los Alamos National Laboratory (LANL) doesn't have data for. } \\
\text { Intended users - Internal analyst at LANI }\end{array}$}} \\
\hline & & \\
\hline & & \\
\hline \multicolumn{3}{|c|}{$\begin{array}{l}\text { System output - Graphs representing the impact on multiple state variables such as hospital beds } \\
\text { occupied, etc. }\end{array}$} \\
\hline \multicolumn{3}{|c|}{$\begin{array}{l}\text { Maturity - Development - Initiated as a proof-of-concept in August 2003. Completed a } \\
\text { prototype model and two case studies in February } 2004 \text {. }\end{array}$} \\
\hline $\begin{array}{l}\text { Areas modelec } \\
\text { Customers/spc }\end{array}$ & Areas modeled - Not specified. & \\
\hline \multicolumn{3}{|c|}{ Model Framework } \\
\hline \multicolumn{3}{|c|}{$\begin{array}{l}\text { Underlying model - The national and metropolitan consequence models are implemented using } \\
\text { Vensim, which reads input parameters from and writes output time series to an Oracle relational } \\
\text { database of "consequence" metrics, which are abstracted into a much smaller set of "decision" metrics. } \\
\text { The decision support software (written in Visual Basic) accesses the decision database to compute } \\
\text { utility values for various scenarios and alternatives. }\end{array}$} \\
\hline \multicolumn{3}{|c|}{$\begin{array}{l}\text { Simulation - Vensim is used for developing, analy } \\
\text { models. Models are constructed graphically or in a } \\
\text { subscripting (arrays), Monte Carlo sensitivity analy } \\
\text { interfaces. } \\
\text { Data format - Vensim Model. } \\
\text { Sensor data - No ability to input live data feeds. }\end{array}$} \\
\hline
\end{tabular}




\section{Coupling with other models - No.}

Human activity modeling - Human activity can be modeled directly or as the result of policy/procedure enactment.

\section{System Requirements}

Hardware $\quad$ The Vensim family of software runs on Windows (95/98/Millennium/NT/2000/XP) and the Power Macintosh running System 7 or higher (in Classic mode under OSX). Vensim requires $8 \mathrm{MB}$ of memory and $8 \mathrm{MB}$ of disk space for a full installation. A demonstration version of Vensim is available free for either Windows or Macintosh.

\section{Software}

CIPDSS is a model built within Vensim simulation software by Ventura (http://www.vensim.com/brochure.html).

\section{Other Notes}

CIP/DSS (Critical Infrastructure Protection Decision Support System) simulates the dynamics of individual infrastructures and couples separate infrastructures to each other according to their interdependencies. CIP/DSS models asset information at the aggregate level. For example with a focus area, it can estimate the number of hospital beds affected by an event, but it cannot directly retrieve information relative to a particular hospital. It utilizes the commercial simulation software Vensim.

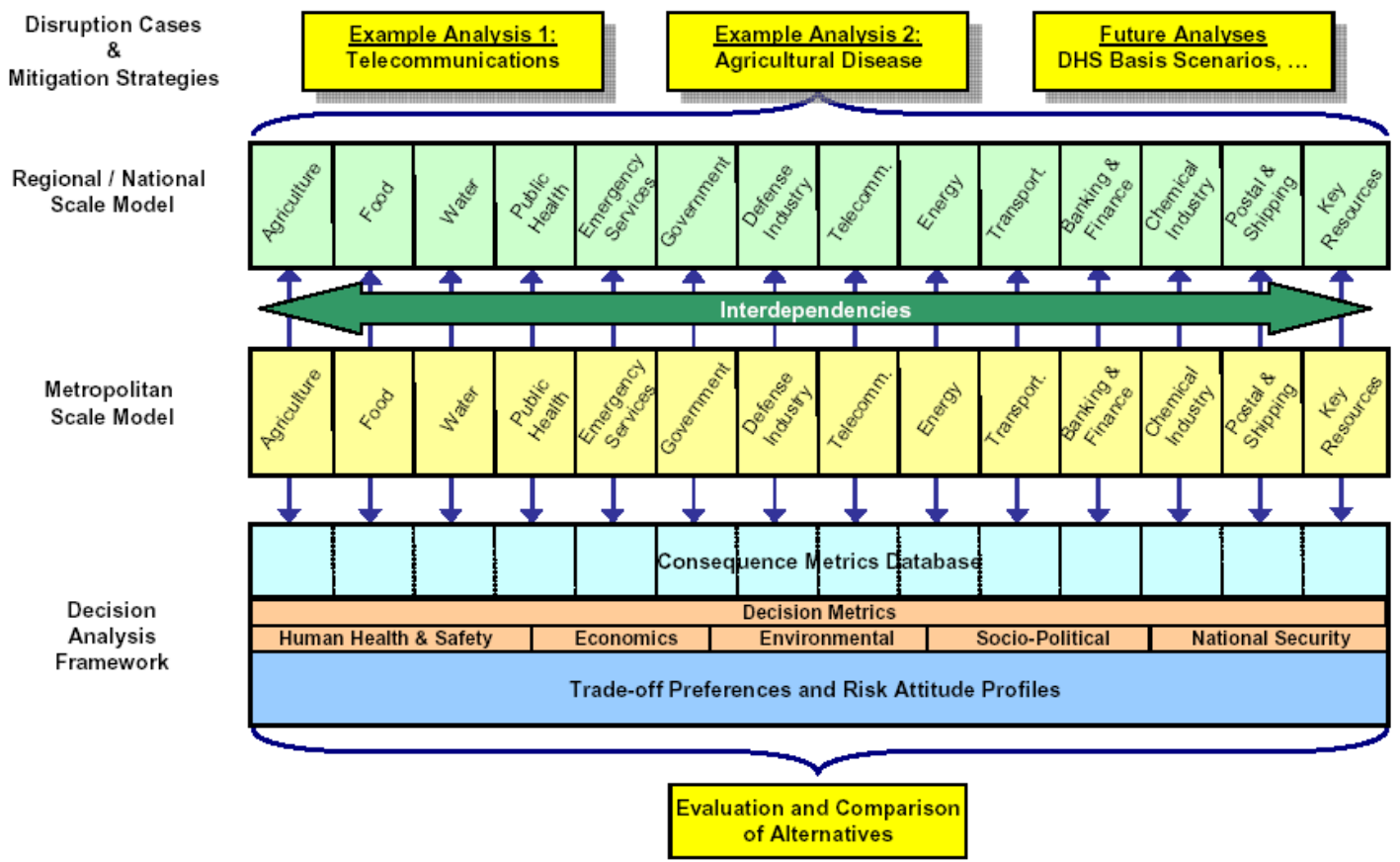




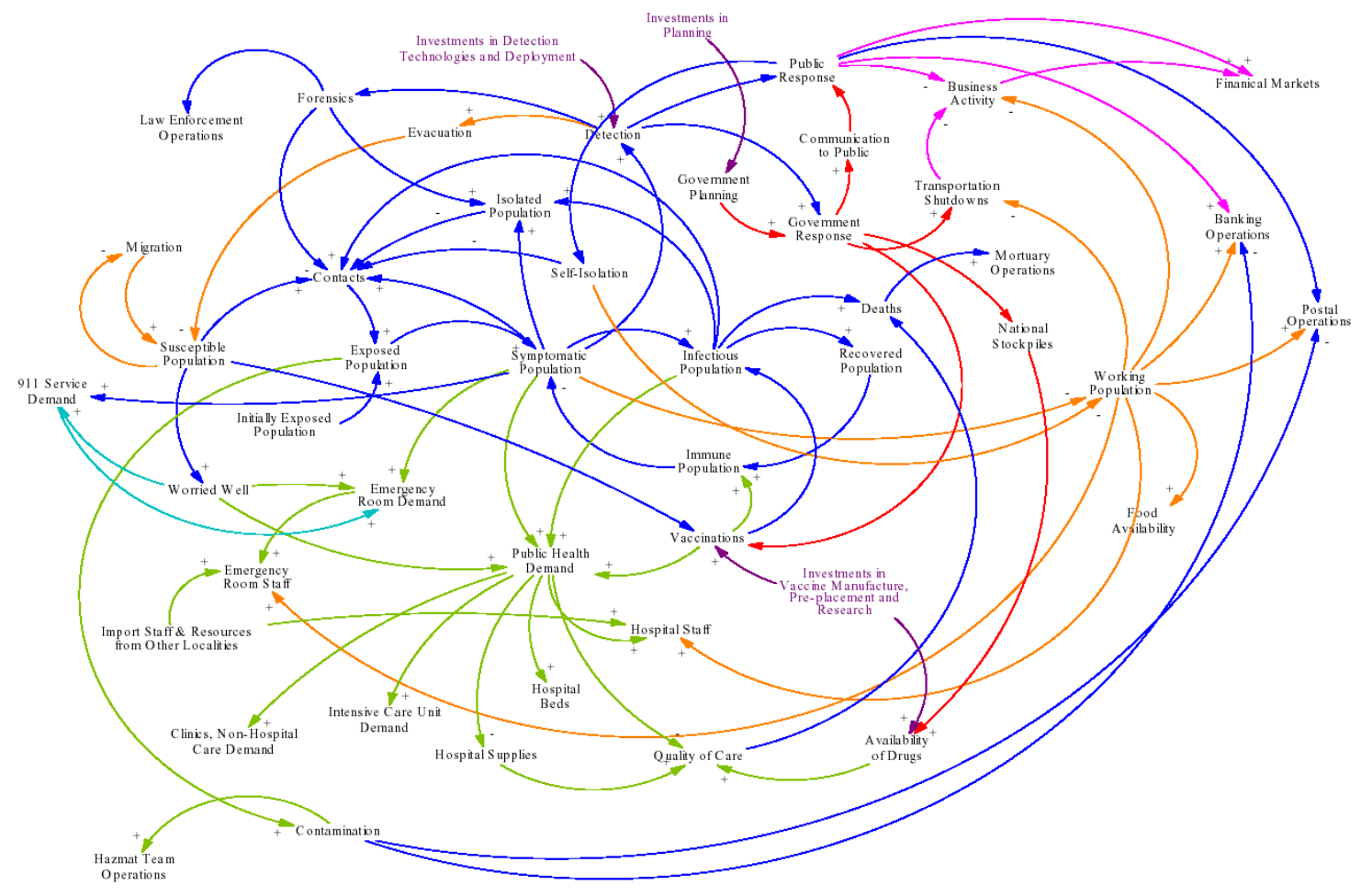

References

Bush B, L. Dauelsberg, R. LeClaire, D. Powell (LANL), S. DeLand (SNL), and M. Samsa (ANL), Critical Infrastructure Protection Decision Support System (CIP/DSS) Project Overview, LA-UR-051870 , July 2005. 


\begin{tabular}{|c|c|c|}
\hline Model Name & \multicolumn{2}{|c|}{ Critical Infrastructure Protection (CIP) Modeling and Analysis (CIPMA) Program } \\
\hline \multirow{2}{*}{$\begin{array}{l}\text { Organization } \\
\text { POC }\end{array}$} & & Infrastructures \\
\hline & $\begin{array}{l}\text { Department (AGL } \\
\text { Michael Jerks - D } \\
\text { Michael.Jerks@a }\end{array}$ & OL \\
\hline \multicolumn{3}{|l|}{ Description } \\
\hline \multicolumn{3}{|c|}{$\begin{array}{l}\text { Overview - The Critical Infrastructure Protection Modeling and Analysis program (CIPMA) is a } \\
\text { computer based tool to support business and government decision making for critical infrastructure } \\
\text { (CI) protection, counter-terrorism and emergency management, especially with regard to prevention, } \\
\text { preparedness, and planning and recovery. CIPMA is designed to examine the relationships and } \\
\text { dependencies within and between critical infrastructure systems, and to demonstrate how a failure in } \\
\text { one sector can greatly affect the operations of critical infrastructure in other sectors. CIPMA uses a vas } \\
\text { array of data and information from a range of sources to model and simulate the behavior and } \\
\text { dependency relationships of critical infrastructure systems. The capability will include a series of } \\
\text { impact models to analyze the effects of a disruption to CI services. The CIPMA Program currently } \\
\text { focuses on three priority sectors: banking and finance, communications, and energy. The capability was } \\
\text { launched by the Attorney-General in February 2006. "Proof of concept" of the capability was } \\
\text { successfully demonstrated to key business and government stakeholders in May 2006. Although } \\
\text { CIPMA is still in development, results from the capability are already assisting the development and } \\
\text { direction of government policy in national security and critical infrastructure protection (CIP), and } \\
\text { helping owners and operators to better protect their critical infrastructure. }\end{array}$} \\
\hline \multicolumn{3}{|c|}{$\begin{array}{l}\text { Development goals - The current focus is on broadening and deepening CIPMA coverage of the three } \\
\text { priority sectors, the Sydney commercial business district (CBD) precinct, and development of impact } \\
\text { models for the Decision Support Module. The impact models will assess the flow-on consequences of a } \\
\text { CI service disruption, the economic impacts of the disruption, the effects on population, time/duration } \\
\text { and area of the disruption, and the behavior of networks and clusters of infrastructure as a result of the } \\
\text { service interruption. Work on a fourth sector will commence by July } 2007 \text {. }\end{array}$} \\
\hline \multicolumn{3}{|c|}{ Intended users - Users include CI owners and operators and Australian local governments. } \\
\hline \multicolumn{3}{|c|}{$\begin{array}{l}\text { System output - Output will include geographic information system (GIS) functionality for data } \\
\text { capture, management, and visualization. System behavior will determine dependencies and time-based } \\
\text { impacts of disruptive events on infrastructure networks. }\end{array}$} \\
\hline \multicolumn{3}{|c|}{ Maturity - In development, some tools are complete. } \\
\hline \multicolumn{3}{|c|}{$\begin{array}{l}\text { Areas modeled - Australian critical infrastructure networks and high priority precincts (e.g., capital } \\
\text { cities). }\end{array}$} \\
\hline \multicolumn{3}{|c|}{$\begin{array}{l}\text { Customers/sponsors - Australian government, state and territory governments, CI owners and } \\
\text { operators. }\end{array}$} \\
\hline \multicolumn{3}{|c|}{ Model Framework } \\
\hline \multicolumn{3}{|c|}{$\begin{array}{l}\text { Underlying model(s) - System Dynamic Models. } \\
\text { Simulation - Telecommunication connectivity matrix and expert systems. } \\
\text { Data format - The format is geographic information system (GIS) and rel } \\
\text { Sensor data - Not currently equipped for sensor input. } \\
\text { Human activity - Contains human activity model. } \\
\text { Coupling with other models - Model couples with earthquake, tsunami in } \\
\text { plume models. }\end{array}$} \\
\hline \multicolumn{3}{|c|}{ System Requirements } \\
\hline & & \\
\hline & & \\
\hline
\end{tabular}




\section{Java Runtime Environment (JRE).}

\section{Other Notes}

CIPMA is a very detailed modeling and analysis initiative which contains sensitive business information about the operation of Australia's critical infrastructure networks, relationships and dependencies. The IP is owned and managed by Attorney-General Department (AGD) on behalf of the Australian Government. The CIPMA Development Team of AGD, Geoscience Australia (GA) and the Commonwealth Scientific and Industrial Research Organization (CSIRO) has been in discussions with the US Department of Homeland Security (DHS) and Argonne, Sandia, and Los Alamos National Laboratories regarding the Critical Infrastructure Decision Support System (CIP-DSS), and the similarities and differences between the two capabilities, since November 2004. AGD is currently preparing a Project Arrangement for ongoing consultation with DHS and the three National labs under the Homeland Security Science and Technology Treaty (HSST).

\section{References}

Fact sheet on CIPMA program

http://www.tisn.gov.au/agd/WWW/rwpattach.nsf/VAP/(7A188806B7893EBA0402BC1472412E58)

Overview+of+CIPMA.PDF/\$file/Overview+of+CIPMA.PDF, Webpage visited July 3, 2006.

AusGeo News, Protecting the Nation, http://www.ga.gov.au/ausgeonews/ausgeonews200509/cip.jsp, Issue No. 79, September 2005, Webpage visited July 3, 2006. 


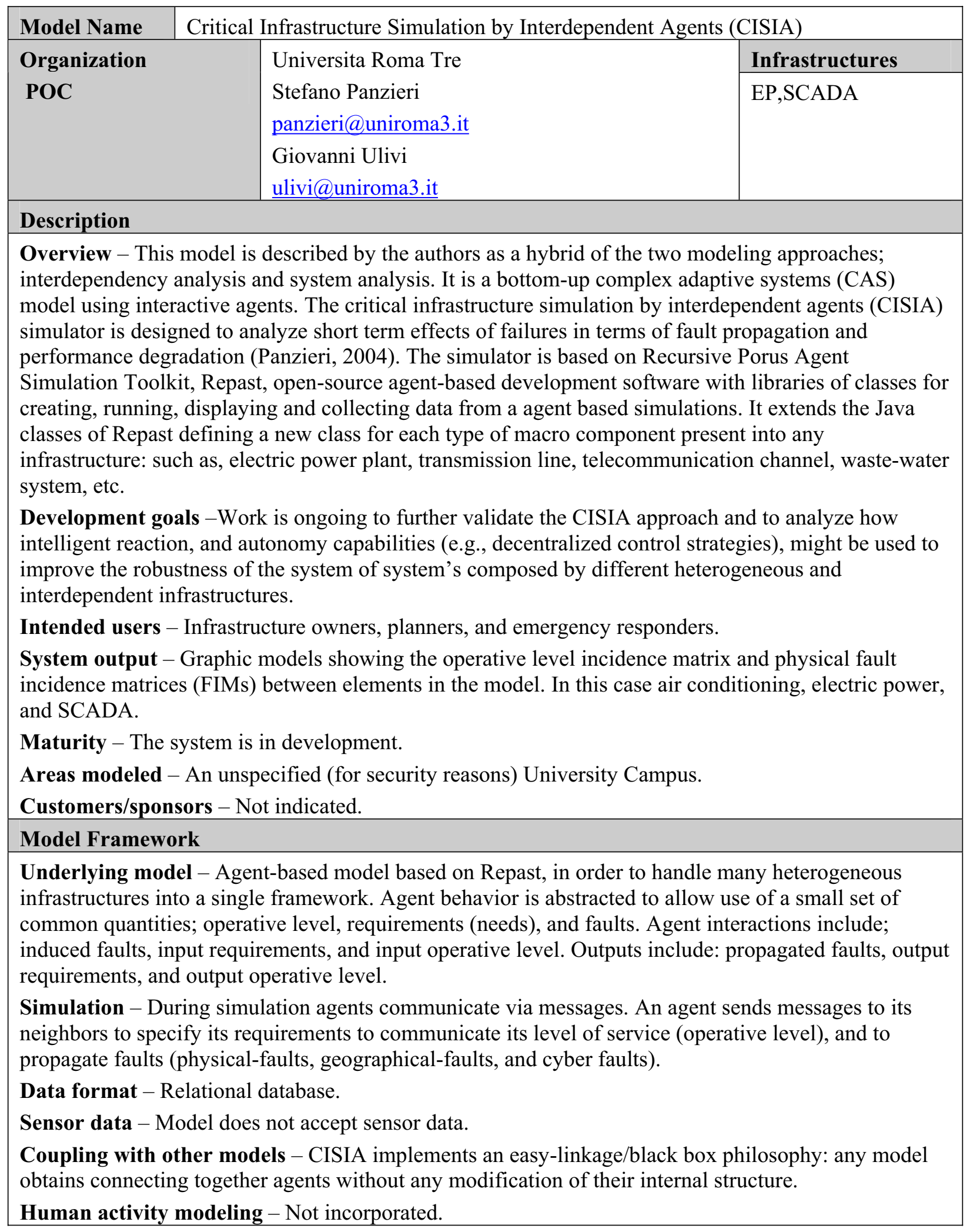




\section{System Requirements}

\section{Hardware $\quad$ Not specified. \\ Software $\quad$ Not specified.}

\section{Other Notes}

Each agent class defines the behavioral roles of the element and its input/output quantities in term of which resources the agent needed and supply. Moreover, the class defines which type of failure can be propagated to (generated from) the agent. An agent may propagate different types of failure to a different set of neighbors.

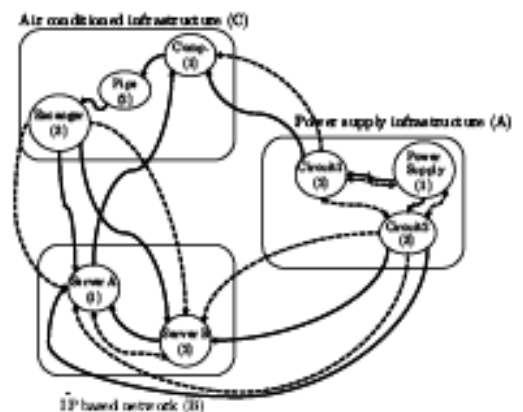

Fig. 3. CISIA model of the test-bed; inks related to operative level incidence matrix (continuce line) and the Pbysical FIM ineidence matrix (dotted line).

\section{References}

Panzieri, S., R. Setola, G. Ulivi (2004). An agent based simulator for critical interdependent infrastructures. Proc. 2nd International Conference on Critical Infrastructures, October 24-27, 2004.

Panzieri, S., R. Setola, G. Ulivi , An Approach to Model Complex Interdependent Infrastructures, International Federation of Automatic Control (IFAC), http://www.dia.uniroma3.it/ panzieri/Articoli/WorldIFAC05-

CIIP.pdfAsearch='An\%20Approach\%20to\%20Model\%20Complex\%20Interdependent\%20Infrastructur es', Webpage visited July 10, 2006. 


\begin{tabular}{|c|c|c|}
\hline Model Name & \multicolumn{2}{|l|}{ Distributed Engineering Workstation (DEW) } \\
\hline \multirow{2}{*}{$\begin{array}{l}\text { Organization } \\
\text { POC }\end{array}$} & Electrical Distribution Design, Inc. & Infrastructures \\
\hline & & EL, SCADA \\
\hline \multicolumn{3}{|l|}{ Description } \\
\hline \multicolumn{3}{|c|}{$\begin{array}{l}\text { Overview - The Distribution Engineering Workstation (DEW) provides over } 30 \text { applications for } \\
\text { analysis, design, and control of electrical and other physical network systems. DEW allows all of its } \\
\text { components (data sets and algorithms) to be reused by a new application, allowing new solutions to } \\
\text { build on top of existing work. This provides for cross collaborations among different groups and the } \\
\text { emergence of solutions to complex problems. DEW is being used to identify and analyze } \\
\text { interdependencies in large scale electrical power systems and fluid systems of aircraft carriers. DEW is } \\
\text { open architecture, non-proprietary. }\end{array}$} \\
\hline \multicolumn{3}{|c|}{$\begin{array}{l}\text { Development goals - Electrical Distribution Design, Inc. (EDD) continues to develop and support } \\
\text { DEW. They aspire to achieve combined analysis of systems with millions of nodes and to develop a } \\
\text { seamless approach to asset management. DEW's architecture provides an open platform for } \\
\text { development. The DEW system model can be linked to asset management records, daily operational } \\
\text { procedures, events, long- and short-term planning, and more. }\end{array}$} \\
\hline \multicolumn{3}{|c|}{ Intended users - Users are utilities, analysts, and military. } \\
\hline \multicolumn{3}{|c|}{$\begin{array}{l}\text { System output - The system is used for operation and control of electrical system and analysis of } \\
\text { reconfiguration of damaged systems. }\end{array}$} \\
\hline \multicolumn{3}{|c|}{ Maturity - Mature product is in broad use. } \\
\hline \multicolumn{3}{|c|}{$\begin{array}{l}\text { Areas modeled - This model has been used in St. Louis, MO, Detroit, MI, Consolidated Edison, NY, } \\
\text { Aircraft Carriers. }\end{array}$} \\
\hline \multicolumn{3}{|c|}{$\begin{array}{l}\text { Customers/sponsors - Electric Power Research Institute (EPRI) along with Department of Defense } \\
\text { and Department of Energy sponsored the original development. Users include Northrop Grumman } \\
\text { (naval applications), Detroit Edison (Detroit, MI), Ameren (St. Louis, MO), Orange and Rockland } \\
\text { (Pearl River, NY), and Consolidated Edison (New York). }\end{array}$} \\
\hline \multicolumn{3}{|c|}{ Model Framework } \\
\hline \multicolumn{3}{|c|}{$\begin{array}{l}\text { Underlying model - EDD's approach is built around a combination of concepts from graph theory, } \\
\text { physical network modeling, and generic programming. The DEW model incorporates power flow, } \\
\text { fault, reliability, reconfiguration for restoration, and over } 30 \text { other algorithms. }\end{array}$} \\
\hline \multicolumn{3}{|c|}{$\begin{array}{l}\text { Simulation - Simulations may be run manually with mouse and keyboard, automatically controlled } \\
\text { from user developed applications, or set up to run in batch mode over numerous systems and/or time } \\
\text { points. }\end{array}$} \\
\hline \multicolumn{3}{|c|}{$\begin{array}{l}\text { Data format - Model data is stored in relational SQL-compliant databases; real-time measurement } \\
\text { data comes from common object request broker architecture (CORBA) interface or plant information } \\
\text { (PI) time series databases. }\end{array}$} \\
\hline \multicolumn{3}{|c|}{$\begin{array}{l}\text { Sensor data - DEW can handle any number of measurements and any types of measurements that are } \\
\text { modeled, through its PI or CORBA interface. }\end{array}$} \\
\hline \multicolumn{3}{|c|}{$\begin{array}{l}\text { Coupling with other models - DEW can attach to other models, such as geographic information } \\
\text { system (GIS) models, via provided interface. }\end{array}$} \\
\hline \multicolumn{3}{|c|}{ System Requirements } \\
\hline Hardware & \multicolumn{2}{|l|}{ Laptop/Server/Circuit server. } \\
\hline Software & \multicolumn{2}{|l|}{ Win 2000, XP, User interface. } \\
\hline \multicolumn{3}{|l|}{ Other Notes } \\
\hline & & \\
\hline
\end{tabular}


comprehensive Integrated System Model (ISM) based design, operations and maintenance management system. This concept is being applied to critical infrastructures including naval ships and gas and water utilities. Through work with the utility industry and Department of Energy, EDD has demonstrated it is possible to use the same ISM for analysis, design, operations, and real-time control. EDD has also used ISM based analysis to manage reconfigurable system models with more than 3 million objects and 200 million attached historical measurement values. The ISM provides a complete, seamless view of a physical plant that forms a common context for multi-discipline team collaboration, distributed processing, synergistic research and development, and providing infinite extensibility. Any data or algorithm that can be attached to the ISM is also associated with all other data and algorithms attached to the ISM. The ISM uses linked list type traces to dynamically adapt data management and analysis whenever the system is changed through modification, maintenance or operation.

EDD is structuring its current research and development work so that it that can eventually be combined into a generic integration platform for collaborative analysis, design, and operations for energy systems (CADOE). CADOE will directly support and structure low overhead collaboration among electric utilities, gas utilities, regulatory and policy making agencies, suppliers, integrators, aggregators, and customers. CADOE is envisioned to encompass simulation, analysis, alternative design evaluation, training, and real-time operations support.

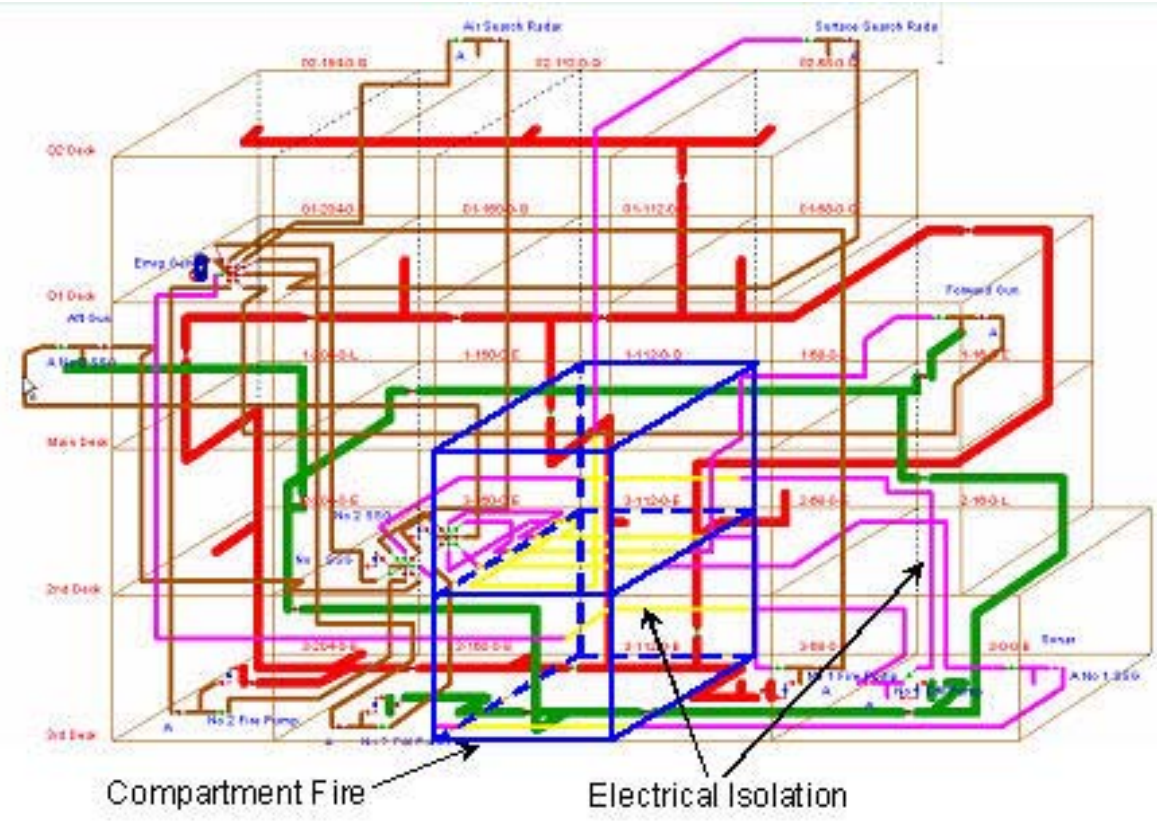

Model of Ship Critical Infrastructure. 


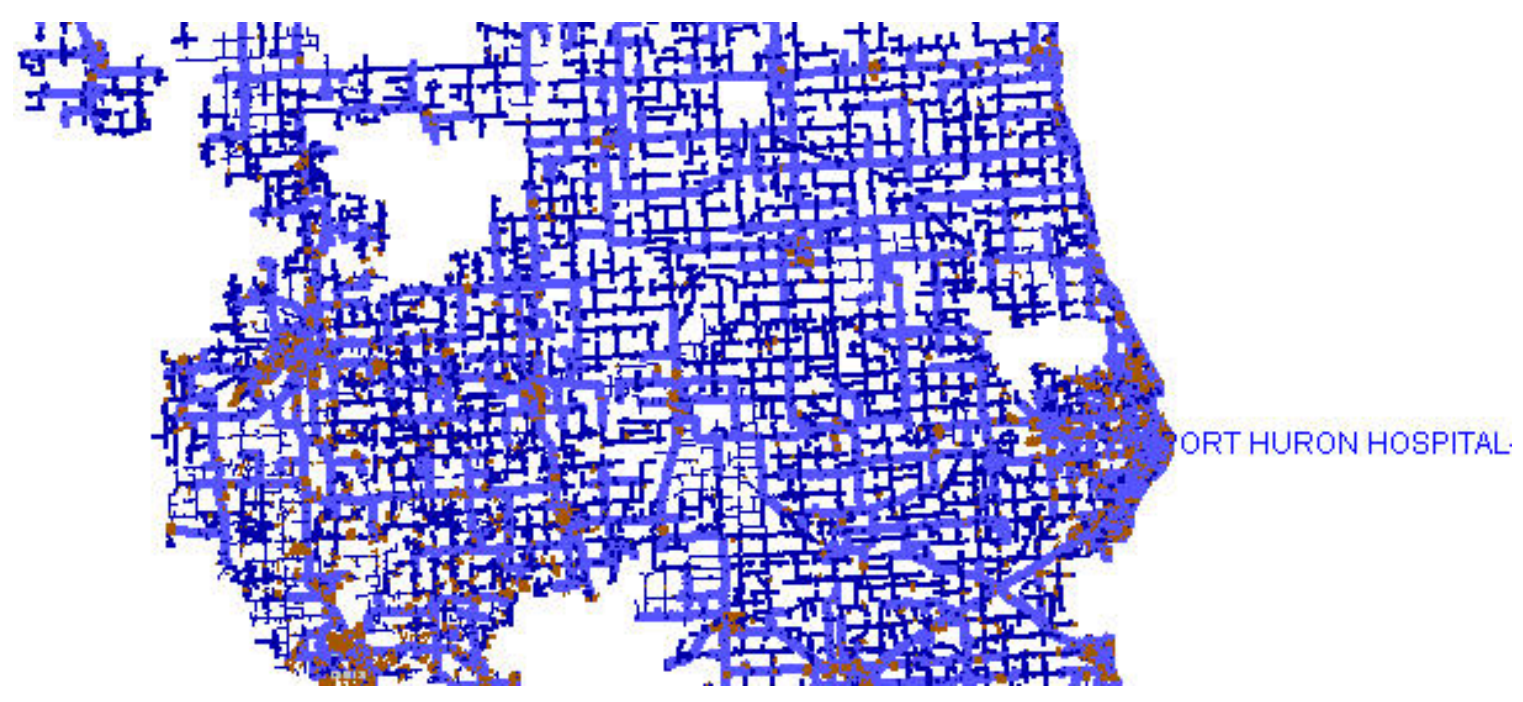

Dense Electrical Power System Model

\section{References}

Broadwater, Robert, et al., Power Engineering, http://www.ecpe.vt.edu/news/ar04/power2004.pdf\#search='distributed\%20engineering \%20workstation\%20epri', Webpage visited July 3, 2006.

SAM Six, Products: Dew, http://www.samsix.com/dew.htm, Webpage visited July 3,2006.

Tam, Kwa-Sur and Robert Broadwater, Virginia Tech Presentation, http://www.eng.vt.edu/research/dom pres/TamBroadwater\%20Systems\%20Presentation.pdf\#search='vt\%20dew' Webpage visited July 3, 2006. 


\begin{tabular}{|c|c|c|}
\hline Model Name & \multicolumn{2}{|c|}{ Electricity Market Complex Adaptive System (EMCAS) } \\
\hline \multirow{2}{*}{$\begin{array}{l}\text { Organization } \\
\text { POC }\end{array}$} & Argonne National Laboratory & Infrastructures \\
\hline & & \\
\hline \multicolumn{3}{|l|}{ Description } \\
\hline \multicolumn{3}{|c|}{$\begin{array}{l}\text { Overview - Electricity Market Complex Adaptive System (EMCAS) uses agent-based modeling to } \\
\text { simulate the operation of complex power systems. EMCAS can be used as an "electronic-laboratory" } \\
\text { to probe the possible operational and economic impacts on the power system of various external } \\
\text { events. Market participants are represented as "agents" with their own set of objectives, decision- } \\
\text { making rules, and behavioral patterns. Agents are modeled as independent entities that make decisions } \\
\text { and take actions using limited and/or uncertain information available to them, similar to how } \\
\text { organizations and individuals operate in the real world. EMCAS includes all the entities participating } \\
\text { in power markets, including consumers, generation companies (GenCos), Transmission Companies } \\
\text { (TransCos), Distribution Companies (DisCos), Demand Companies (DemCos), Independent System } \\
\text { Operators (ISO) or Regional Transmission Organizations (RTO), and regulators. }\end{array}$} \\
\hline \multicolumn{3}{|c|}{$\begin{array}{l}\text { Development goals - Continue to develop EMCAS as a new approach to model and simulate the } \\
\text { operations of restructured electricity markets. }\end{array}$} \\
\hline \multicolumn{3}{|c|}{$\begin{array}{l}\text { Intended users - EMCAS was first applied for a regulatory commission in the mid-western United } \\
\text { States. At the beginning of } 2005 \text {, the software became commercially available and current clients } \\
\text { include research institutes, power companies, transmission companies, and regulatory offices in South } \\
\text { Korea, Portugal, and Spain. The Iberian EMCAS application includes the simulation of hydropower, } \\
\text { wind power, and a variety of other renewable resources. }\end{array}$} \\
\hline \multicolumn{3}{|c|}{$\begin{array}{l}\text { System output - EMCAS utilizes a graphical user interface to develop market configurations, display } \\
\text { model inputs, and analyze simulation results (see screen captures on next page). Results are stored in } \\
\text { HDF format and can be exported in text and spreadsheet formats. In addition to the energy spot } \\
\text { markets and bilateral financial contract markets, EMCAS also includes a simplified representation of } \\
\text { ancillary services markets; Detailed representation of the transmission system, using a Direct Current } \\
\text { Optimal Power Flow (DC OPF) algorithm to compute locational marginal prices (LMP) and identify } \\
\text { transmission congestion and price impacts of congestion; Chronological simulation of hourly market } \\
\text { prices over short or long time periods; Hourly bid-based market clearing, scheduling and dispatch in } \\
\text { day-ahead and real-time markets; Representation of different bidding strategies, from production cost } \\
\text { bidding to various forms of physical and economic withholding strategies; Ability to change prevailing } \\
\text { market rules (regarding congestion management, pricing mechanisms, price caps etc.) provides the } \\
\text { opportunity to test the robustness and vulnerability to gaming of different market designs; and } \\
\text { Calculation of cost, revenues, and profits for all relevant agents in the system. }\end{array}$} \\
\hline \multicolumn{3}{|c|}{ Maturity - Commercial Product distributed by ADICA Consulting, LLC. } \\
\hline \multicolumn{3}{|c|}{ Areas modeled - Illinois electrical market, Iberia, France, South Korea, Poland, Central Europe } \\
\hline \multicolumn{3}{|c|}{$\begin{array}{l}\text { Customers/sponsors - At the beginning of } 2005 \text {, the software } \\
\text { current clients include research institutes, power companies, tr } \\
\text { offices in South Korea, Portugal, and Spain. }\end{array}$} \\
\hline
\end{tabular}




\section{Model Framework}

Underlying model(s) - Agent-based modeling and simulation.

Simulation - EMCAS simulates the operation of a power system and computes electricity prices for each hour and each location in the transmission network. Electricity prices are driven by demand for electricity, cost of electricity production, the extent of transmission congestion, external random or non-random events, such as unit outages or system disruptions, and company strategies. Model results include the economic impacts on individual companies and consumer groups under various scenarios.

Data format - The user builds the system configuration either within the EMCAS graphical user interface or by preparing and importing a set of well-defined input files.

Sensor data - The model also includes bilateral financial contracts. Real-time prices are calculated in a real-time dispatch using a DC optimal power flow model.

Human activity - Model includes different types of consumers (e.g., residential, industrial, and commercial) with their respective electricity consumption profiles.

Coupling with other models - Couples with hydropower models (e.g., VALORAGUA) and detailed power flow models (e.g., PowerWorld).

\section{System Requirements}

\begin{tabular}{|l|l|}
\hline Hardware & $\begin{array}{l}\text { A network with 10 nodes (buses or locations), 70 aggregated thermal generating units, } \\
13 \text { generation companies, one transmission company, one ISO, and one regulator takes } \\
\text { approximately } 60 \text { minutes for a one-year simulation (8760 hours) on a desktop PC } \\
\text { with a 2.0 GHz AMD Athlon2000+ processor and 1 GB of RAM. For multi-year } \\
\text { simulations, it is recommended to use a brand-new, high-end PC, preferably with dual } \\
\text { core processors and 2+ GB of RAM. }\end{array}$ \\
\hline Software & Commercial optimizer (LINGO), long-term hydro model (e.g., VALORAGUA). \\
\hline Other Notes & $\begin{array}{l}\text { Adaptability to Local Market and System Conditions: } \\
\text { The EMCAS model is fully customizable and not hardwired to any particular system. Network } \\
\text { configurations can be simple and aggregate consisting of a few to several dozen network nodes and } \\
\text { links, or detailed bus-level representations with several thousand network elements. The level of detail } \\
\text { largely depends on data availability and particular analysis objectives. }\end{array}$ \\
\hline
\end{tabular}

\section{References}

ADICA Consulting, LLC., Innovative Solutions for Analyzing Energy Markets, http://www.adica.com/media/downloads/ADICA_Overview_2006.pdf, Webpage visited July 3, 2006.

ADICA Consulting, LLC., Electricity Market Complex Adaptive System (EMCAS) Software, http://www.adica.com/media/downloads/EMCAS_Model_Overview.pdf, Webpage visited July 3, 2006.

ADICA Consulting, LLC., Electricity Market Complex Adaptive Systems (EMCAS), http://www.adica.com/media/downloads/EMCAS_Specifications_2006.pdf, Webpage visited July 3, 2006.

Argonne National Laboratory, Simulating GenCo Bidding Strategies in Electricity Markets with an Agent-Based Model, http://www.iaee.org/documents/denver/Thimmapuram.pdf\#search='emcas', Webpage visited July 3, 2006. 


\section{Electricity Markets Complex Adaptive Systems (EMCAS)}
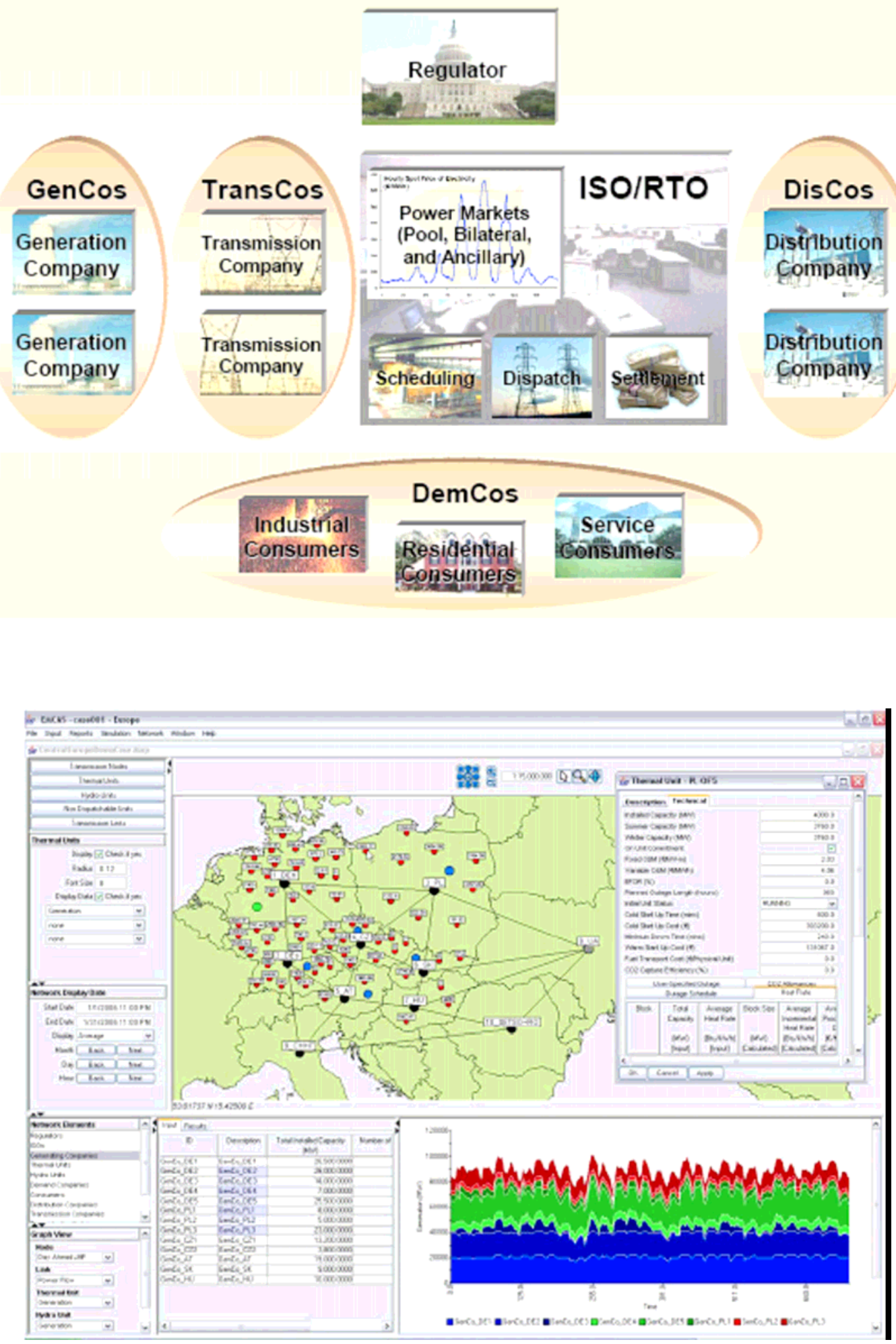

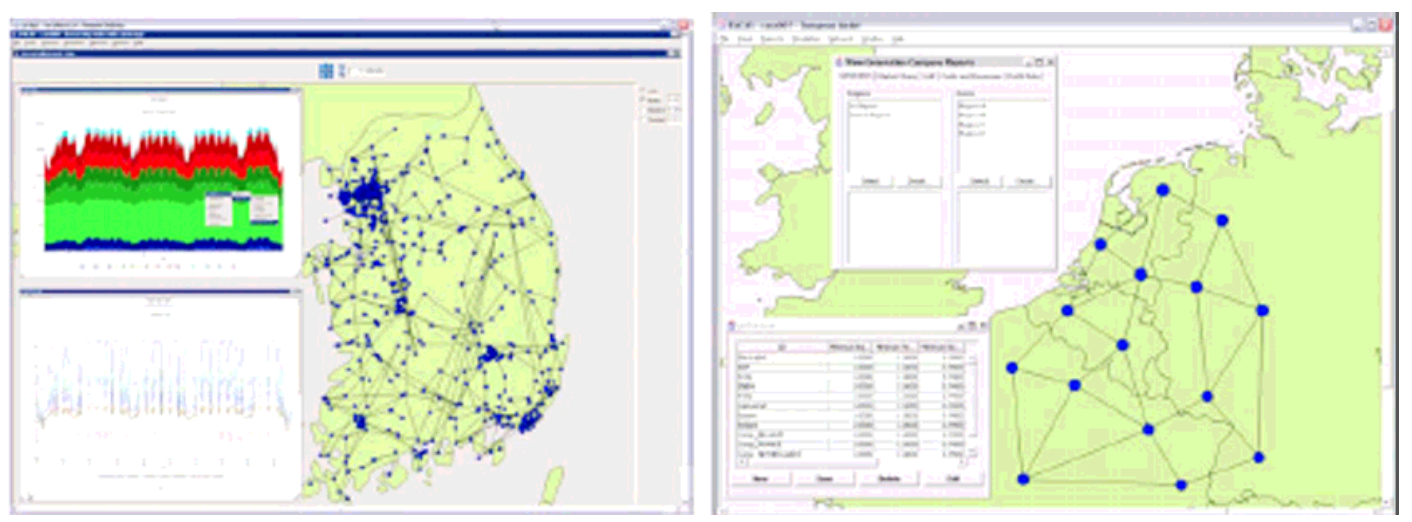


\begin{tabular}{|c|c|c|}
\hline Model Name & \multicolumn{2}{|l|}{ Fast Analysis Infrastructure Tool (FAIT) } \\
\hline \multirow{2}{*}{$\begin{array}{l}\text { Organization } \\
\text { POC }\end{array}$} & Sandia National Laboratory (SNL) & es \\
\hline & & \\
\hline \multicolumn{3}{|l|}{ Description } \\
\hline \multicolumn{3}{|c|}{ 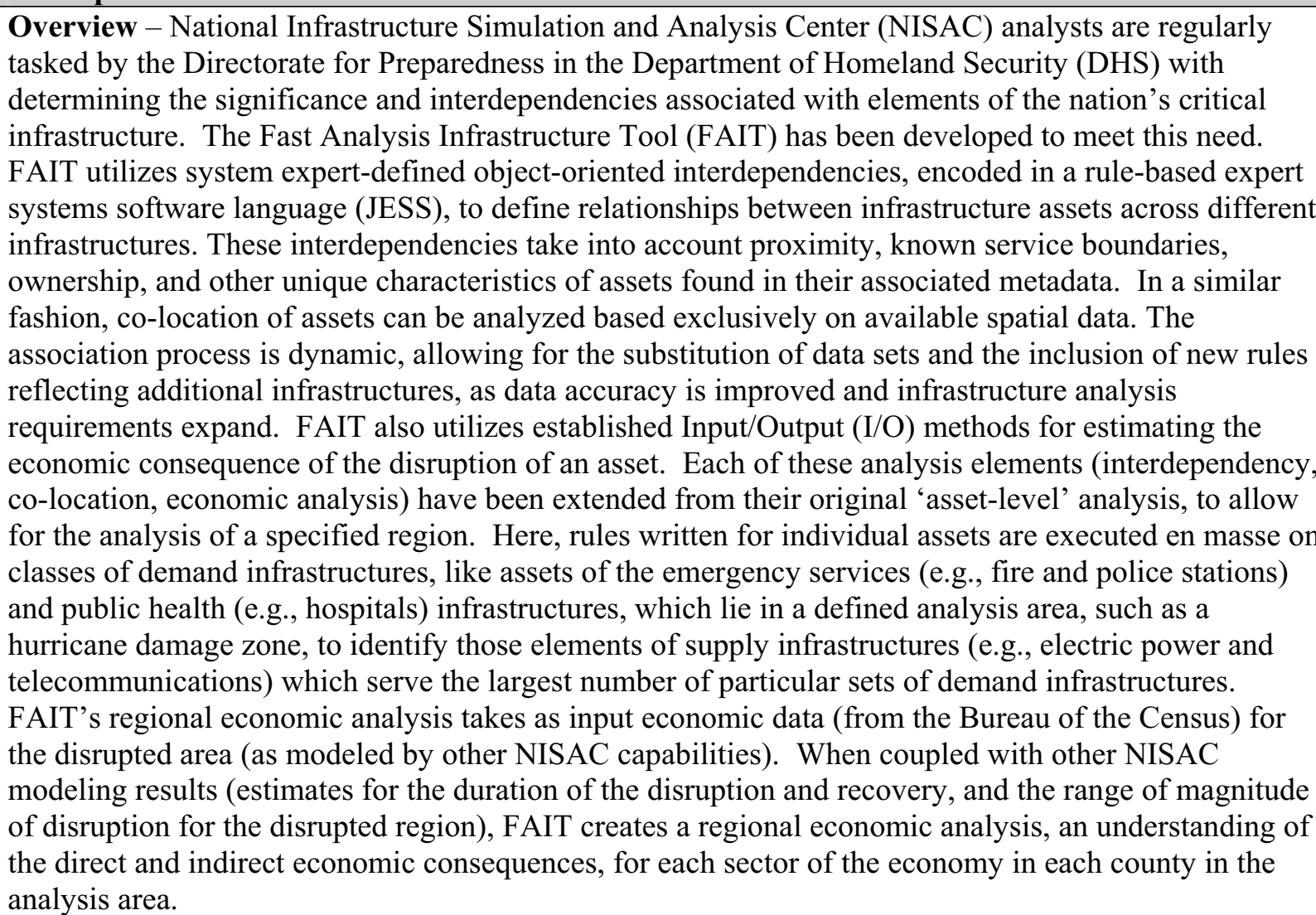 } \\
\hline
\end{tabular}




\section{Model Framework}

Underlying model - Dependency model is an object-oriented expert system model of infrastructure interdependencies. The economic model centers on the economic disruption over an area or region from a discrete event. Economic methodology best employed for disruptions with a timeframe of 1 week to 1 month.

Simulation - For identification of interdependencies, FAIT utilizes an expert system developed in JESS. Economic analysis within FAIT is performed utilizing Input-Output methodologies. Both elements are coded in Java.

Data format - FAIT utilizes spatial and tabular data

Sensor data - None.

Ability to couple with other models - None; though results of other models (documents, files) can be coupled through the FAIT architecture to particular assets, classes of assets, or infrastructures with which they are associated.

Human Activity modeling - None.

\section{System Requirements}

Hardware $\quad$ None, for the end user. Program resides on a SNL server and supports web access.

Software Internet Browser

\section{Other Notes}

FAIT allows for external information, (e.g. web addresses or files), to be 'attached' to specific assets, classes of assets, or infrastructure sectors, such that when those areas are examined in the future, the associated information is accessible to future users.

\section{References}

National Infrastructure Simulation and Analysis Center, Fait Analysis Infrastructure Tool Fact Sheet,http://www.sandia.gov/mission/homeland/factsheets/nisac/FAIT factsheet.pdf. 


\begin{tabular}{|c|c|c|}
\hline Model Name & Financial System Infrastructure (FinSim) & \\
\hline \multirow{2}{*}{$\begin{array}{l}\text { Organization } \\
\text { POC }\end{array}$} & \multirow{2}{*}{$\begin{array}{l}\text { Los Alamos National Laboratory } \\
\text { Sam Flaim }\end{array}$} & Infrastructures \\
\hline & & FIN \\
\hline
\end{tabular}

\section{Description}

Overview - The Financial System Infrastructure (FinSim) is an agent-based model of cash and barter transactions that is dependant on contractual relationships and a network at the federal reserve level. Agent based models create transactions which rely on telecommunications and electric power. Dependencies can cause deadlocks in the situation where one is unable to pay until being paid. The MIITS module asks every transaction whether there is an electronic connection available to make the transaction. The payments and settlement systems (PSS) module makes the validity checks.

Development goals - Development started in January 2005 to protect the physical infrastructure of payment and trading systems initiated by the events of 9-11. All current models didn't address the transaction system, just the economic impact.

Intended users - Internal analyst.

System output - The system output is the number of financial institutions affected. Output is in a textbased format.

Maturity - Development.

Areas modeled - National Federal Reserve Banking System — Financial

Customers/sponsors - Sponsor is the National Infrastructure Simulation and Analysis Center (NISAC), Department of Homeland Security (DHS).

\section{Model Framework}

Underlying model - Agent-based model.

Simulation - FinSim models financial transactions modeling the 12 FRB, about 9,700 FedWire participants, and almost 28,000 financial institutions registered with FedACH.

This includes the electronic PSS - networks with contractual as well as electronic links and nodes PSSs include: FedWire, FedNet, CHIPS, FedACH, Commercial ACHS 50

Cash \& barter (excluded from FinSim)

Data format - Not specified.

Sensor data - No direct sensor feeds.

Coupling with other models - Yes, coupling is done indirectly. Electrical power failure (IEISS output) $M$ Telecom failure (MIITS output) $\cdots$ PSS failures (FINSIM)

Human activity modeling - None.

\section{System Requirements}

\begin{tabular}{l|l}
\hline Hardware & Larger models require a computer cluster. \\
\hline Software & Java.
\end{tabular}

\section{Other Notes}




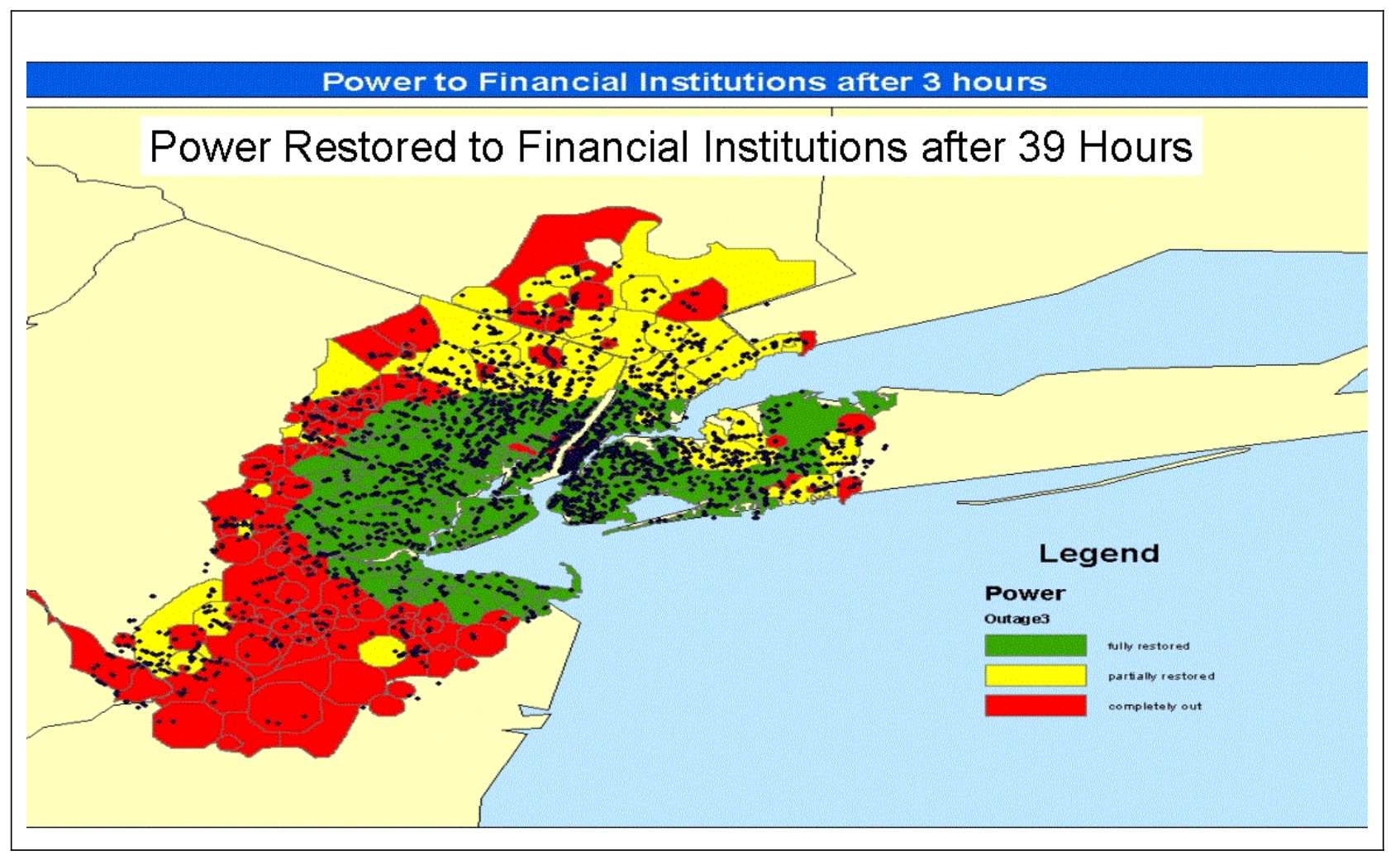

\section{References}

Financial System Infrastructure-FinSim, LAUR-05-9147. 


\begin{tabular}{|c|c|c|}
\hline \multicolumn{3}{|c|}{ Fort Future } \\
\hline \multirow[t]{2}{*}{ Organization } & S. Army Corps of Engineers, Engineer & Infrastructures \\
\hline & $\begin{array}{l}\text { Research and Development Center, Construction } \\
\text { Engineering Research Laboratory (CERL) } \\
\text { Dr. Michael P. Case } \\
\text { Michael.P.Case@erdc.usace.army.mil }\end{array}$ & $\begin{array}{l}\text { 11 support } \\
\text { frastructures for a } \\
\text { iilitary installation }\end{array}$ \\
\hline \multicolumn{3}{|l|}{ Description } \\
\hline \multicolumn{3}{|c|}{$\begin{array}{l}\text { Overview - Fort Future is a collaborative, web-based planning system that uses simulation to test plans } \\
\text { for Department of Defense (DoD) installations. It uses an open, service-oriented architecture to allow } \\
\text { multiple simulations to be run simultaneously from the same set of alternative, organized into a study. } \\
\text { The web-based workbench provides geographic information system (GIS)-based plan editors, controls } \\
\text { simulations, and organizes results into a decision matrix. Fort Future assesses the impact of critical } \\
\text { infrastructure on mission using a "Virtual Installation" simulation that contains models for } \\
\text { transportation, electrical power, water systems, including waterborne chemical/biological/radiological } \\
\text { (CBR) agents, airborne CBR plume, facilities, mission tasks and processes, agents, and dynamic plans. } \\
\text { The Virtual Installation simulation was built using Argonne National Laboratory's Dynamic } \\
\text { Information Architecture System (DIAS) framework and will be ported to the Repast agent modeling } \\
\text { toolkit by September of 2006. Other models support analysis of encroachment, sustainability, and } \\
\text { facility design. }\end{array}$} \\
\hline \multicolumn{3}{|c|}{$\begin{array}{l}\text { Development goals - Demonstrate the use of simulation to improve planning for DoD Installations. } \\
\text { Incorporate scenario descriptions into Simulation Interoperability Standards Organization (SISO) } \\
\text { Military Scenario Definition Language (MSDL). }\end{array}$} \\
\hline \multicolumn{3}{|c|}{$\begin{array}{l}\text { Intended users - Users will include installation and regional planners, US Army Corps of Engineers, } \\
\text { and researchers. }\end{array}$} \\
\hline \multicolumn{3}{|c|}{$\begin{array}{l}\text { System output - Output of the simulations is collected by a web-based collaborative workbench and } \\
\text { presented as a decision matrix. The workbench can be customized to present output specific to } \\
\text { particular simulations. }\end{array}$} \\
\hline \multirow{2}{*}{\multicolumn{3}{|c|}{$\begin{array}{l}\text { Maturity - This product is in development with some tools complete. The pr } \\
\text { October, } 2006 . \\
\text { Areas modeled - Fort Benning, Fort Shafter, Fort Bragg, and Fort Carson. } \\
\text { Customers/sponsors - United States Army. }\end{array}$}} \\
\hline & & \\
\hline \multicolumn{3}{|c|}{ Model Framework } \\
\hline \multicolumn{3}{|c|}{$\begin{array}{l}\text { Underlying model(s) - The agent-based Virtual Installation is based on DIAS } \\
\text { modeling uses EPAnet. CBR plume model uses the Defense Threat Reduction } \\
\text { Hazardous Prediction and Assessment Capability (HPAC) Tool. }\end{array}$} \\
\hline \multicolumn{3}{|c|}{ Simulation - This model supports complex and lengthy scenario simulations } \\
\hline \multicolumn{3}{|c|}{$\begin{array}{l}\text { Data format - GIS - Environmental Systems Research Institute, Inc. (ESRI) Geodatabase and SHP } \\
\text { files (Tri-service Spatial Data Standards). Scenarios - XML. }\end{array}$} \\
\hline \multicolumn{3}{|c|}{ Sensor data - Not accepted. } \\
\hline \multicolumn{3}{|c|}{$\begin{array}{l}\text { Human activity - Human activities are modeled, however there are no humans in the simulation loop. } \\
\text { Coupling with other models - Fort Future is built to collaborate with multiple models using simple } \\
\text { object access protocol (SOAP). }\end{array}$} \\
\hline
\end{tabular}




\begin{tabular}{|c|c|}
\hline \multicolumn{2}{|c|}{ System Requirements } \\
\hline Hardware & $\begin{array}{l}\text { Fort Future is a server-based application, accessed over the internet using a } \\
\text { web-browser. }\end{array}$ \\
\hline Software & $\begin{array}{l}\text { Fort Future has been tested on Windows and Linux servers. The workbench runs as a } \\
\text { J2EE application on JBoss 3.x. Persistence is provided by MySQL or Oracle relational } \\
\text { databases. Geospatial information is provided by ESRI ArcSDE and ArcGIS server. } \\
\text { Users access the workbench using a web-browser. }\end{array}$ \\
\hline \multicolumn{2}{|l|}{ Other Notes } \\
\hline \multicolumn{2}{|c|}{$\begin{array}{l}\text { Users of Fort Future at the installation, regional, or national level will be able to set up planning } \\
\text { scenarios, conduct dynamic analyses over time periods of up to } 30 \text { years, and compare scenario results. } \\
\text { Fort Future will allow decision makers to: }\end{array}$} \\
\hline \multicolumn{2}{|c|}{$\begin{array}{l}\text { Provide an integrated sustainability planning capability to support mission-essential task list } \\
\text { (METL) analysis, master planning, and natural and cultural resource planning. }\end{array}$} \\
\hline \\
\hline \multicolumn{2}{|c|}{$\begin{array}{l}\text { - Simulate and optimize planning for force projection. Metrics will focus on risk-based } \\
\text { evaluation of an installation's ability to project forces over time. }\end{array}$} \\
\hline \multicolumn{2}{|c|}{$\begin{array}{l}\text { - Simulate urban and regional growth around installations as a foundation for analysis of mission } \\
\text { sustainability. Factors to be evaluated include encroachment, noise, traffic congestion, habitat, and } \\
\text { threatened and endangered species. }\end{array}$} \\
\hline \multicolumn{2}{|c|}{$\begin{array}{l}\text { Manage facility requirements to rapidly generate, visualize, and analyze facilities for the } \\
\text { Objective Force. The analysis will include force protection and sustainability issues. }\end{array}$} \\
\hline
\end{tabular}

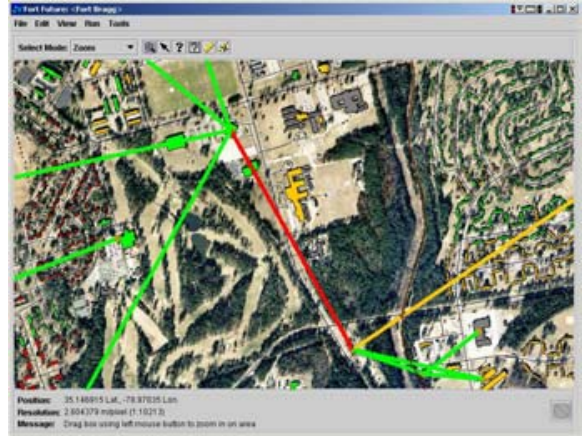

Electrical Infrastructure (capacity \& interruption)

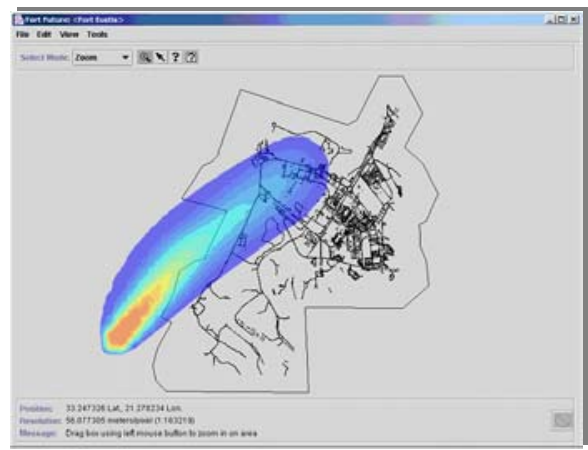

CBR Plume Modeling

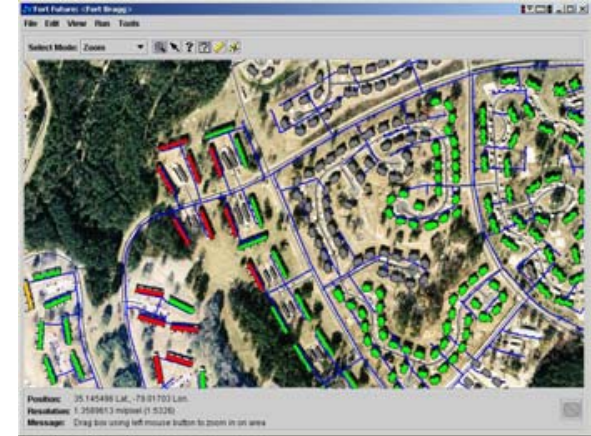

Water Infrastructure(flow \& CBR)

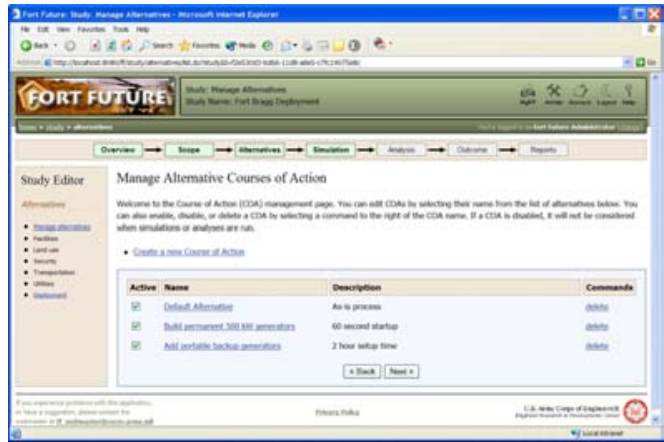

Collaborative Web-based Decision Support 

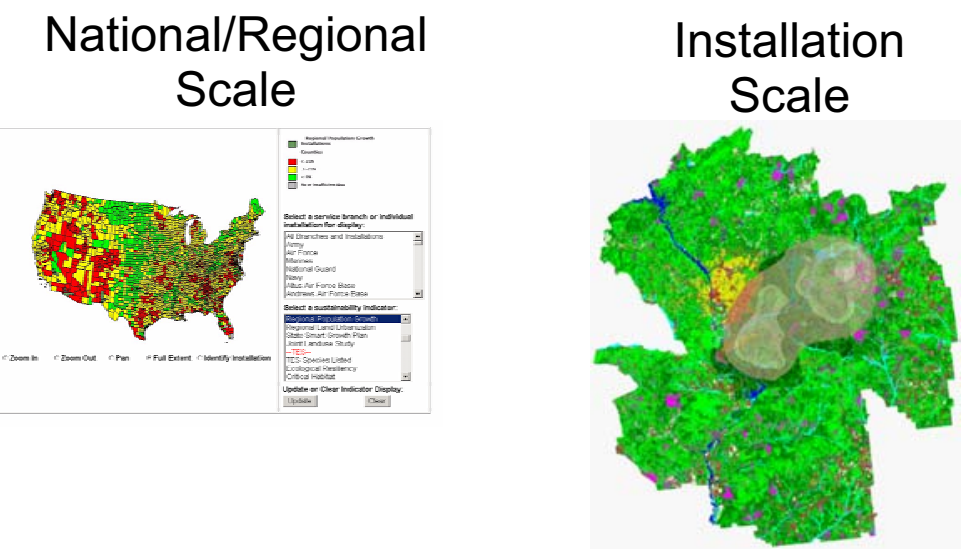

SIRRA

Sustainable Installation

Regional Resource Assessment
Facility Scale

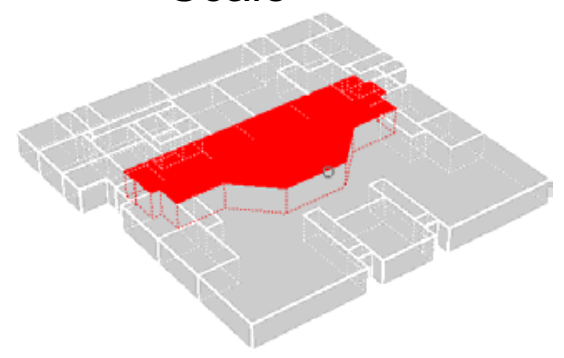

Facility Composer: Accelerating MILCON Transformation SPIRiT \& LEED Sustainability Rating AT Standards

\section{References}

Fact sheet on Fort Future, www.erdc.usace.army.mil/pls/erdcpub/docs/erdc/images/ERDCFactSheet Research_FortFuture.pdf\#search='fort\%20future', Webpage accessed July 3, 2006.

US Army Corps of Engineers, www.erdc.usace.army.mil, Webpage visited July 3, 2006.

Discussion of US Army Corps of Engineers ongoing research, http://www.erdc.usace.army.mil/pls/erdcpub/WWW_WELCOME.NAVIGATION PAGE?tmp next page $=61605 \&$ tmp_Main_Topic $=51585$, Webpage visited July 3, 2006 . 


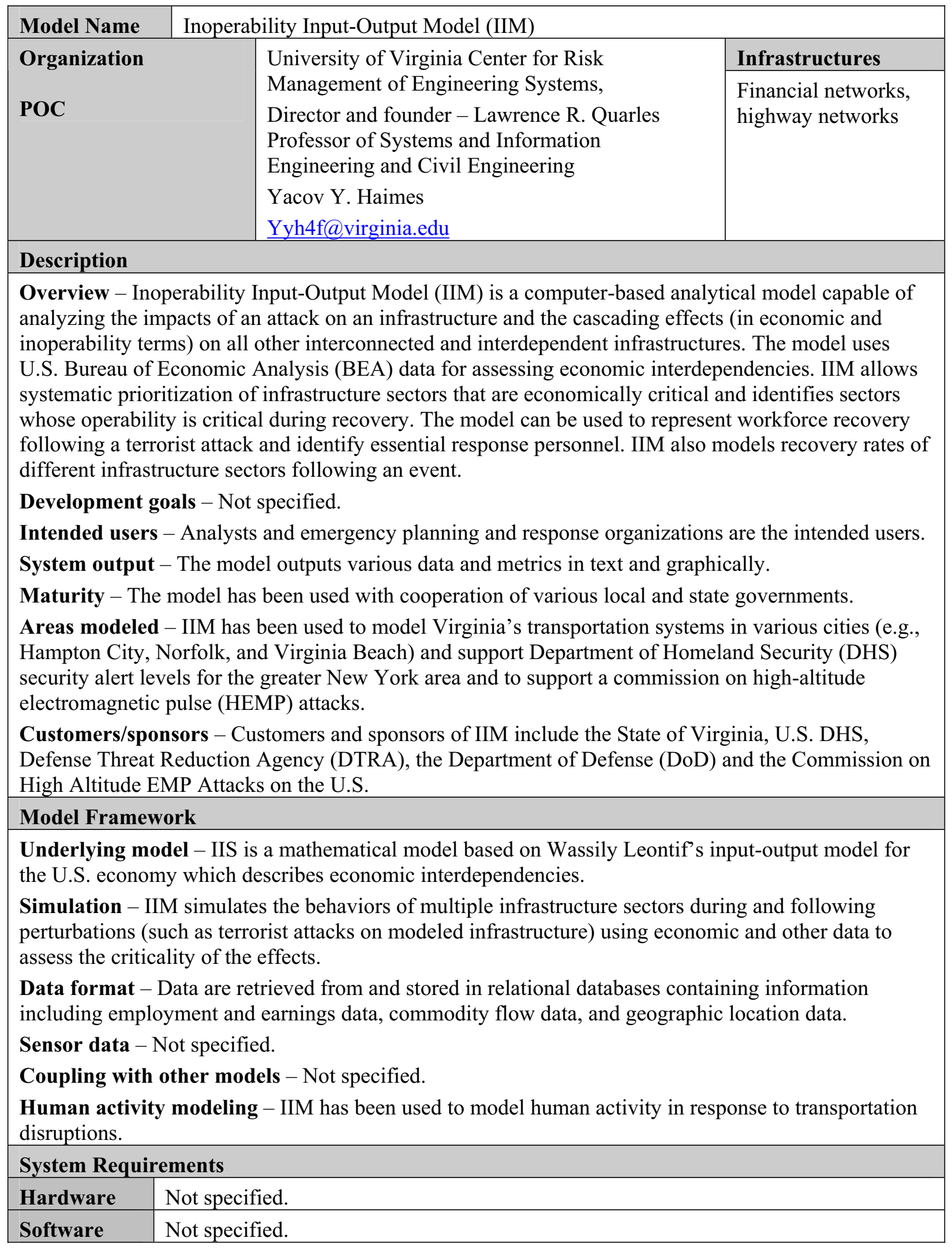

\section{Other Notes}




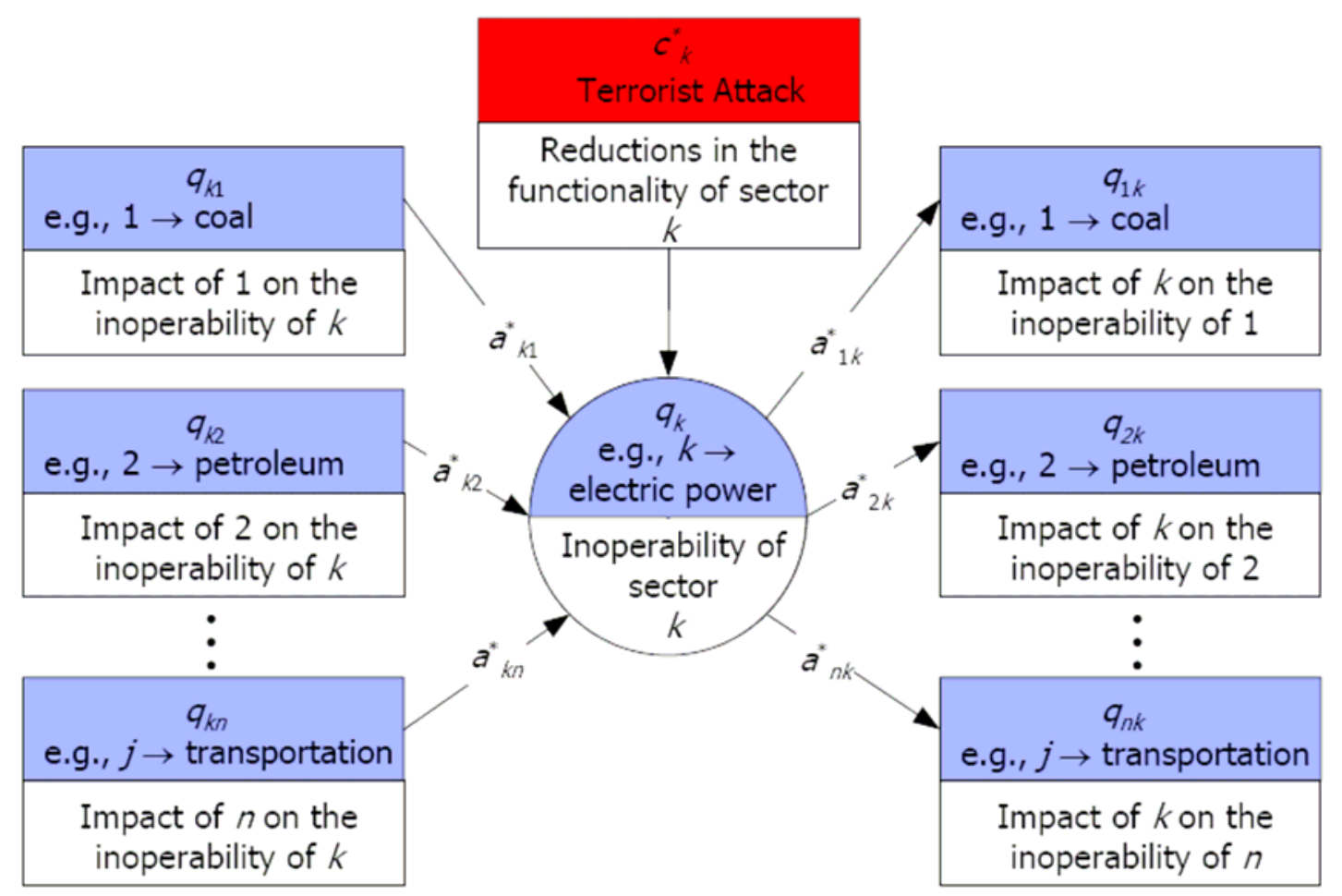

IIM Calculates Propagating Effects.

\section{References}

Haimes, Y. (2005), Risk-Based Framework for Modeling Infrastructure Interdependencies, University of Southern California Terrorism Risk Analysis Symposium, Los Angeles, California, January 14, 2005, http://www.usc.edu/dept/create/events/2005 01_31/Risk_Based_Framework_for_Modeling_Infrastructure Interdependencies.pdf\#search='yacov\%20Haimes\%20interdependencies', Webpage visited July 12, 2006.

Haimes, Yacov Y., et al., "Inoperability input-output model for interdependent infrastructure sectors. I: Theory and methodology," Journal of Infrastructure Systems, Vol. 11, No. 2, June 2005, pp. 67-79.

Haimes, Y. (2004). Assessment and Management of Transportation Infrastructure Security using the Inoperability Input-Output Model (IIM), October 19, 2004, http://www.virginiadot.org/infoservice/resources/TransConfHaimes\%20-\%20VDOT-Roanoke-October-192004-2.pdf\#search='Yacov\%20Y.\%20Haimes\%20interdependencies', Webpage visited July 12, 2006. 


\begin{tabular}{|l|l|l|}
\hline Model Name & \multicolumn{2}{|l|}{ Interdependent Energy Infrastructure Simulation System (IEISS) } \\
\hline $\begin{array}{l}\text { Organization } \\
\text { POC }\end{array}$ & $\begin{array}{l}\text { Los Alamos National Laboratory } \\
\text { Joe Holland }\end{array}$ & Infrastructures \\
\cline { 2 - 3 } & & EP, NG \\
\hline
\end{tabular}

\section{Description}

Overview - The Interdependent Energy Infrastructure Simulation System (IEISS) is an actor-based infrastructure modeling, simulation, and analysis tool designed to assist individuals in analyzing and understanding interdependent energy infrastructures. The actor-based infrastructure components were developed in IEISS to realistically simulate the dynamic interactions within each of the infrastructures, as well as, the interconnections between the infrastructures. In particular, it has the ability to analyze and simulate the interdependent electric power and natural gas infrastructures. IEISS Water is a water distribution simulation capability for simulating urban scale water infrastructures and their interdependencies.

Development goals - The ultimate goal for IEISS is a multi-infrastructure modeling framework that can be used to analyze the complex, nonlinear interactions (interdependencies) among interdependent infrastructures including electric power, natural gas, petroleum, water, and other network based infrastructures that is scalable to multiple spatial (e.g., urban to regional) and temporal resolutions

Intended users - Internal Analyst - IEISS used to support the development of an impact report on for specific infrastructure events (such as, hurricanes, terrorist attacks, etc.).

System output - System output include the identification of outage areas (e.g., electrical outage areas). Output visualization is current in Java OpenMaps and is exportable to ESRI compatible shape files.

Maturity - Mature Internal.

Areas modeled - numerous US metropolitan areas.

Customers/sponsors - Sponsor is NISAC - DHS.

Model Framework

Underlying model - IEISS is an actor-based infrastructure modeling, simulation, and analysis tool designed to assist individuals in analyzing and understanding interdependent energy infrastructures. Simulation - A continuous time based model with an underling physical engine for system dynamics. Data format - Data is input via xml format from a variety of databases.

Sensor data - no direct sensor feeds.

Coupling with other models - Yes, coupling is done indirectly. The output of IEISS will serve as the input to other infrastructure models to identify cross infrastructure effects.

Human activity modeling - None at this time.

\section{System Requirements}

Hardware $\quad$ Cross platform compatibility - Windows and LINUX compatibility.

\begin{tabular}{l|l} 
Software & Requires the Java Virtual Machine.
\end{tabular}

\section{Other Notes}

IEISS is coupled with other LANL modeling tools. Of particular note is the Scenario Library Visualizer (SLV). SLV is a scenario library of outage simulations, which includes a custom visualization tools to provide map-based view of scenarios that have been evaluated in IEISS. The goal has been to identify potential impacts to critical infrastructures dependent upon electric power. SLV has principally been used during fast-response exercises for analysis of hurricane impacts (restoration of hurricanes Charlie and Ivan in '04; Dennis, Katrina, Ophelia, Rita, Wilma in '05) SLV has also modeled electric power restoration during ice storms and during DOE-sponsored exercises involving low-voltage scenarios. 


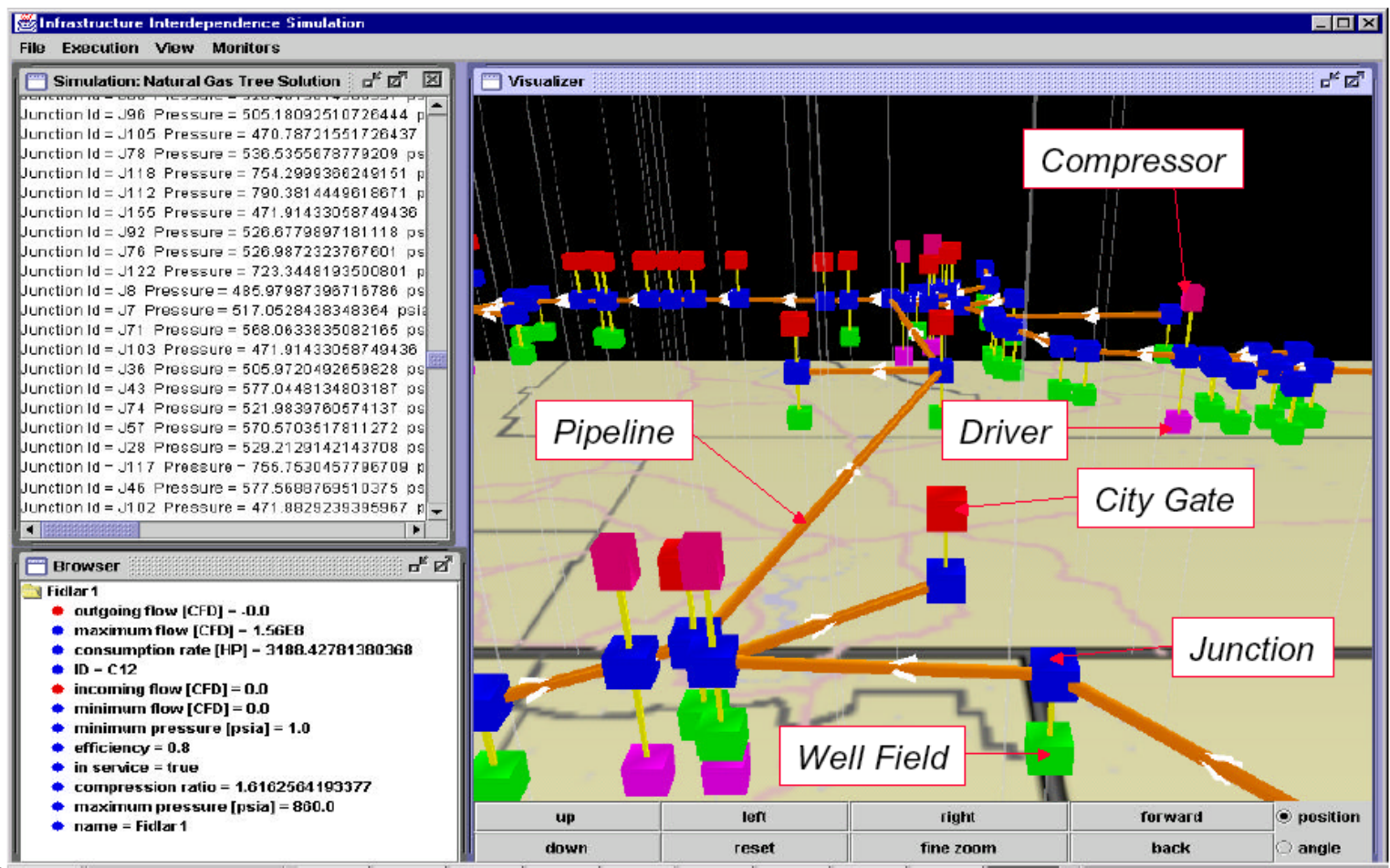

\section{References}

"NISAC Energy Sector - IEISS," NISAC Capabilities Workshop, LA-UR-03-1159, Portland, Oregon, 26-27 March 2003.

Los Alamos National Laboratory, "Energy Infrastructure Modeling at LANL," LALP-03-027, LA-UR-03-0658.

Los Alamos National Laboratory, "Energy and Environmental Programs Compendium," LA-LP-02-216. 


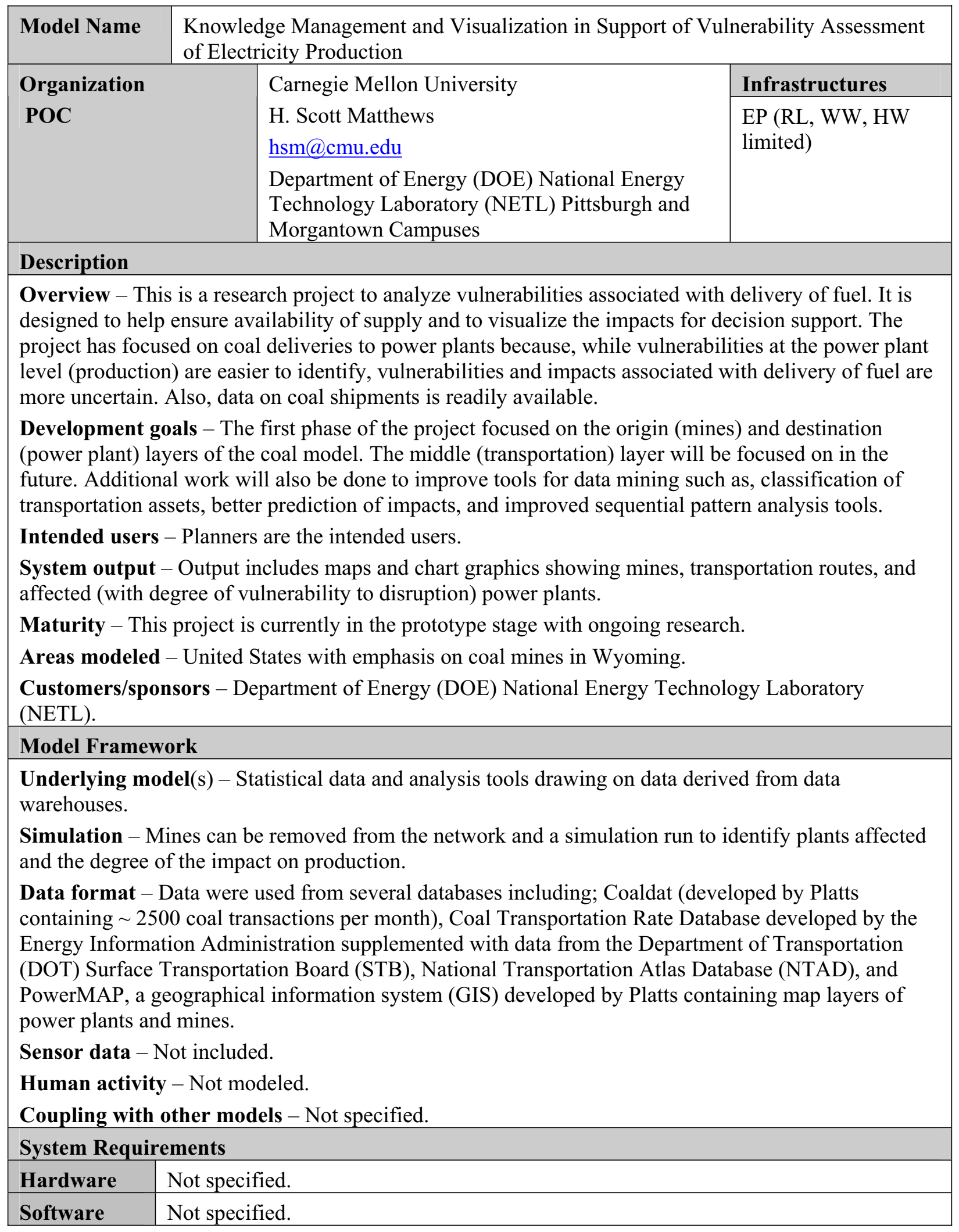




\section{Other Notes}

The Transportation Routing Analysis Geographic Information System (TRAGIS) developed by Oak Ridge National Laboratory (ORNL) was evaluated to help with the problem of routing (of coal supplies). TRAGIS is designed to schedule possible routes by selecting the origin and destination with one transportation mode (e.g., highway, rail, and waterway modes) and route type (e.g., commercial [default], quickest, shortest, and others). Currently, it is not able to schedule routes for multimodal transportation as is often used to deliver coal. While the most frequently used mode of transporting coal is railroad, many transactions are shipped multimode, such as by barge then by railroad. Therefore, a multimodal route scheduling solution is necessary for acquiring more accurate transportation analyses.
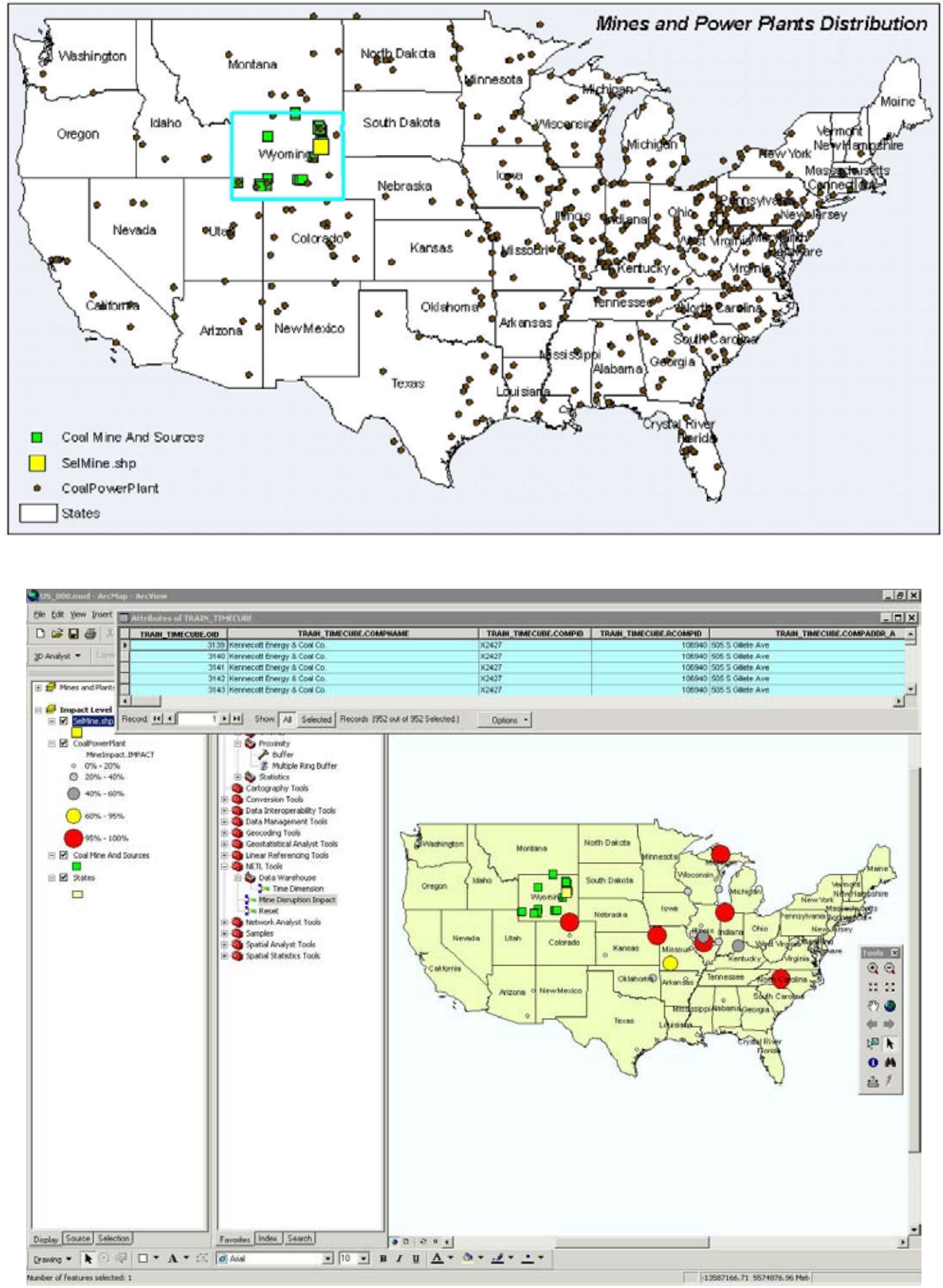


\section{References}

Information in the preceding section was obtained from draft report and communications with point of contact. 


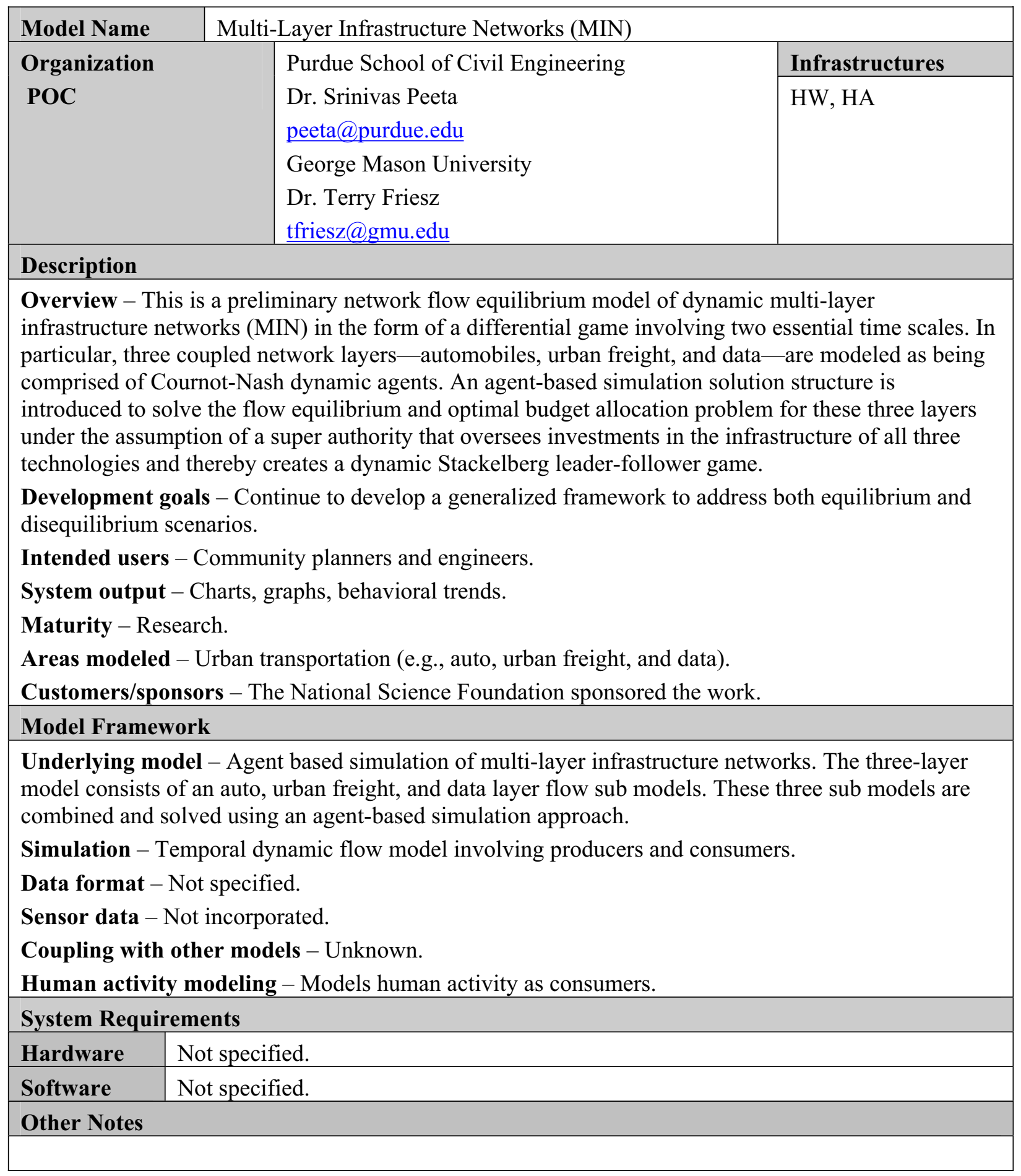

\section{References}




\begin{tabular}{|c|c|c|}
\hline Model Name & \multicolumn{2}{|c|}{$\begin{array}{l}\text { Multi-Network Interdependent Critical Infrastructure Program for Analysis of } \\
\text { Lifelines (MUNICIPAL) }\end{array}$} \\
\hline \multirow{2}{*}{$\begin{array}{l}\text { Organization } \\
\text { POC }\end{array}$} & Rensselaer Polytechnic Institute (RPI) & Infrastructures \\
\hline & $\begin{array}{l}\text { Earl E. Lee II } \\
\text { Leee7@,rpi.edu } \\
\text { William A. Wallace } \\
\text { wallaw@,rpi.edu } \\
\text { John E. Mitchell } \\
\text { mitchj@rpi.edu } \\
\text { David M. Mendonca } \\
\text { mendonca@njit.edu }\end{array}$ & $\mathrm{TC}, \mathrm{EP}, \mathrm{RL}$ \\
\hline \multicolumn{3}{|l|}{ Description } \\
\hline \multicolumn{3}{|c|}{$\begin{array}{l}\text { Overview - Multi-Network Interdependent Critical Infrastructure Program for Analysis of Lifelines } \\
\text { (MUNICIPAL) is a geographic information system (GIS) user interface, built on a formal, } \\
\text { mathematical representation of a set of civil infrastructure systems that explicitly incorporates the } \\
\text { interdependencies among them. The mathematical foundation or decision support system is called the } \\
\text { Interdependent Layered Network (ILN) model. ILN is a mixed-integer, network-flow based model } \\
\text { implemented in software drawing on a database containing infrastructure attributes. MUNICIPAL } \\
\text { provides the capability to understand how a disruptive event affects the interdependent set of civil } \\
\text { infrastructures. This can help communities train for and respond to events that disrupt services required } \\
\text { for their health, safety, and economic well being. It can be used to help assess the vulnerability of } \\
\text { systems due to their reliance on other systems. The model is generic (applicable to more than one } \\
\text { location) and not specific to a particular type of event, such as an earthquake or hurricane. }\end{array}$} \\
\hline \multicolumn{3}{|c|}{$\begin{array}{l}\text { Development goals - Once the Los Angeles and Manhattan data sets are complete, mathematical and } \\
\text { technical assessments will be conducted. The system will also be evaluated by infrastructure system } \\
\text { managers and emergency response organizations. }\end{array}$} \\
\hline \multicolumn{3}{|c|}{$\begin{array}{l}\text { Intended users - MUNICIPAL is intended for use by personnel in charge of response and restoration } \\
\text { efforts following a disruptive event and as a training tool for personnel who guide response and } \\
\text { restoration efforts. }\end{array}$} \\
\hline \multicolumn{3}{|c|}{$\begin{array}{l}\text { System output - A GIS interface displays systems and identifies affected areas. An operator can } \\
\text { update the conditions of components of the set of systems modeled, add temporary systems during } \\
\text { restoration, and display areas affected by inabilities to meet demands. }\end{array}$} \\
\hline \multicolumn{3}{|c|}{ Maturity - Prototype system. } \\
\hline \multicolumn{3}{|c|}{ Areas modeled - Manhattan, NY and Los Angeles, CA. } \\
\hline \multicolumn{3}{|c|}{ Model Framework } \\
\hline \multicolumn{3}{|c|}{$\begin{array}{l}\text { Underlying model - MUNICIPAL consists of a GIS interface for the user, a database with the } \\
\text { attributes of the set of infrastructures, the ILN module, and the vulnerability module. }\end{array}$} \\
\hline \multicolumn{3}{|c|}{$\begin{array}{l}\text { Simulation - With identification of paths or components of concern, MUNICIPAL identifies } \\
\text { components in the parent system which these paths or components rely on. For example, placing power } \\
\text { supply components in a failed condition will identify telecommunications components that rely on } \\
\text { these sections of power to fail. By proposing new connections within telecomm, MUNICIPAL can help } \\
\text { to determine if a feasible path (or paths) exists and the set of nodes that constitute this path (or set of } \\
\text { paths). MUNICIPAL can also be used for the addition of temporary or alternative power sources or any } \\
\text { other analyses relating to improving reliability by adding redundancy. } \\
\text { Data format - ESRI ArcGIS, relational database, text. }\end{array}$} \\
\hline
\end{tabular}


Sensor data - Not currently configured for sensor data.

Coupling with other models - Not specified.

Human activity modeling - Not specified.

\section{System Requirements}

\begin{tabular}{l|l}
\hline Hardware & Not specified. \\
\hline Software & Not specified. \\
\hline
\end{tabular}

Other Notes

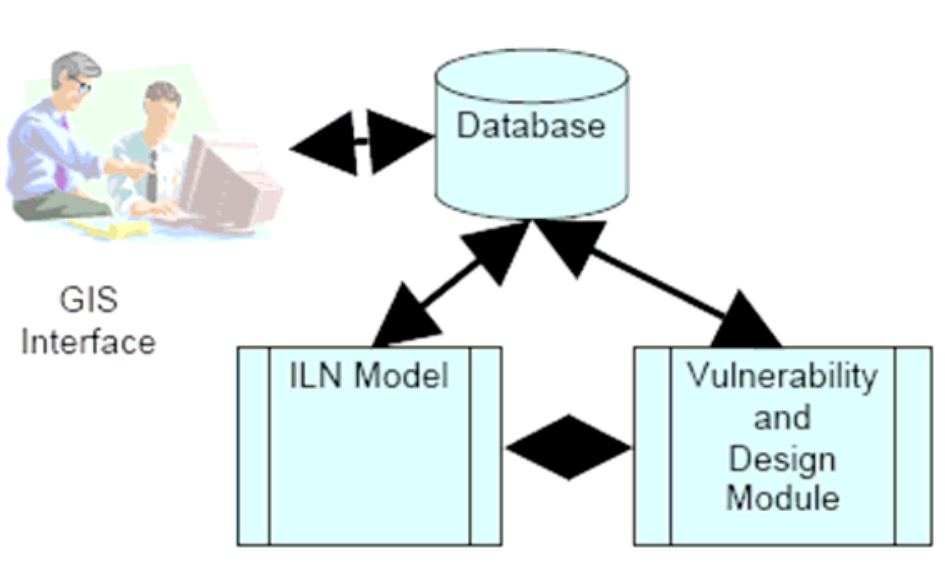

Figure 1

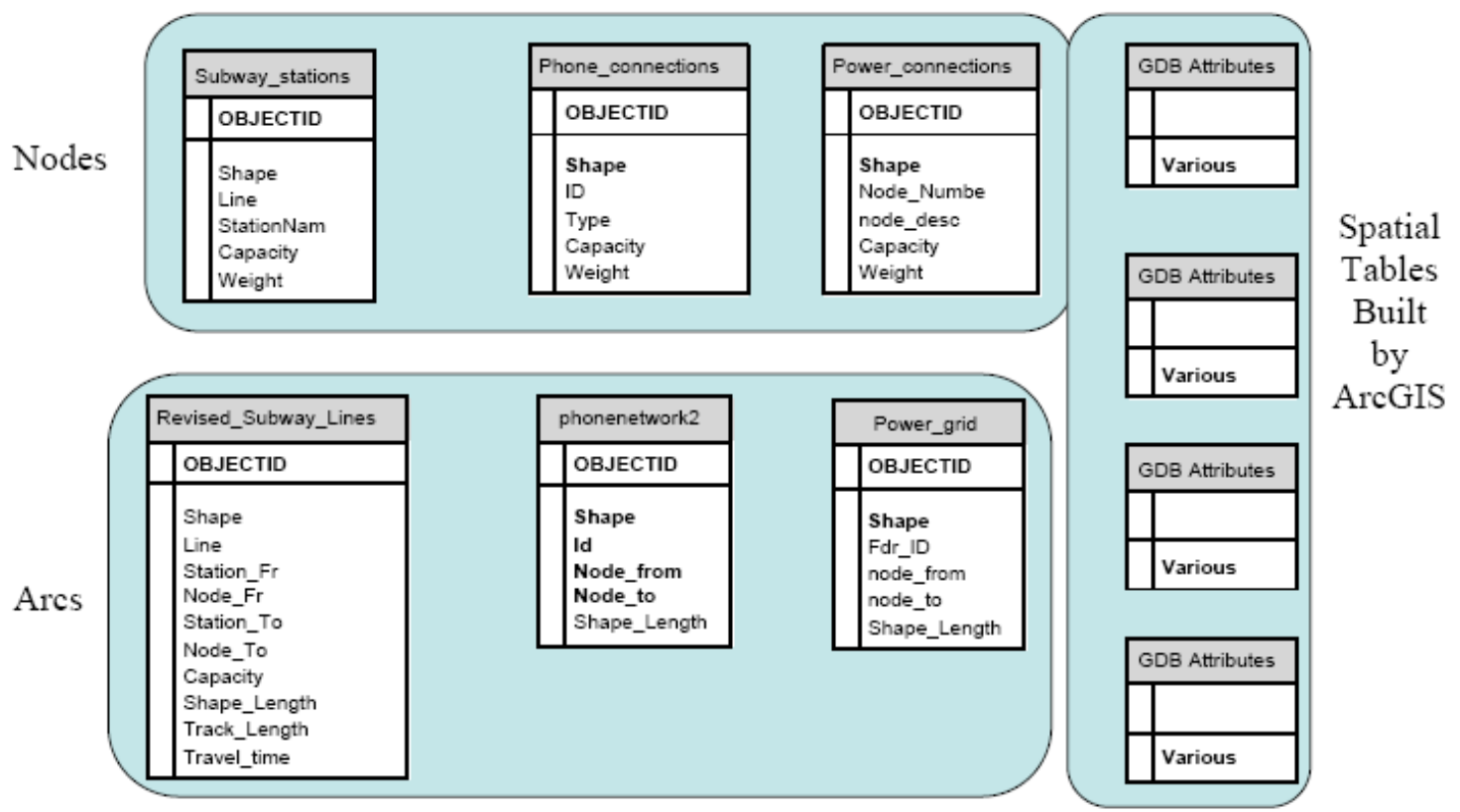

\section{References}

Lee, Earl E. II, et al., Decision Technologies for Protection of Critical Infrastructures, http://www.rpi.edu/ mitchj/papers/decisiontechnologies.pdf\#search='decision\%20technologies, Webpage visited July 10, 2006. 


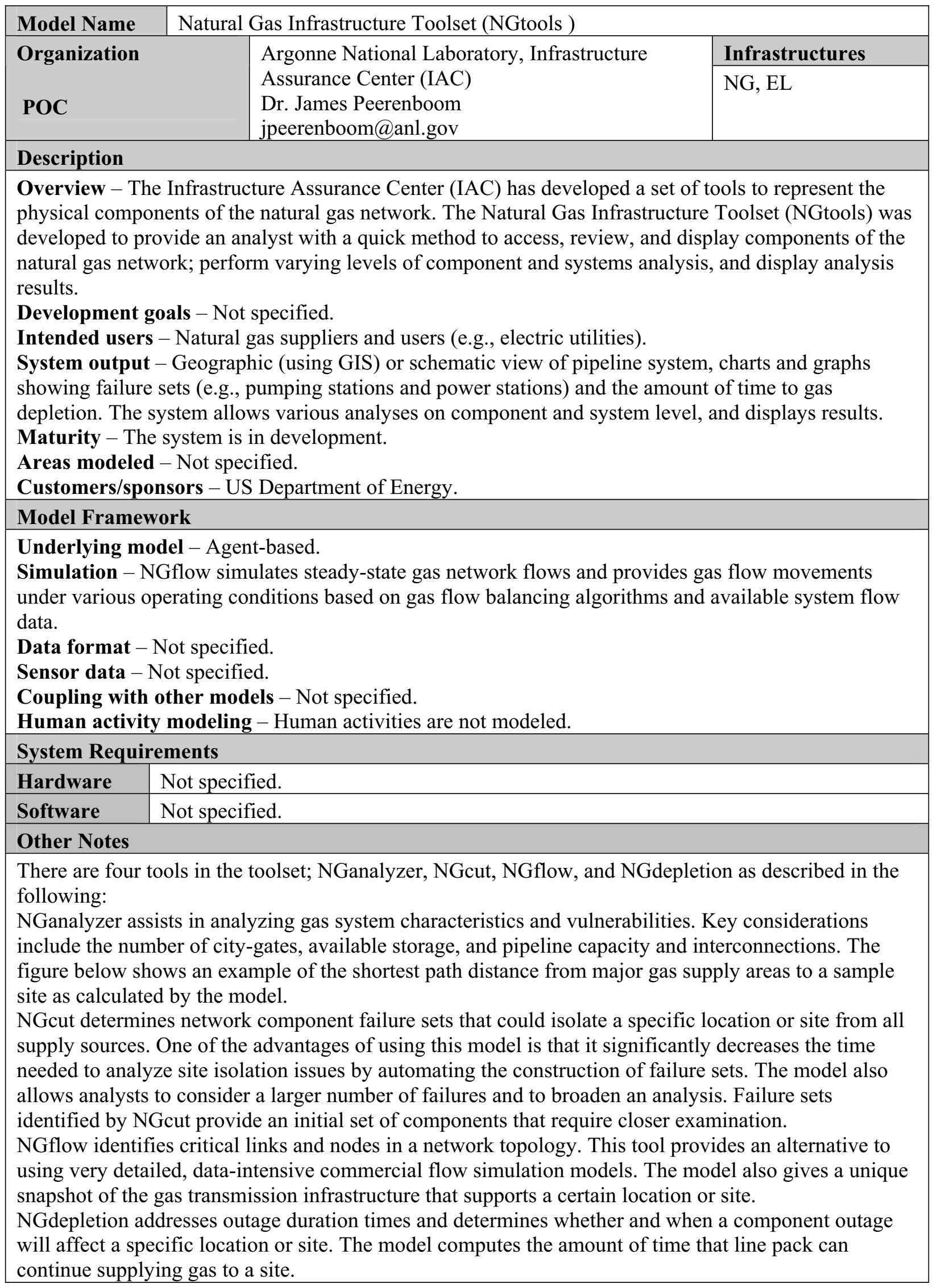



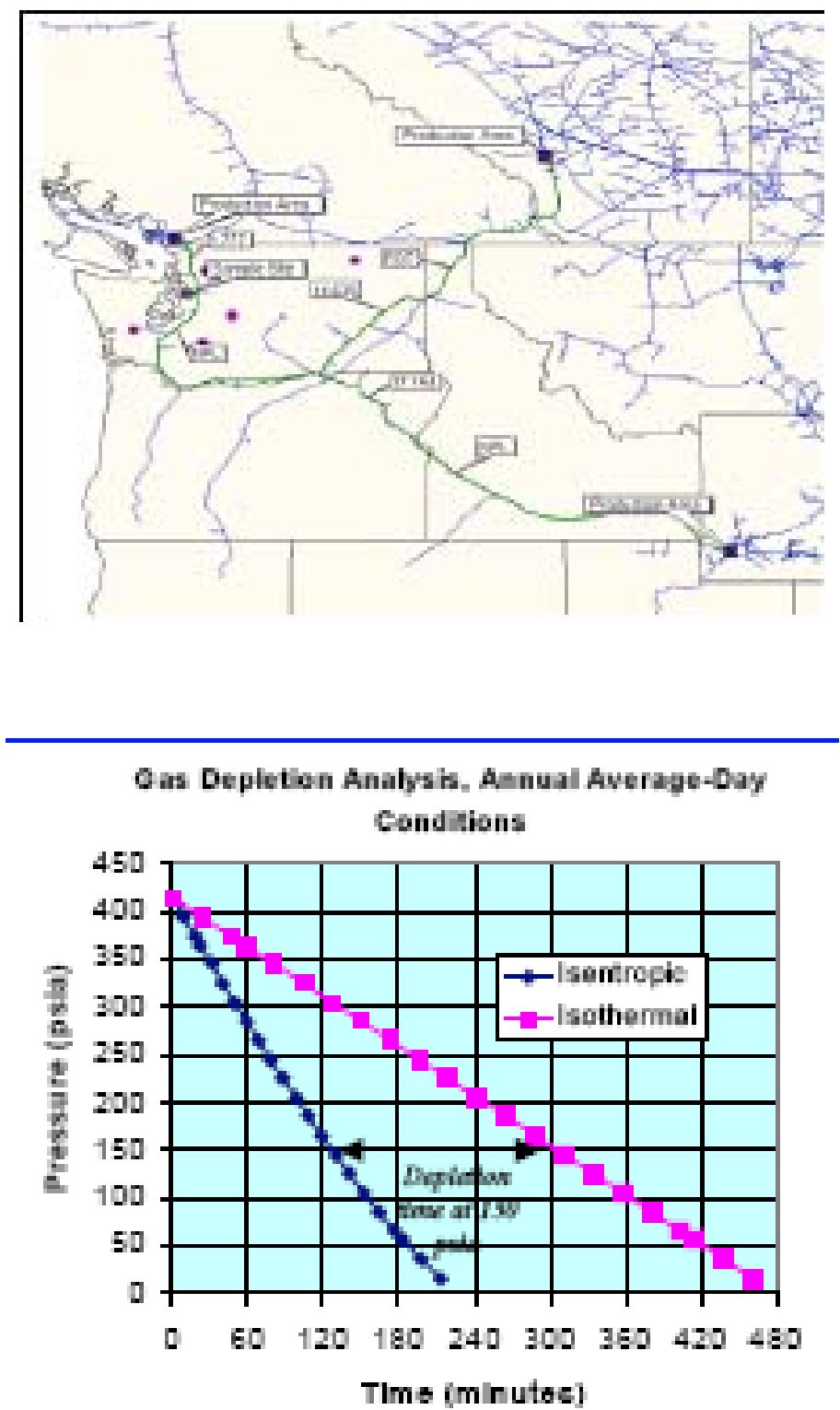

References 


\begin{tabular}{|c|c|c|}
\hline Model Name & \multicolumn{2}{|c|}{ Net-Centric Effects-based operations MOdel ( $\mathrm{N}$} \\
\hline \multirow{2}{*}{$\begin{array}{l}\text { Organization } \\
\text { POC }\end{array}$} & & Infrastructures \\
\hline & $\begin{array}{l}\text { Goodwin } \\
\text { dwin@sparta.com }\end{array}$ & TC, EP, NG, DW \\
\hline \multicolumn{3}{|l|}{ Description } \\
\hline \multicolumn{3}{|c|}{$\begin{array}{l}\text { Overview - Net-Centric Effects-based operations MOdel (NEMO) is an effects-based planning and } \\
\text { analysis application for modeling the cascading effects of events across multiple infrastructure } \\
\text { networks. It is a Net-Centric compliant application, relying on a service oriented architecture (SOA) } \\
\text { approach to access infrastructure models, data repositories, and mapping tools. NEMO models } \\
\text { interactions across electrical power, water, gas, and road networks using an on/off interaction behavior } \\
\text { between the components of the different networks, and provides a solid foundation for advancement. } \\
\text { NEMO provides a first of its kind capability for observing second and higher order effects of } \\
\text { operations against opponents' infrastructure networks. } \\
\text { Development goals - Efforts are underway to integrate social/political networks into the effects-based } \\
\text { operation (EBO) process. Future development needs to enhance the program capabilities for integrating } \\
\text { additional relationship definitions, multi-agent capabilities, and optimization. } \\
\text { Intended users - Planners and analysts are the intended users. } \\
\text { System output - NEMO displays maps overlaid with nodes and linkages between various } \\
\text { infrastructures. Disruptions and cascading effects are highlighted during simulations. } \\
\text { Maturity - This is a prototype system. } \\
\text { Areas modeled - Not specified. } \\
\text { Customers/sponsors - NEMO was internally developed by SPARTA. }\end{array}$} \\
\hline \multicolumn{3}{|c|}{ Model Framework } \\
\hline \multicolumn{3}{|c|}{$\begin{array}{l}\text { Underlying model - The graphical user interface (GUI) is backed by an SOA consisting of two web } \\
\text { services; one accesses to a geo-spatial database for storage and retrieval of network databases, and the } \\
\text { other coordinates interaction with the various infrastructure models used to provide network status } \\
\text { feedback. The geo-spatial database web service, Earth Resource Terrain Hierarchical Archive } \\
\text { (ERTHA), contains nearly 200GB of network definitions that may be accessed via the NEMO GUI and } \\
\text { used to support effects-based analysis. ERTHA is a geographical information system (GIS) database, } \\
\text { based on ESRI products, of infrastructure data items (e.g., power lines, road networks) that were } \\
\text { developed as an unclassified source. Abstracting access to data through a web service decouples } \\
\text { NEMO from a specific database and specific vendors, making it possible to integrate other data sources } \\
\text { in the future. } \\
\text { Simulation - NEMO provides a basic capability for effects-based planning and performing "what if" } \\
\text { analysis of actions. } \\
\text { Data format - Data is in Environmental Systems Research Institute's (ESRI) ERTHA relational } \\
\text { database format. Other models utilize a model interface client (MIC) translator and eXtensible Markup } \\
\text { Language (XML). } \\
\text { Sensor data - Not included. } \\
\text { Human activity modeling - Changes to include human activity modeling are in progress. } \\
\text { Coupling with other models - NEMO integrates four infrastructure models: lines of communications, } \\
\text { electrical power, gas pipelines, and water pipelines. The models used to evaluate these networks are } \\
\text { industry best-of-breed simulation tools for their domains. CitiLabs' Voyager simulation provides road } \\
\text { and rail network analysis, while Advantica (formerly Stoner Engineering) provides the Solver tools for } \\
\text { electrical power networks as well as the water and gas pipelines. }\end{array}$} \\
\hline \multicolumn{3}{|c|}{ System Requirements } \\
\hline & & \\
\hline & & \\
\hline
\end{tabular}




\section{Other Notes}

Efforts are ongoing and mostly complete to integrate social/political networks into the EBO process. For the most part, these efforts are complete. We have integrated the Political Science-Identity (PSI) model (from University of Pennsylvania, Dr. Ian Lustick) into our architecture, and have developed operators that alter the contentedness of a population based on associated physical infrastructure. Further information on PS-I is available at http://jasss.soc.surrey.ac.uk/5/3/7.html.
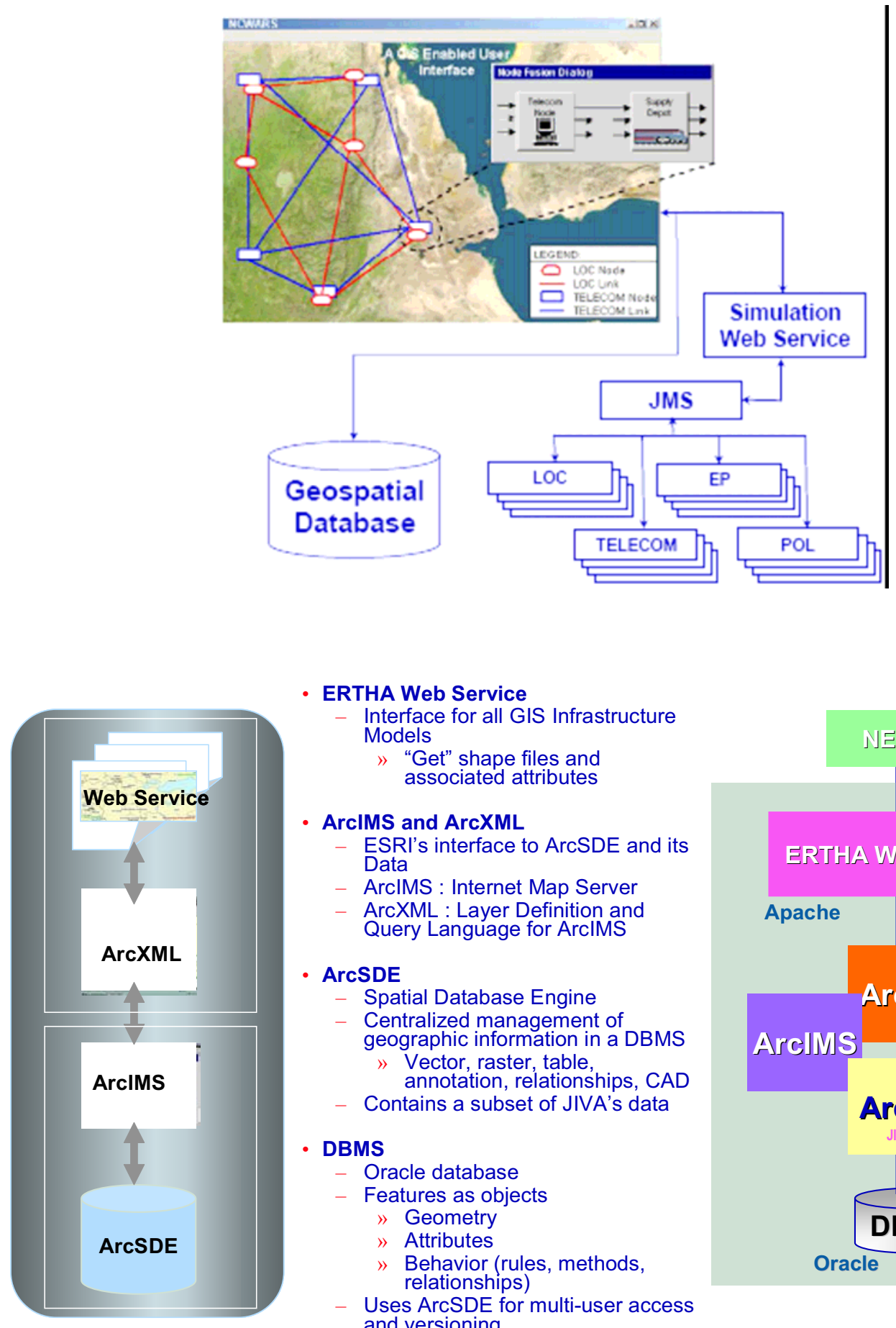

- ERTHA Web Service

Interface for all GIS Infrastructure Models

»"Get" shape files and associated attributes

- ArcIMS and ArcXML

ESRI's interface to ArcSDE and its Data

ArcIMS : Internet Map Server

- ArcXML : Layer Definition and Query Language for ArclMS

\section{- ArcSDE}

- Spatial Database Engine

- Centralized management of geographic information in a DBMS

" Vector, raster, table, annotation, relationships, CAD

Contains a subset of JIVA's data

- DBMS

- Oracle database

- Features as objects

» Geometry

"Attributes

" Behavior (rules, methods, relationships)

Uses ArcSDE for multi-user access and versioning

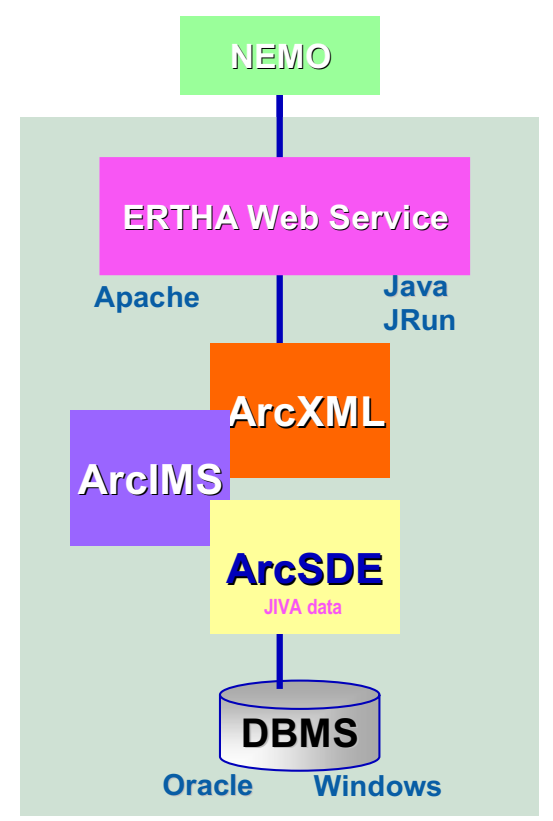




\section{References}

JASSS, PS-1: A User-Friendly Agent-Based Modeling Platform for Testing Theories of Political

Identity and Political Stability, http://jasss.soc.surrey.ac.uk/5/3/7.html, Webpage visited July 3, 2006.

Sparta, Planning and Assessing Effects Based Operations, www.sparta.com/sew/publications/NEMO-

for-ICCRTS.pdf, Webpage visited July 3, 2006. 


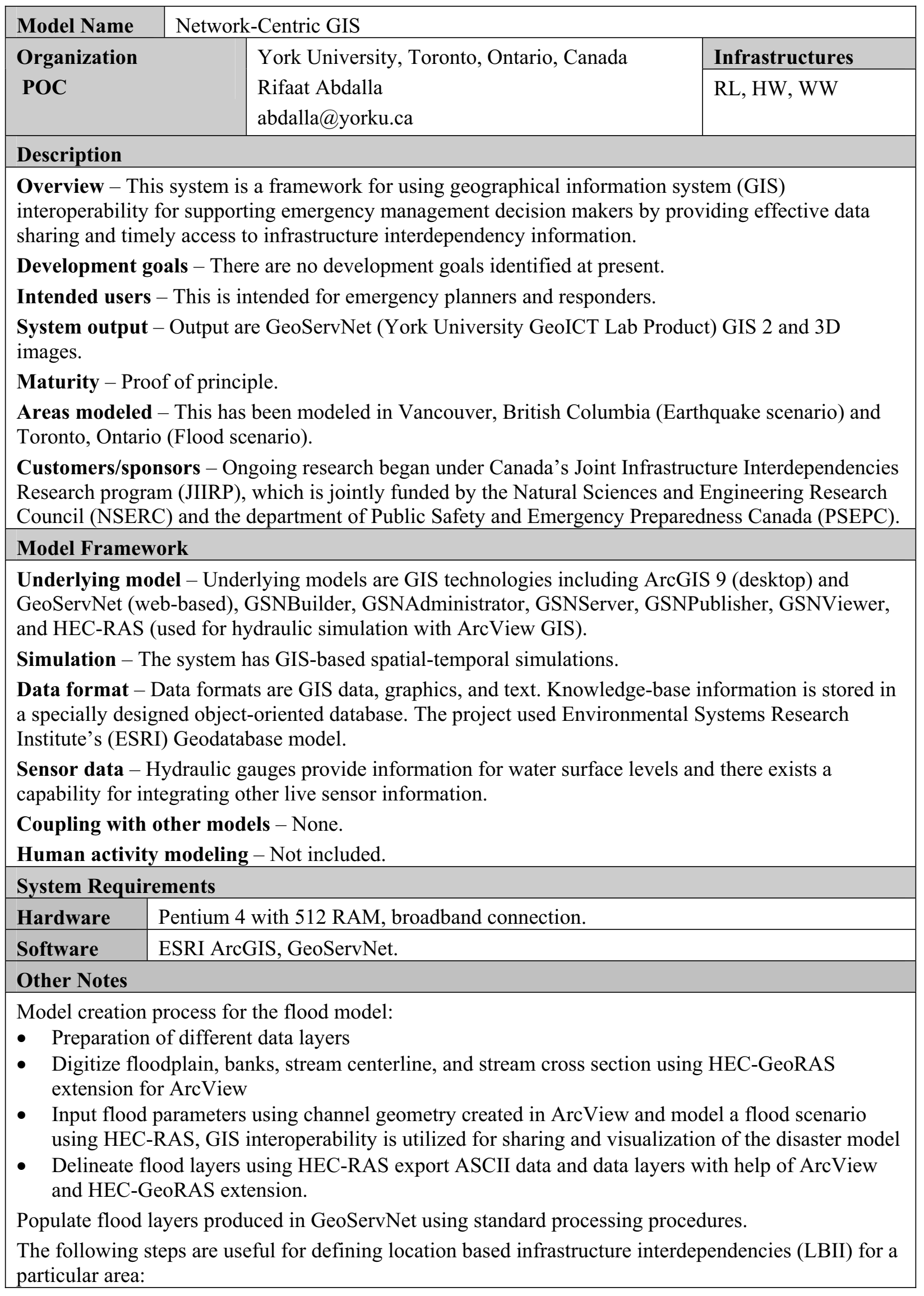


- Identify critical infrastructure sectors in the study area

- Analyze processes and operations for each sector

- Analyze dependencies

- Determine Interdependencies

- Collect data

- Model and visualize (interoperable 3D internet-based).

Earthquake scenario modeling is based on using a Geological Survey of Canada Shakemap for the city of Vancouver.

Critical infrastructure at risk was identified based on GIS modeling.

Building damage density was analyzed based on IKONOS satellite imagery.

Population at risk was identified based on census information and the Shakemap.

Location based infrastructure interdependency was modeled.

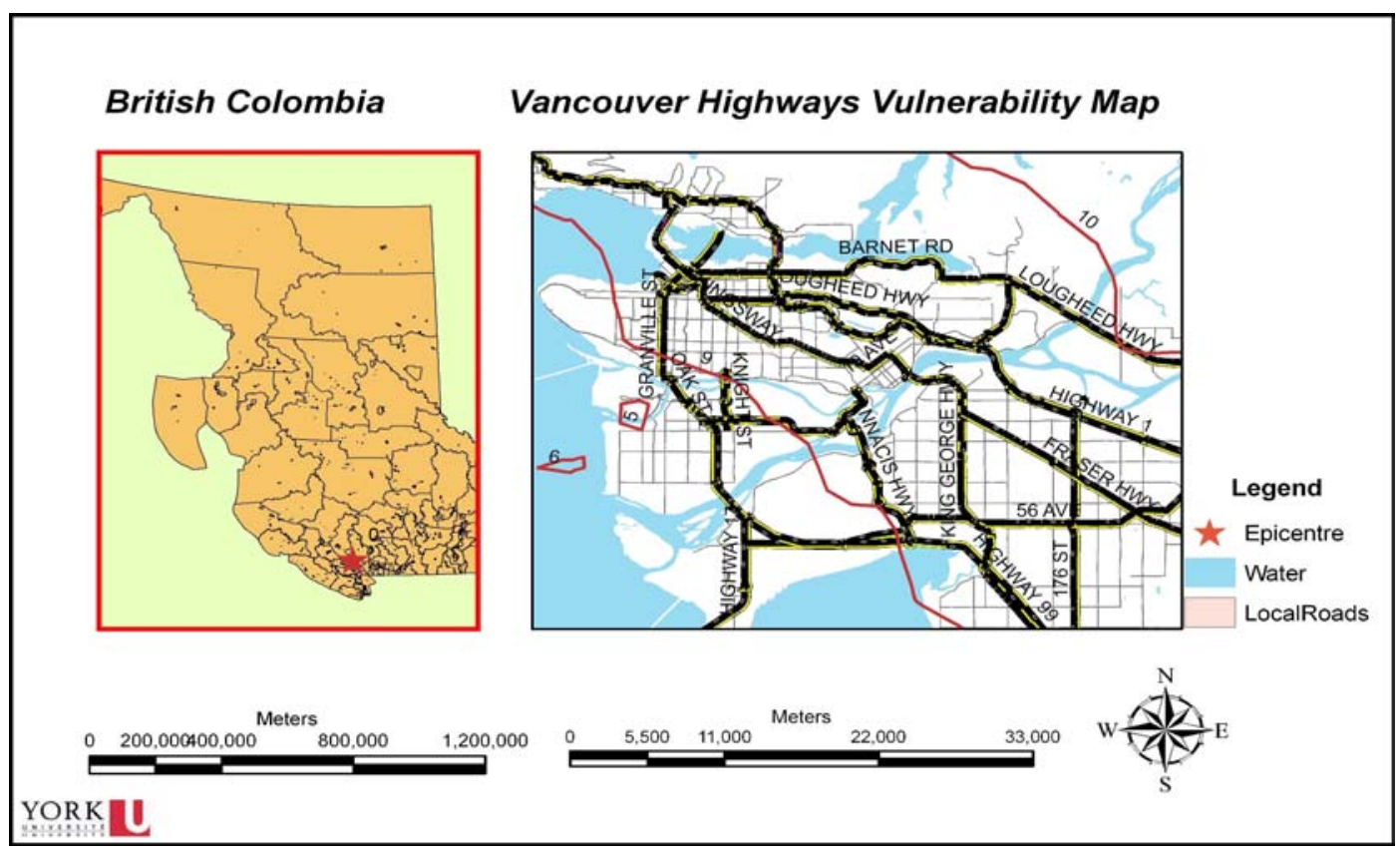

Spatial Model Showing Critical Infrastructures at Risk 


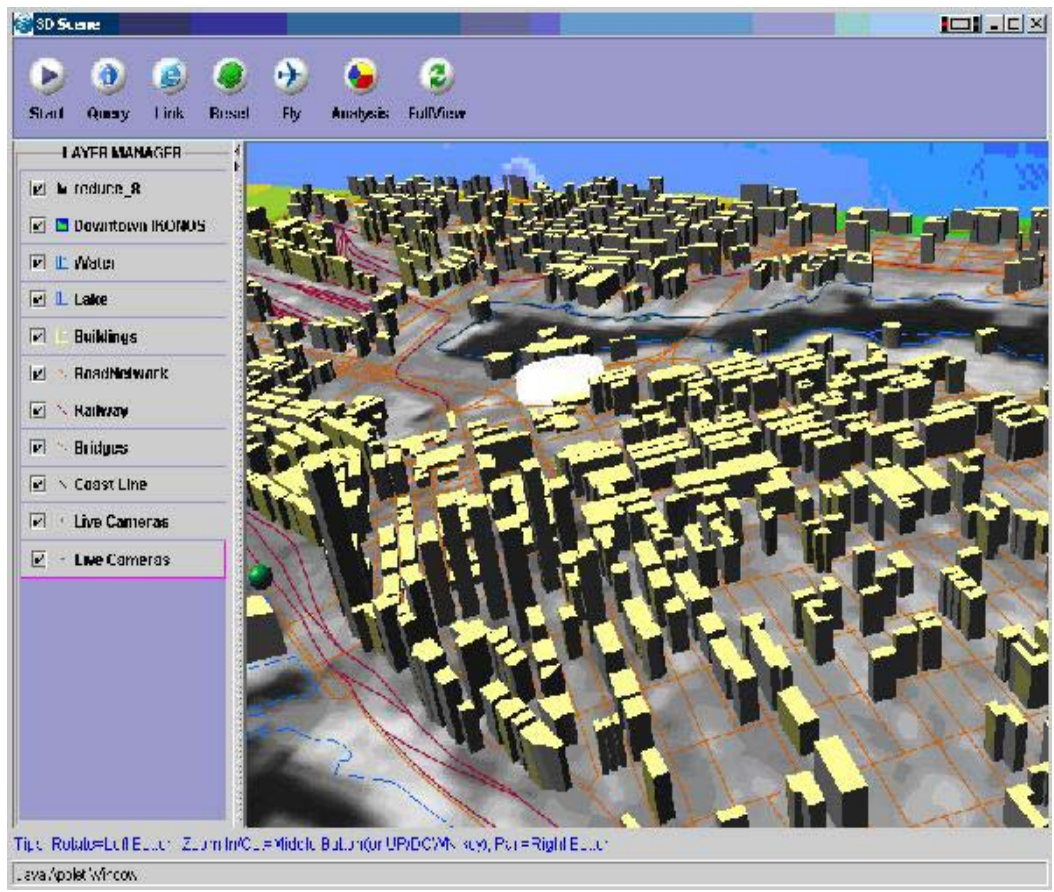

GeoServNet 3D Damage Assessment Model of Downtown Vancouver

\section{References}

Abdalla, R. Tao, V. and H. Ali., 2005. "Location-Based Infrastructure Interdependency: New Term, New Modeling Approach," Proceedings of Geoinformatics 2005, Toronto, August 17-19, 2005 CD.

Abdalla, R., K. Niall, and V. Tao, 2005. "A framework for modeling Critical Infrastructure Interdependency Using GIS," Canadian Risk and Hazard Symposium, Toronto, 19-21 November 2005.

Joint Infrastructure Interdependency Research Program, Modeling Infrastructure Interdependency for Emergency Management Using a Network-Centric Spatial Decision Support System Approach, www.geoict.yorku.ca/JIIRP/Jiirp.htm, Webpage visited July 10, 2006. 


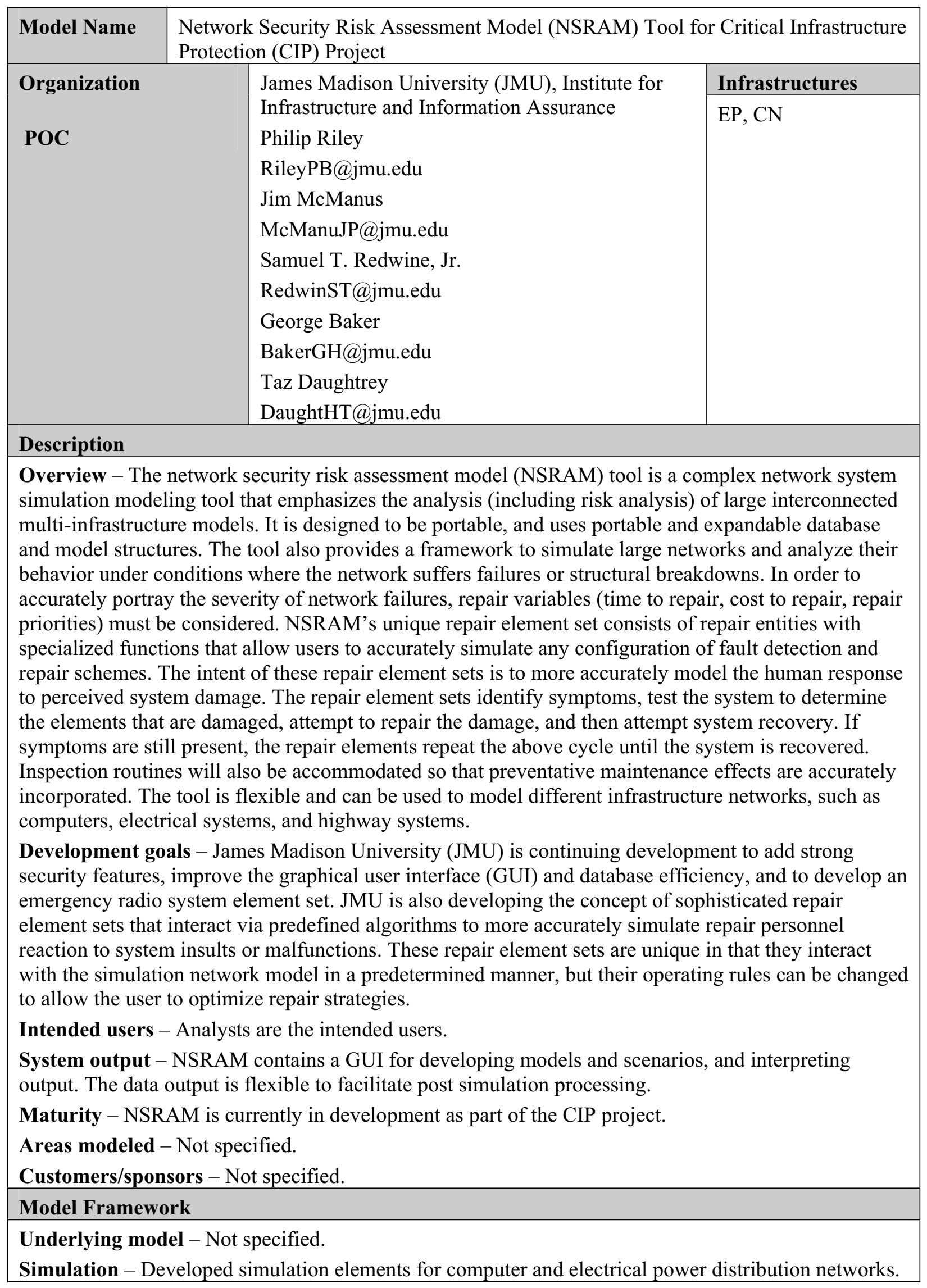


Data format - Not specified.

Sensor data - Not specified.

Human Activity - NSRAM models human activities such as responses to system damage.

Coupling with other models - Not specified.

System Requirements

Hardware $\quad$ Not specified.

Software $\quad$ Not specified.

\section{Other Notes}

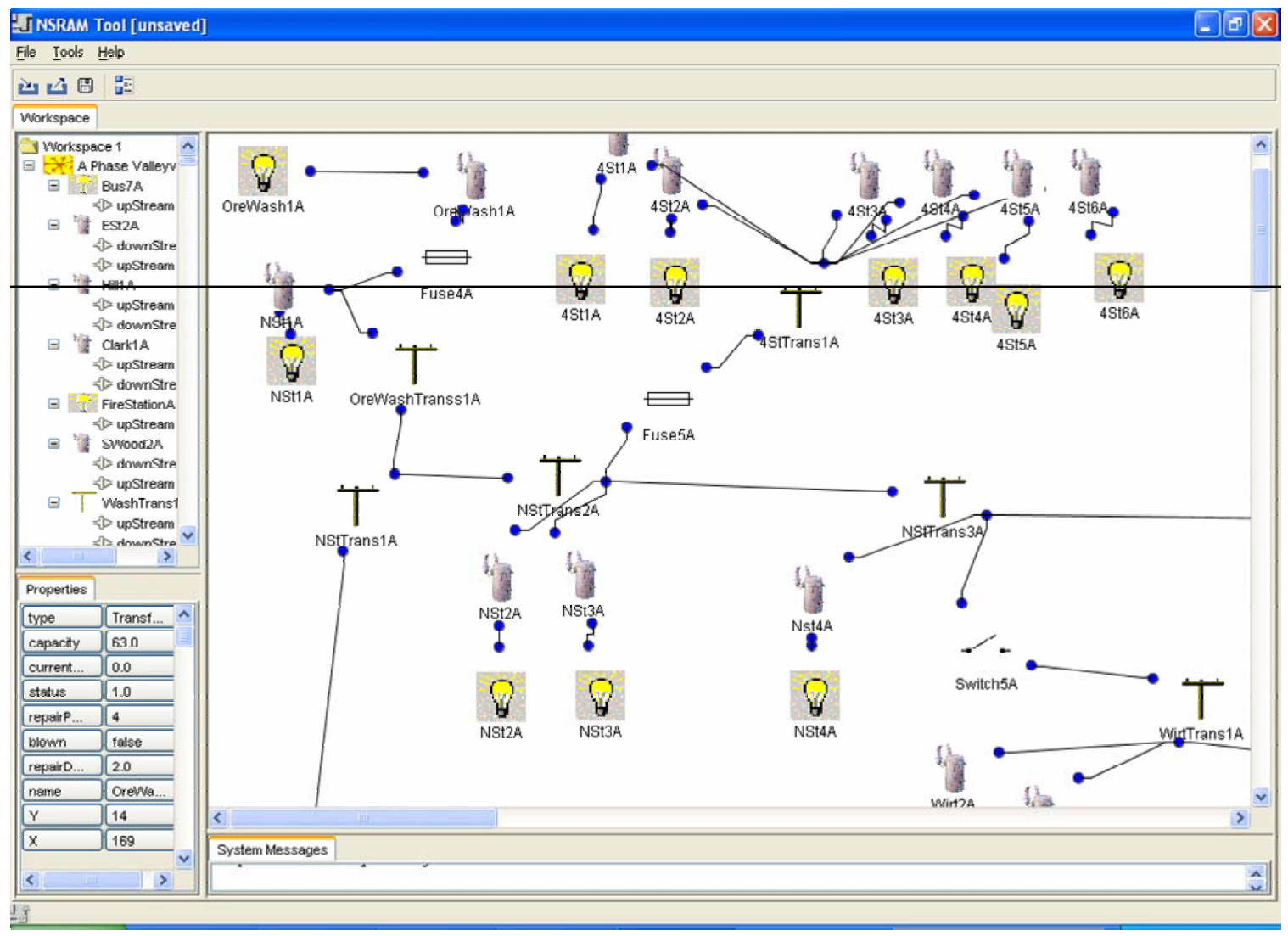

\section{References}

McManus, Jim, et al., Network Security Risk Assessment Model(NSRAM) Tool for Critical

Infrastructure Protection Project, http://www.jmu.edu/iiia/webdocs/ppt_NSRAM Tool.ppt, July 12, 2006.

Redwine, Sam, et al., Network Security Risk Assessment Model Tool, http://www.jmu.edu/cisat/frd/abstracts04/redwine_sam.html, April 3, 2006.

\begin{tabular}{|l|l|l|}
\hline Model Name & \multicolumn{2}{|l|}{ Next-generation agent-based economic 'laboratory' (N-ABLE) } \\
\hline $\begin{array}{l}\text { Organization } \\
\text { POC }\end{array}$ & $\begin{array}{l}\text { Sandia National Laboratory } \\
\text { Theresa Brown } \\
\text { tjbrown@sandia.gov }\end{array}$ & Infrastructures \\
\cline { 2 - 3 } & FIN, POL \\
\hline
\end{tabular}




\section{Description}

Overview - The NISAC Agent-Based Laboratory for Economics (N-ABLE) is a software system for analyzing the economic factors, feedbacks, and downstream effects of infrastructure interdependencies. $\mathrm{N}-\mathrm{ABLE}$ is a simulation environment in which hundreds of thousands to millions of individual economic actors simulate real-world manufacturing firms, households, and government agencies. NABLE can specifically address questions such as: 1 . Which economic sectors are most vulnerable to infrastructure disruptions and interdependencies? 2. What firms are most affected - who does well, poorly? 3 . What are the different qualitative and quantitative ways in which economic sectors use the energy, transportation, financial, and communication sectors? 4. What short-run infrastructure changes affect economic performance (and vice versa)? 5. How do systems of firms and individuals respond and adapt over time and over regions? 6. What economic mechanisms do national, state, and local governments have or need to have to assist firms and other economic sectors in their regions?

Development goals - Developed to provide decision makers with a firm-level understanding of the interdependencies between infrastructure sectors and the economy.

Intended users - Economic Analysts.

System Output - Geographical charts and statistical output.

Maturity - Mature Internal.

Areas modeled - Examples: chemical, food, financial, manufacturing sectors.

Customers/sponsors - Department of Homeland Security

\section{Model Framework}

Underlying model - N-ABLE models the economy at the level of the individual firm; each N-ABLE firm is complete with individual buyers, production supervisors, sellers, and strategic planners who collectively navigate through economic disruption and recovery. N-ABLE's simulations of thousands to millions of firms provide the fidelity necessary to understand and implement better infrastructure policies.

Simulation - Agent Based. N-ABLE microsimulates the economy using an agent-based discrete-event model. This modeling approach is well suited for investigating the behavior of complex, nonlinear stochastic systems like the economy. Agents start each time increment making decisions much like their real-life counterparts. Decisions about what actions to take are based either on probabilities computed from actual microeconomic data or on results of learning models such as genetic algorithms. These decisions include setting sales prices, purchasing products, setting production schedules, hiring workers, buying and selling financial instruments, conducting open market operations, and others. Macroeconomic variables, such as gross domestic product, inflation (CPI), and the unemployment rate are computed as individual-firm and aggregate system measures of the performance of the economy.

Data format - not specified.

Sensor data - None.

Ability to couple with other models - Not known.

Human activity modeling - Human in the loop activity supported within the simulation.

\section{System Requirements}

\begin{tabular}{l|l} 
Hardware & Computer cluster \\
\hline Software & Not specified. \\
\hline
\end{tabular}




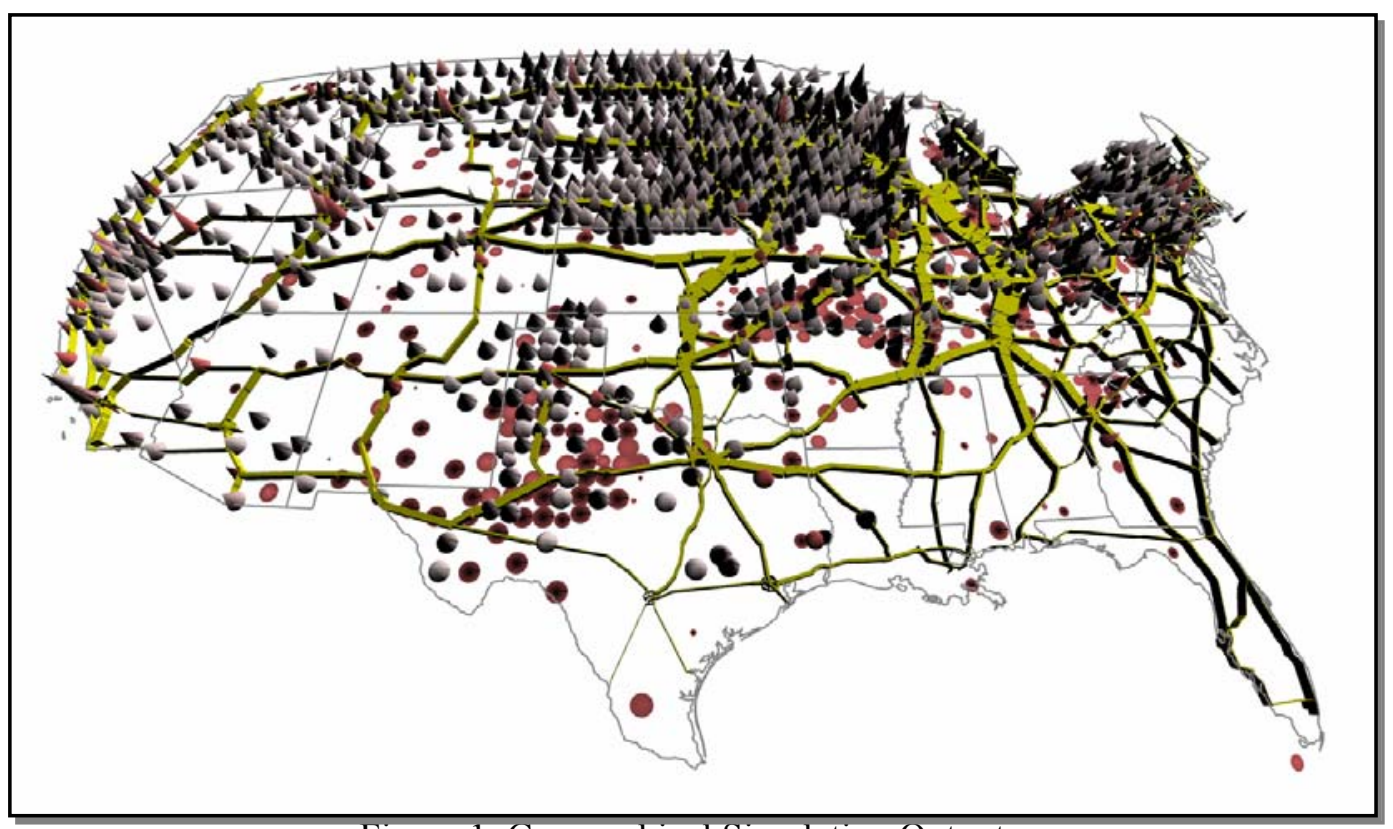

Figure 1. Geographical Simulation Output

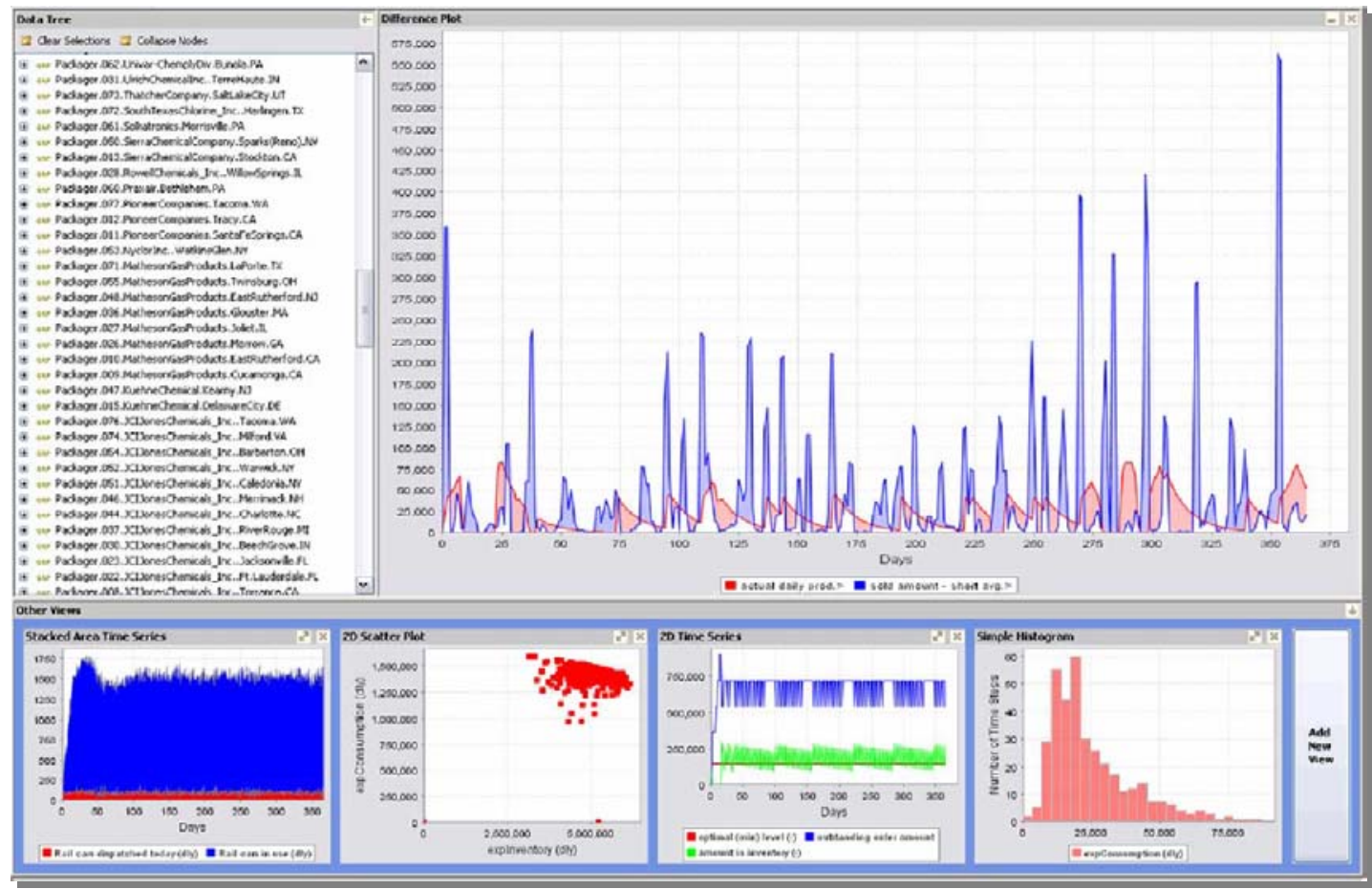

Figure 2. Statistical Simulation Output

\section{References}

NISAC Agent-Based Laboratory for Economics (N-ABLETM) Fact Sheet -

http://www.sandia.gov/mission/homeland/factsheets/nisac/NISAC N-ABLE factsheet.pdf 


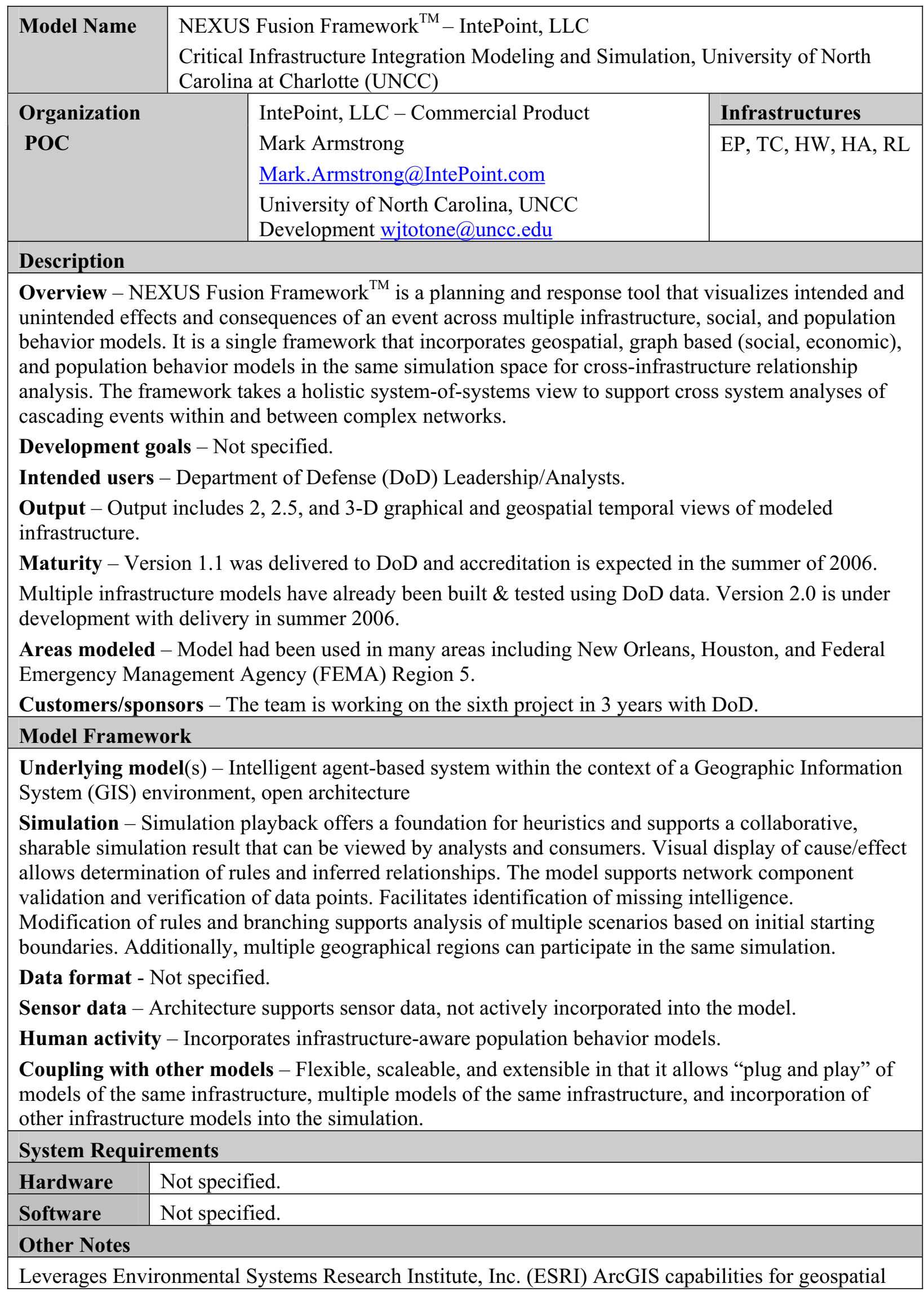


display and analysis.

Uses ESRI ArcGIS Geodatabase to capture:

- Critical attributes

- Critical relationships

- Predictive analytics

- Meta-driven inference engines

- System-of-systems causality analysis

- Temporal view

- Incorporates specialized functionality off-the-shelf as needed.

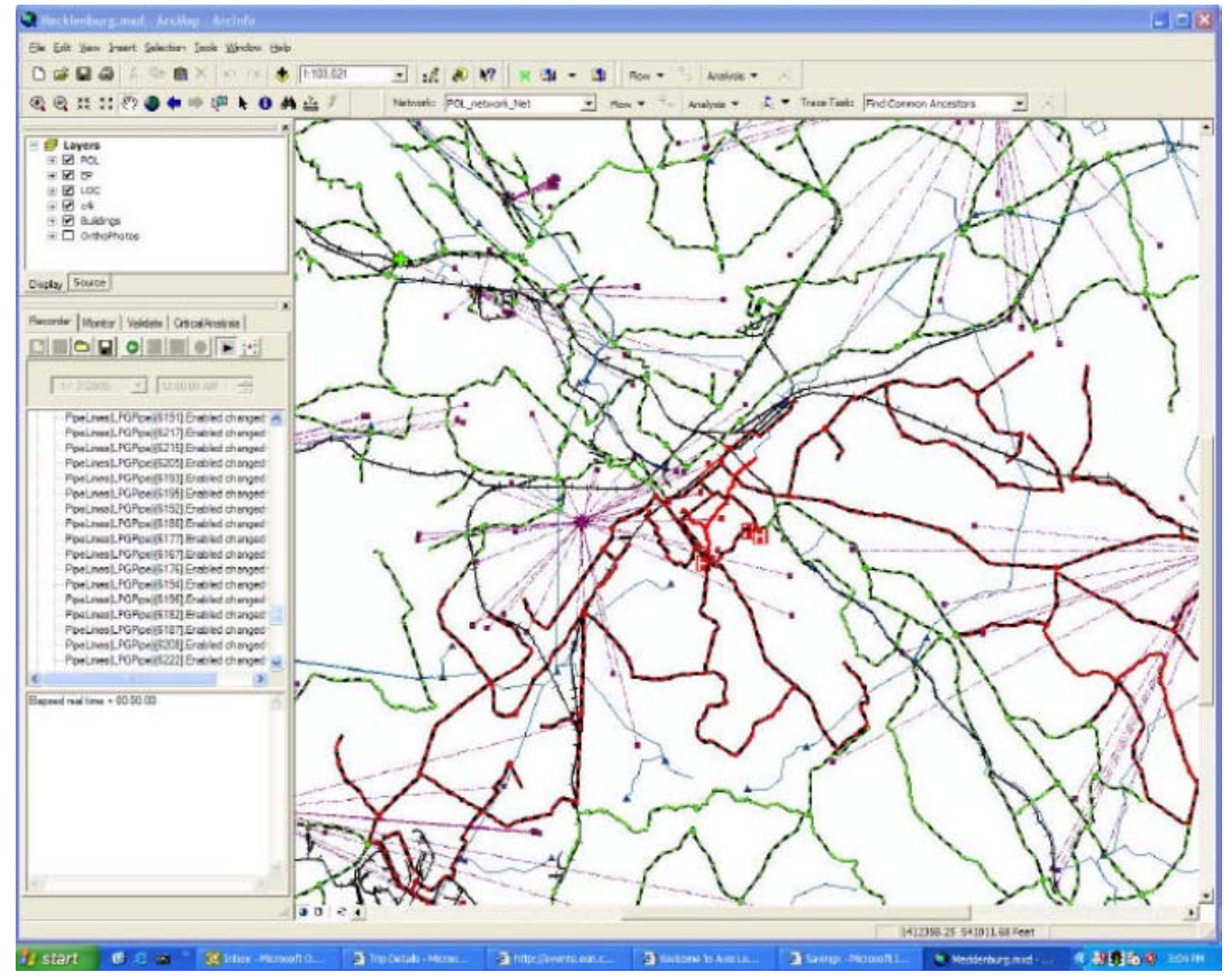




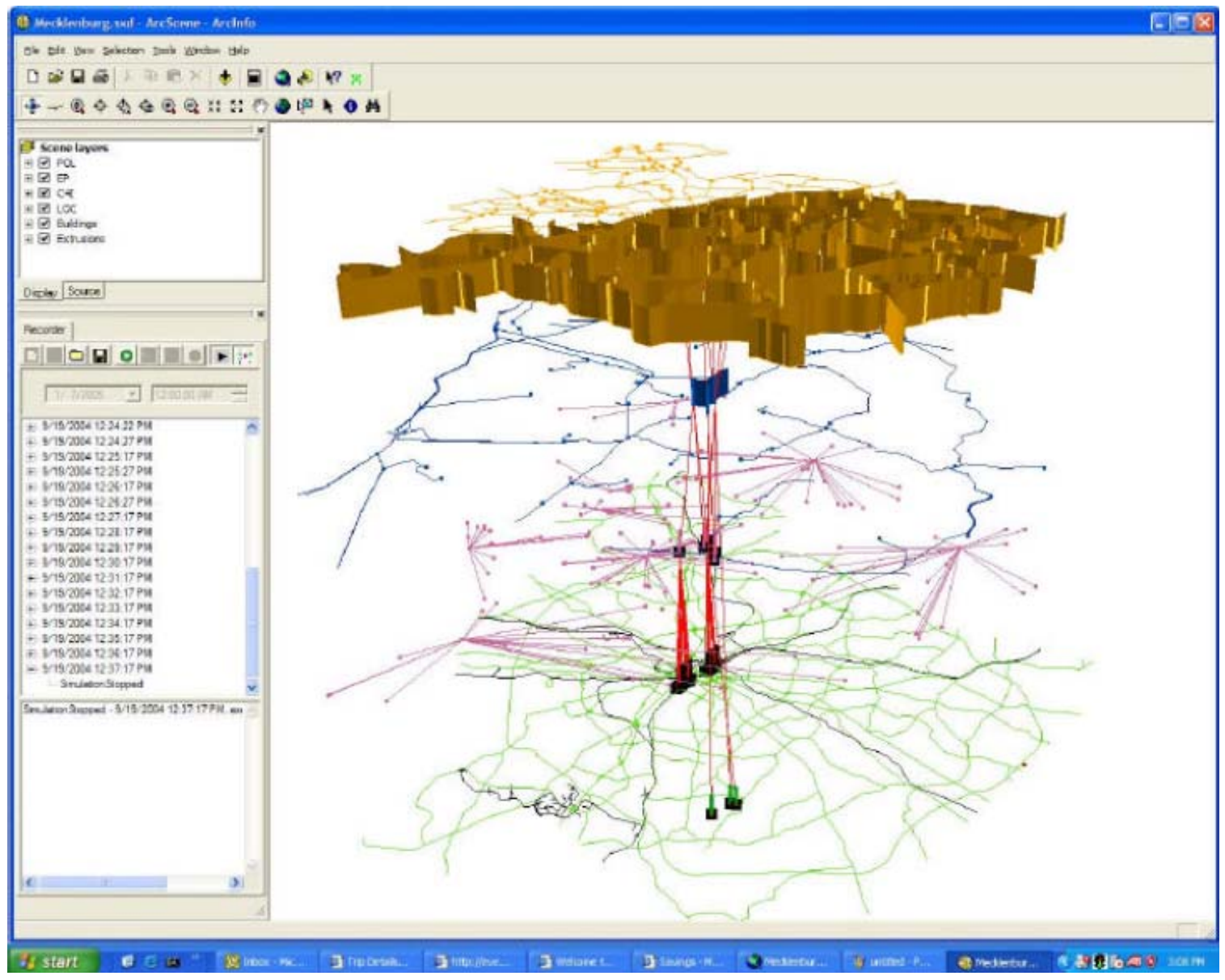

References 


\begin{tabular}{|c|c|c|}
\hline Model Name & \multicolumn{2}{|l|}{ Petroleum Fuels Network Analysis Model (PFNAM) } \\
\hline \multirow{2}{*}{$\begin{array}{l}\text { Organization } \\
\text { POC }\end{array}$} & \multirow{2}{*}{$\begin{array}{l}\text { Argonne National Laboratory, Infrastructure } \\
\text { Assurance Center } \\
\text { Steve Folga } \\
\text { sfolga@anl.gov }\end{array}$} & Infrastructures \\
\hline & & $\mathrm{NG}, \mathrm{OL}$ \\
\hline \multicolumn{3}{|l|}{ Description } \\
\hline \multicolumn{3}{|c|}{$\begin{array}{l}\text { Overview - Petroleum Fuels Network } \\
\text { calculations of pipeline transport of cru } \\
\text { segments), nodes (pipe junctions), pum } \\
\text { tracks the flow of oil in each pipe and t } \\
\text { analyst to create a representative mode } \\
\text { simulation. Graphical and tabular resul } \\
\text { impact of infrastructure disruptions on } \\
\text { framework for introducing pipeline cor }\end{array}$} \\
\hline \multicolumn{3}{|c|}{ Development goals - Not specified. } \\
\hline \multicolumn{3}{|c|}{ Intended users - Not specified. } \\
\hline \multicolumn{3}{|c|}{$\begin{array}{l}\text { System output - Results include graphs and tables for steady-state flow rate, pressure, and line } \\
\text { capacity distributions. The hydraulic gradient along the pipeline is also displayed. After a simulation, } \\
\text { the analysis results indicate the potential effect on pipeline operations. The diagram below indicates } \\
\text { that the long-term loss of a specific pump station can lead to isolation or curtailment of the deliveries of } \\
\text { petroleum fuels. }\end{array}$} \\
\hline \multicolumn{3}{|c|}{ Maturity - The system is in development into the DOT. NET framework. } \\
\hline \multirow{2}{*}{\multicolumn{3}{|c|}{$\begin{array}{l}\text { Areas modeled - Experts at Argonne have applied PFNAM to a number of crude oil and refined } \\
\text { petroleum products pipelines. Other potential applications are being explored. } \\
\text { Customers/sponsors - US Department of Defense. }\end{array}$}} \\
\hline & & \\
\hline \multicolumn{3}{|c|}{ Model Framework } \\
\hline \multirow{4}{*}{\multicolumn{3}{|c|}{$\begin{array}{l}\text { Underlying model - Mathematical model. } \\
\text { Simulation - PFNAM allows the analyst to address a wide range of "what if" questions. Two of the } \\
\text { main outputs of a PFNAM simulation are pressure and pipeline capacity estimates along the pipeline. } \\
\text { This allows the analyst to determine whether an outage of a pipeline component will result in pipeline } \\
\text { shutdown or degradation in pipeline throughput. } \\
\text { Data format - Access database. } \\
\text { Sensor data - Accepts pipeline pressure and flow. } \\
\text { Coupling with other models - This model is compatible with the NG Tool set developed at Argonne. } \\
\text { Human activity modeling - Human activities are not modeled. }\end{array}$}} \\
\hline & & \\
\hline & & \\
\hline & & \\
\hline \multicolumn{3}{|c|}{ System Requirements } \\
\hline Hardware & Not specified. & \\
\hline Software & Not specified. & \\
\hline \multicolumn{3}{|l|}{ Other Notes } \\
\hline
\end{tabular}



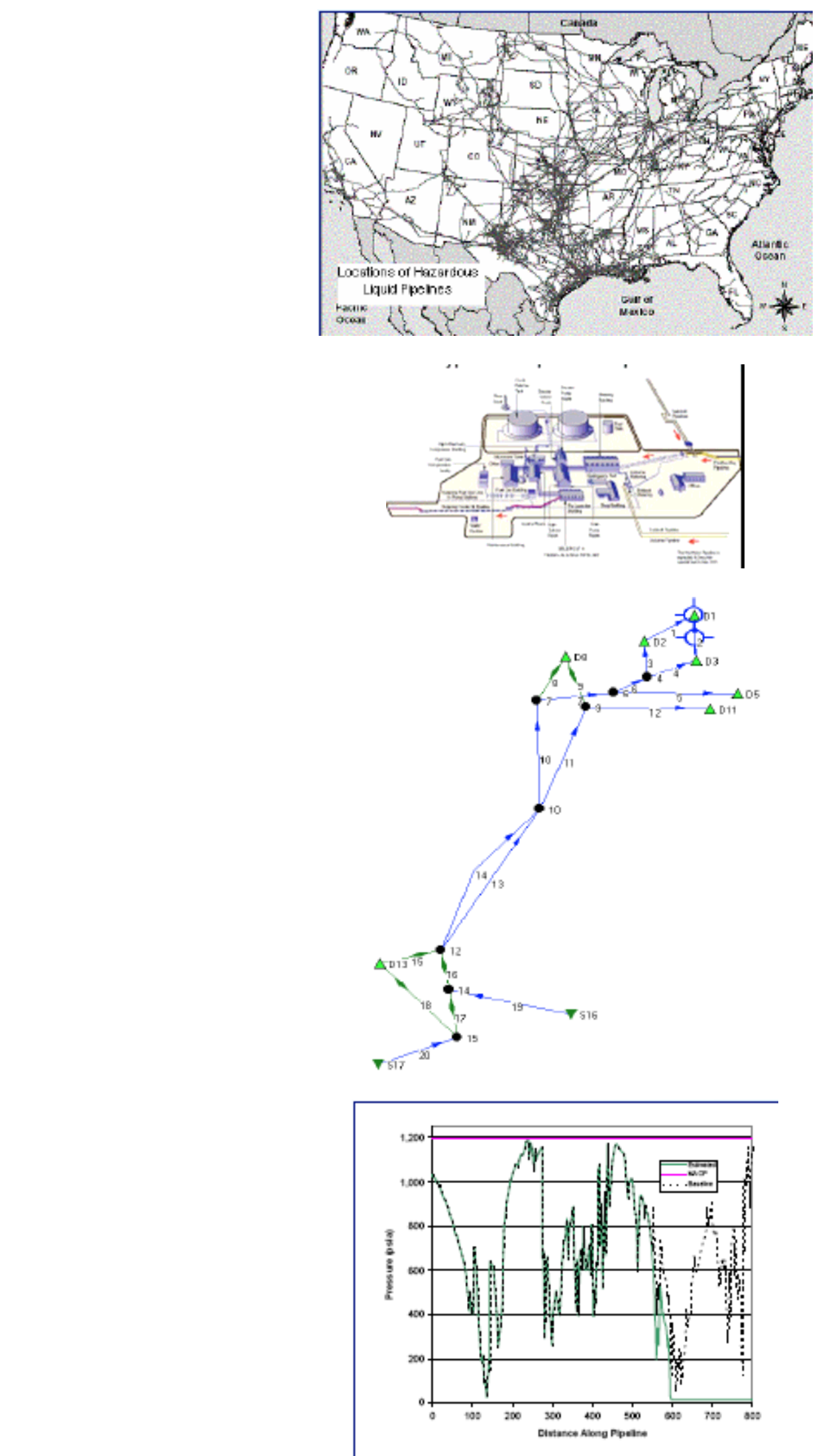

\section{References}




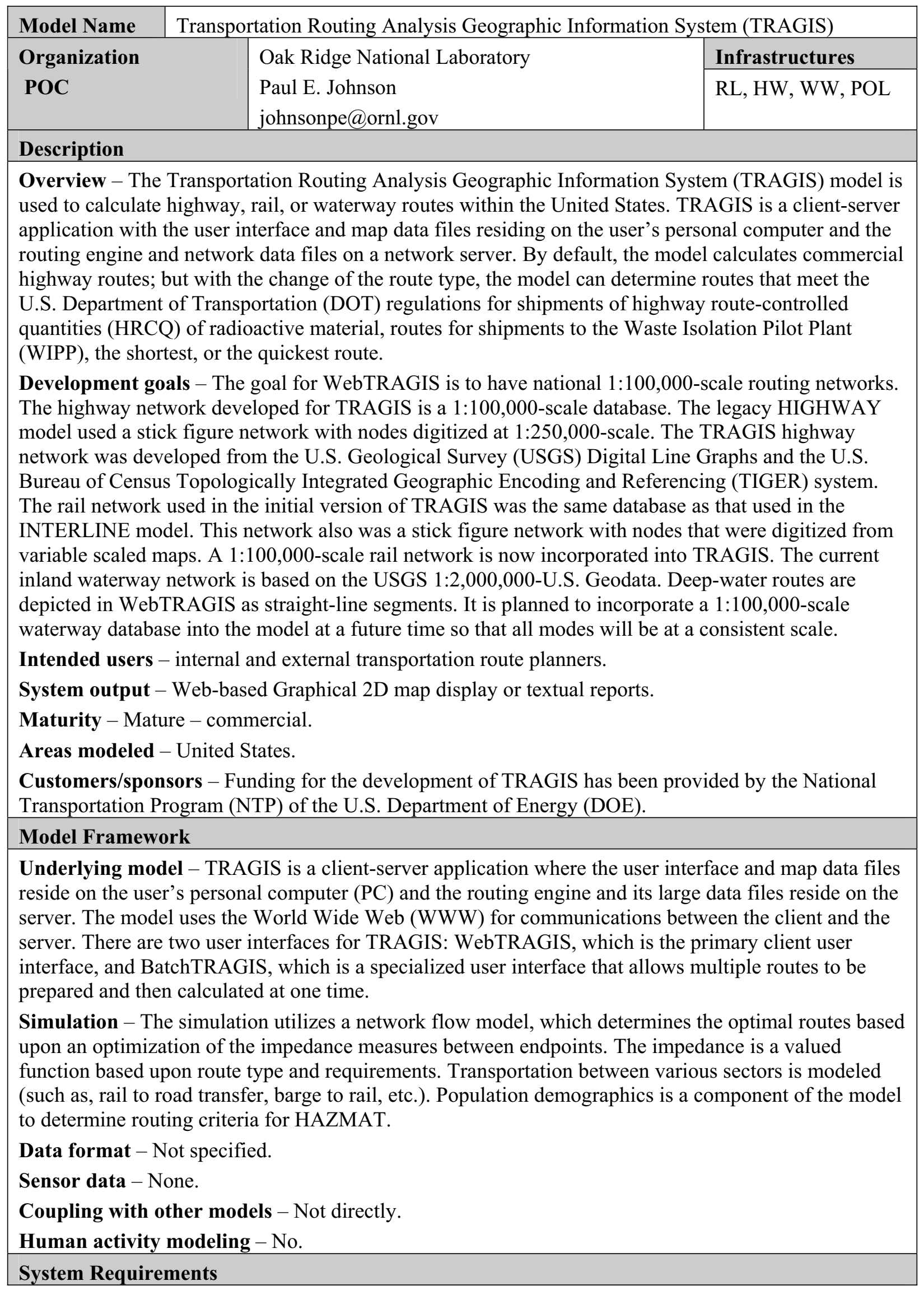




\begin{tabular}{|l|l|}
\hline Hardware & PC with Internet Access. \\
\hline Software & Windows. \\
\hline Other Notes \\
\hline
\end{tabular}

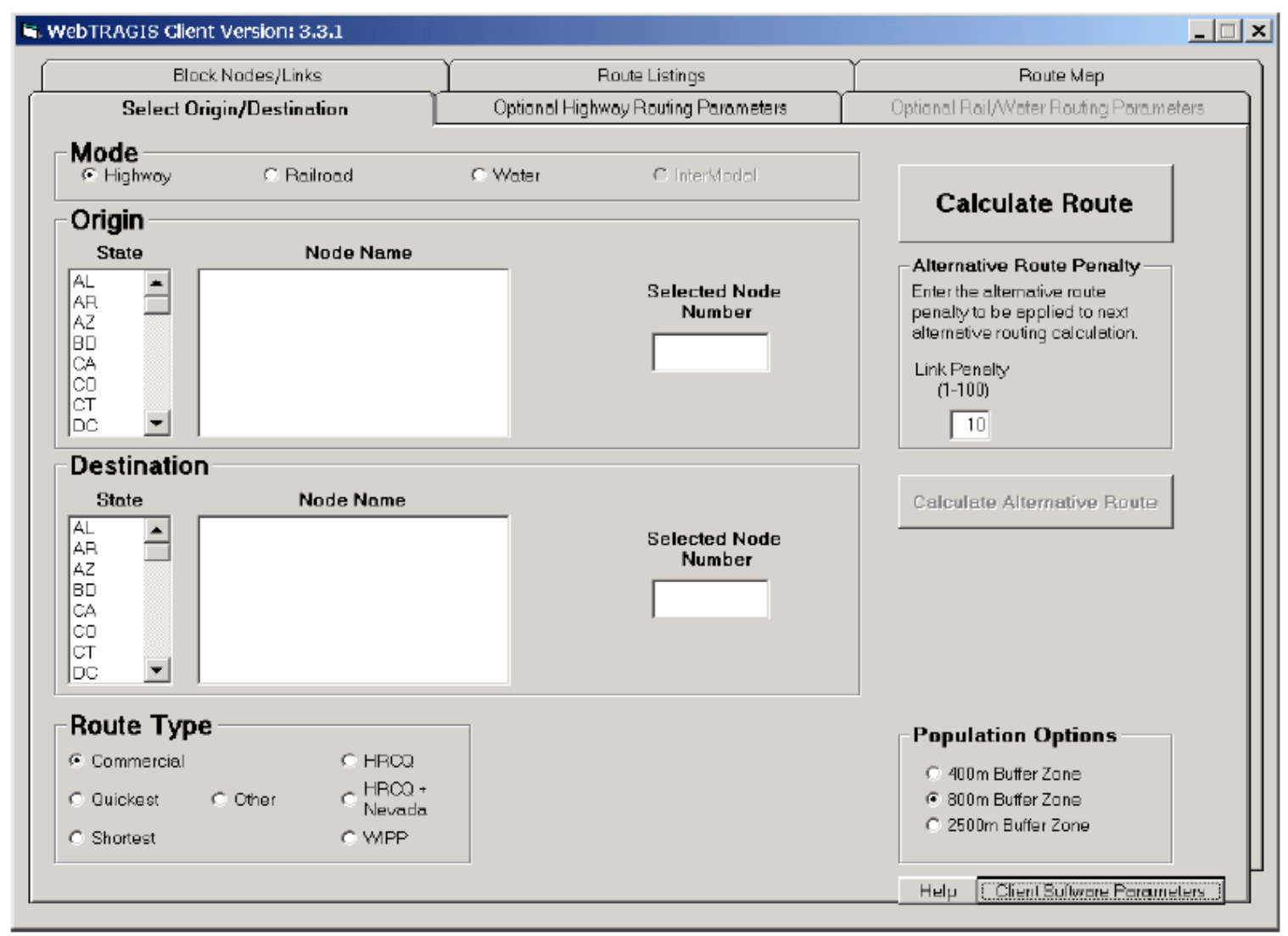




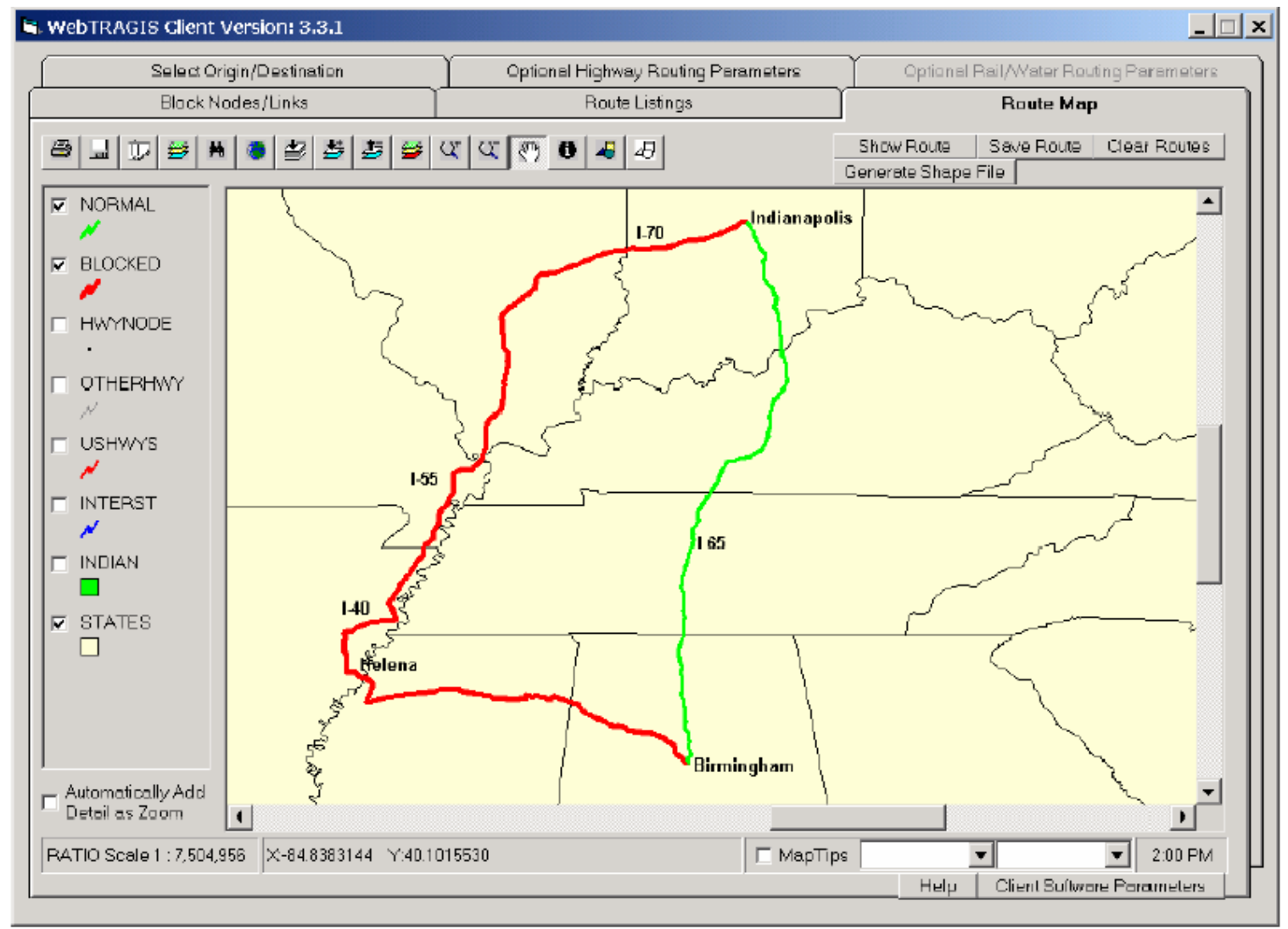

\section{References}

WebTragis https://tragis.ornl.gov/

Transportation RoutingAnalysis Geographic Information System (TRAGIS) User's Manual, Oak Ridge National Laboratory, ORNL/NTRC-006 Rev 0, June 2003. https://tragis.ornl.gov/TRAGISmanual.pdf. 


\begin{tabular}{|c|c|c|}
\hline Model Name & \multicolumn{2}{|l|}{ TRANSIM } \\
\hline \multirow{2}{*}{$\begin{array}{l}\text { Organization } \\
\text { POC }\end{array}$} & \multirow{2}{*}{$\begin{array}{l}\text { Los Alamos National Laboratory } \\
\text { Jim Smith }\end{array}$} & Infrastructures \\
\hline & & HW, HA \\
\hline \multicolumn{3}{|l|}{ Description } \\
\hline \multicolumn{3}{|c|}{$\begin{array}{l}\text { Overview - TRANSIMS is an agent-based simulation system capable of simulating the } \\
\text { second-by-second movements of every person and every vehicle through the transportation network of } \\
\text { a large metropolitan area. }\end{array}$} \\
\hline \multicolumn{3}{|c|}{$\begin{array}{l}\text { It consists of mutually supporting simulations, models, and databases. By employing advanced } \\
\text { computational and analytical techniques, it creates an integrated environment for regional } \\
\text { transportation system analysis. TRANSIMS is an integrated suite of products containing an easy-to-use } \\
\text { graphical user interface for the modeling functions, a GIS-based network editor, 3D data visualization } \\
\text { and animation software, and a reporting system. TRANSIMS is designed to give transportation } \\
\text { planners more accurate, complete information on: }\end{array}$} \\
\hline \multicolumn{3}{|c|}{$\begin{array}{ll}\text { Traffic impacts } \\
\text { Energy consumption } \\
\text { Traffic congestion } \\
\text { Land use planning. }\end{array}$} \\
\hline \multicolumn{3}{|c|}{$\begin{array}{l}\text { The core code version of TRANSIMS (TRANSIMS-LANL), developed at Los Alamos National } \\
\text { Laboratory, is distributed for a nominal fee to universities on this Web site. The commercial version of } \\
\text { TRANSIMS (TRANSIMS-DOT) was developed from the core software package especially for the } \\
\text { Department of Transportation by IBM, and it has a more elaborate interface and specific features to } \\
\text { meet requirements by the DOT. It is not available on this Web site. }\end{array}$} \\
\hline \multicolumn{3}{|c|}{$\begin{array}{l}\text { Development goals - Started as laboratory-directed research and development in the late 1980s for the } \\
\text { Department of Transportation. Funding is continuing under Department of Homeland Security (DHS) } \\
\text { National Infrastructure Simulation and Analysis Center (NISAC). TRANSIMS technology was } \\
\text { developed under U.S. Department of Transportation and EPA funding at the Los Alamos National } \\
\text { Laboratory (LANL) over the last eight years. It is a result of an effort to develop new transportation } \\
\text { and air quality modeling methodologies required by the Clean Air Act, the Transportation Equity Act } \\
\text { for the } 21 \text { st Century (TEA 21), and other regulations. }\end{array}$} \\
\hline \multicolumn{3}{|c|}{$\begin{array}{l}\text { Intended users - Internal analyst - used to support the development of an impact report on for specific } \\
\text { infrastructure events (such as, hurricanes, terrorist attacks, etc.), external analysts. }\end{array}$} \\
\hline \multicolumn{3}{|c|}{$\begin{array}{l}\text { System output - Visualization of demographics data with a city or region illustrating the human } \\
\text { activity such as traffic patterns and work patterns. }\end{array}$} \\
\hline \multicolumn{3}{|c|}{ Maturity - Mature internal and commercial. } \\
\hline \multicolumn{3}{|c|}{ Model Framework } \\
\hline \multicolumn{3}{|c|}{$\begin{array}{l}\text { Underlying model - Cellular Autonoma. } \\
\text { Simulation - Discrete event, agent based simulation. } \\
\text { Data - Multiple data sources including Census data, Household Survey Data, Dunn and Bradstreet } \\
\text { Data. } \\
\text { Sensor data - No direct sensor feeds. } \\
\text { Coupling with other models - Yes, coupling is done directly (EPISIM). } \\
\text { Human activity modeling - Yes - social network and human mobility model. }\end{array}$} \\
\hline \multicolumn{3}{|c|}{ System Requirements } \\
\hline Hardw & tworks require a rarge Limux ciuster. som & \\
\hline
\end{tabular}




\begin{tabular}{|c|c|}
\hline & nts. \\
\hline Software & $\begin{array}{l}\text { The TRANSIMS distribution requires that the user install the following software. } \\
\text { Linux } \\
\text { X11R6 libraries (Xmu, Xi, X11, Xext, Xt) } \\
\text { OpenGL and the OpenGL Utilities Toolkit libraries (Mesa/Glut) } \\
\text { Linux libraries (stdc++, ld-linux, ICE, SM) } \\
\text { Perl. } \\
\text { All of the third-party software used by TRANSIMS is available on Red Hat Linux } \\
\text { distribution CDs. The latest versions of the following packages should be installed: } \\
\text { kernel, kernel-headers, gec, glibc, libstdc++, make, perl, XFree86, Mesa, Mesa-devel, } \\
\text { Mesa-Glut, Mesa-Glut-devel, MPI, and PVM. } \\
\text { Solaris } \\
\text { XllR6 libraries in /usr/openwin, OpenGL, OpenGL Utilities Toolkit libraries (glut), } \\
\text { and Perl. } \\
\text { Metis, PVM, MPI, and SPRNG are supplied with the TRANSIMS distribution. }\end{array}$ \\
\hline \multicolumn{2}{|c|}{ Other Notes } \\
\hline \multicolumn{2}{|c|}{$\begin{array}{l}\text { Los Alamos National Laboratory's TRANSIMS software is based on a computationally intensive, } \\
\text { agent-based simulation technology requiring significant multiprocessor computing hardware. Programs } \\
\text { in the TRANSIMS software suite are distributed applications with components running on different } \\
\text { hardware/software platforms. To install and run all of the components of the TRANSIMS suite, the } \\
\text { customer must procure and set up the following three types of computer systems: } \\
\text { 1. Unix/Linux server(s) for hosting the core TRANSIMS software, Oracle database, and server- } \\
\text { side components of the TRANSIMS modeling interface. Customers who wish to execute large- } \\
\text { size problems must have procured multiserver Linux computing cluster or an equivalent } \\
\text { multiprocessor UNIX-based framework. } \\
\text { Windows workstation(s) for running the Network Editor, the client-side modeling interface, and } \\
\text { Crystal Reports. } \\
\text { Optional Linux workstation(s) for running the Visualizer. Alternatively, the customer may wish } \\
\text { to equip the Linux server with a high-end graphics card and use the server as the Visualizer } \\
\text { platform. A version of the output Visualizer that operates on the Windows workstation is in } \\
\text { development. }\end{array}$} \\
\hline \multicolumn{2}{|c|}{$\begin{array}{l}\text { TRANSIMS was tested in a Linux cluster environment on Red Hat Linux } 6.2 \text { and compiled with } \\
\text { gcc/g++ 2.95.2. Limited tests in a single-CPU environment were done on Red Hat Linux } 7.1 \text { using } \\
\text { gcc } / g++2.96 .\end{array}$} \\
\hline \multicolumn{2}{|c|}{$\begin{array}{l}\text { To run the traffic microsimulator under PVM or MPI, the Linux kernel must be compiled with } \\
\text { networking support and must have an assigned IP address and a host name. An actual network card is } \\
\text { not required. The following options must be selected in the Linux kernel configuration: }\end{array}$} \\
\hline \multicolumn{2}{|c|}{. $\quad$ Networking support (CONFIG_NET) } \\
\hline \multicolumn{2}{|c|}{ System V IPC (CONFIG_SYSVIPC) } \\
\hline \multicolumn{2}{|c|}{ TCP/IP networking (CONFIG_INET) } \\
\hline \multicolumn{2}{|c|}{ Dummy-net driver support (CONFIG_DUMMY) } \\
\hline \multicolumn{2}{|c|}{ The appropriate network card driver. } \\
\hline & shinned with Red Hat 6.2 and \\
\hline
\end{tabular}




\begin{tabular}{ll|}
\hline X Window System \\
Mesa/GL \\
G $\quad$ Glut. \\
Additional package categories should be selected to compile the TRANSIMS components: \\
C Development \\
. \\
Development Libraries \\
C++ Development \\
X Development.
\end{tabular}




\section{TRRANSIII}

An agent-based software system for simulating large realistic scale-traffic in urban environments.

It is based on a cellular automata concept.

Resolution: down to 7.5 meters and 1 second. Cars cannot pass through each other.

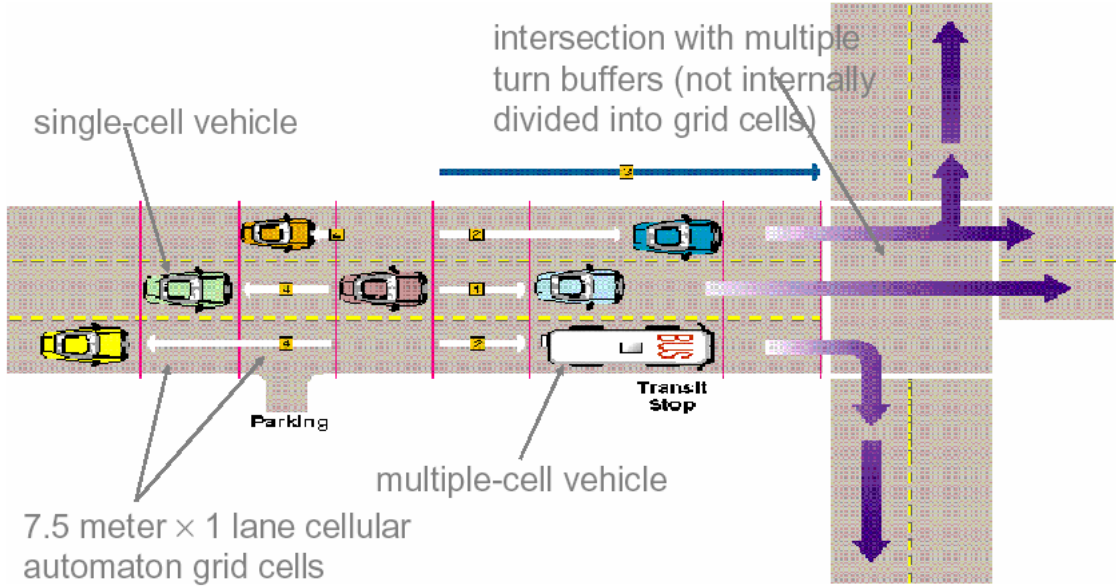

The Portland traffic network:

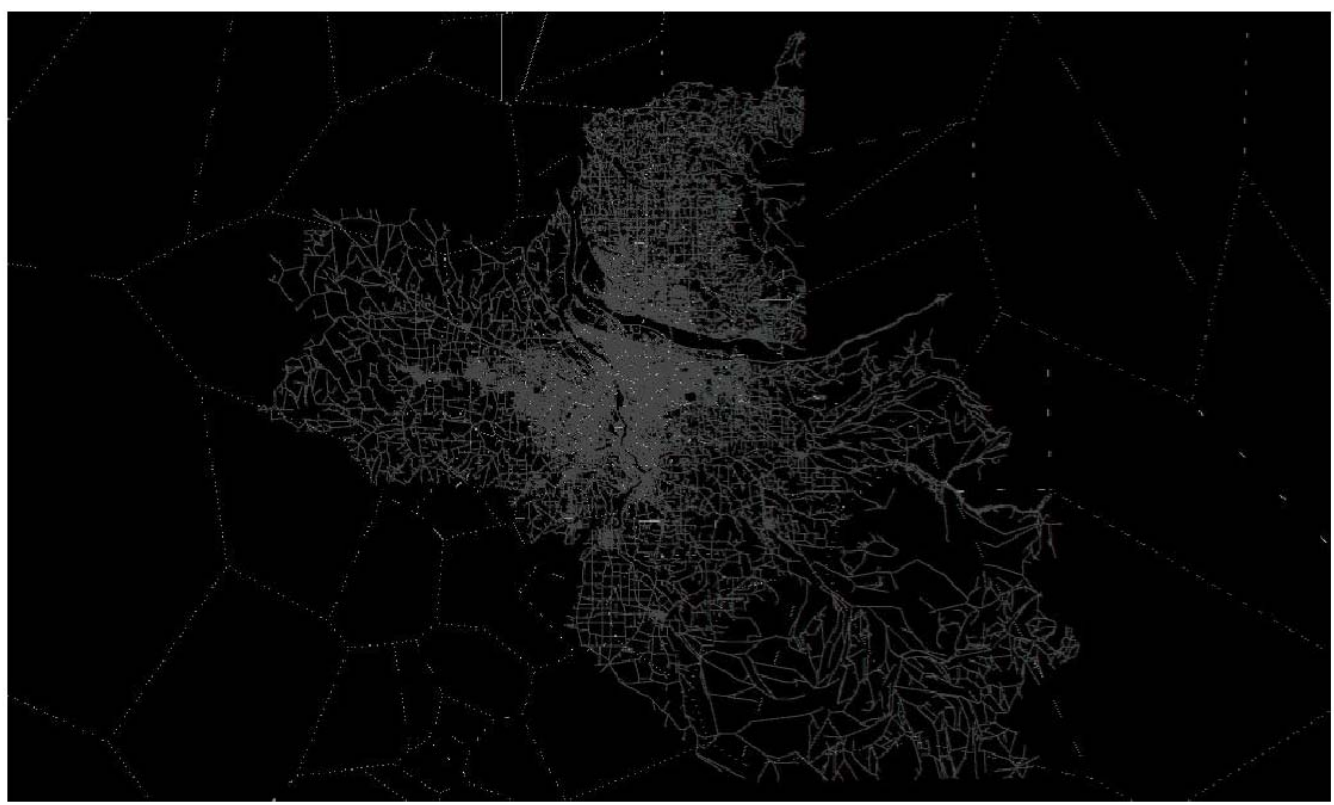


References

http://www.transims.net/home.html

Zoltán Toroczkai “Agent-Based Modeling as a Decision Making Tool: How to Halt a Smallpox Epidemic How to Halt a Smallpox Epidemic", Center for Nonlinear Studies, Theoretical Division, Los Alamos National Laboratory. 


\begin{tabular}{|c|c|c|}
\hline Model Name & \multicolumn{2}{|c|}{ Water Infrastructure Simulation Environment (WISE) } \\
\hline \multirow{2}{*}{$\begin{array}{l}\text { Organization } \\
\text { POC }\end{array}$} & Los Alamos National Laboratory & Infrastructures \\
\hline & Joe Holland & DW, SW, ST \\
\hline \multicolumn{3}{|l|}{ Description } \\
\hline \multicolumn{3}{|c|}{$\begin{array}{l}\text { Overview - The Water Infrastructure } \\
\text { supporting the evaluation of water infr } \\
\text { interdependency issues. }\end{array}$} \\
\hline \multicolumn{3}{|c|}{ Development goals - Not specified. } \\
\hline \multicolumn{3}{|c|}{$\begin{array}{l}\text { Intended users - Internal analyst - IEISS used to support the development of an impact report on for } \\
\text { specific infrastructure events (such as, hurricanes, terrorist attacks, etc.). }\end{array}$} \\
\hline \multicolumn{3}{|c|}{$\begin{array}{l}\text { System output - Key components in the WISE framework are ArcWISE, a GIS based graphical user } \\
\text { interface, and IEISS Water, a water infrastructure interdependency simulation capability within IEISS. } \\
\text { ArcWISE leverages the existing data management, analysis, and display capabilities within geographic } \\
\text { information systems while also extending them to infer, improve, and amend water infrastructure data } \\
\text { in support of running hydraulic simulation engines such as EPANET or IEISS Water. ArcWISE also } \\
\text { provides tools for defining and simulating infrastructure damage events, such as a fire, and generating } \\
\text { water demand/sewage production estimates. IEISS Water is an extension of the IEISS analysis } \\
\text { software to water distribution infrastructure simulation. }\end{array}$} \\
\hline \multicolumn{3}{|c|}{ Maturity - Development. } \\
\hline \multicolumn{3}{|c|}{ Areas modeled - Numerous U.S. metropolitan areas. } \\
\hline \multicolumn{3}{|c|}{ Model Framework } \\
\hline \multicolumn{3}{|c|}{ Underlying model - Flow and Dispersion Model. } \\
\hline \multirow{5}{*}{\multicolumn{3}{|c|}{$\begin{array}{l}\text { Simulation - A continuous time based model with an underling physical engine for system dynamics. } \\
\text { WISE involves the integration of geographic information systems with a wide range of infrastructure } \\
\text { analysis tools including industry standard hydraulic simulation engines (e.g., EPANET and SWMM) as } \\
\text { well as Los Alamos National Laboratory interdependency simulation systems such the Urban } \\
\text { Infrastructure Suite (UIS) and the Interdependent Energy Infrastructure Simulation System (IEISS). } \\
\text { Data format - Not specified. } \\
\text { Sensor data - No direct sensor feeds. } \\
\text { Coupling with other models - Yes, coupling is done indirectly. The output of IEISS will serve as the } \\
\text { input to other infrastructure models to identify cross infrastructure effects. } \\
\text { Human activity modeling - None at this time. }\end{array}$}} \\
\hline & & \\
\hline & & \\
\hline & & \\
\hline & & \\
\hline \multicolumn{3}{|c|}{ System Requirements } \\
\hline Hardware & \multicolumn{2}{|l|}{ Not specified. } \\
\hline Software & \multicolumn{2}{|l|}{ ArcWise, EPANET and SWMM. } \\
\hline \multicolumn{3}{|l|}{ Other Notes } \\
\hline
\end{tabular}




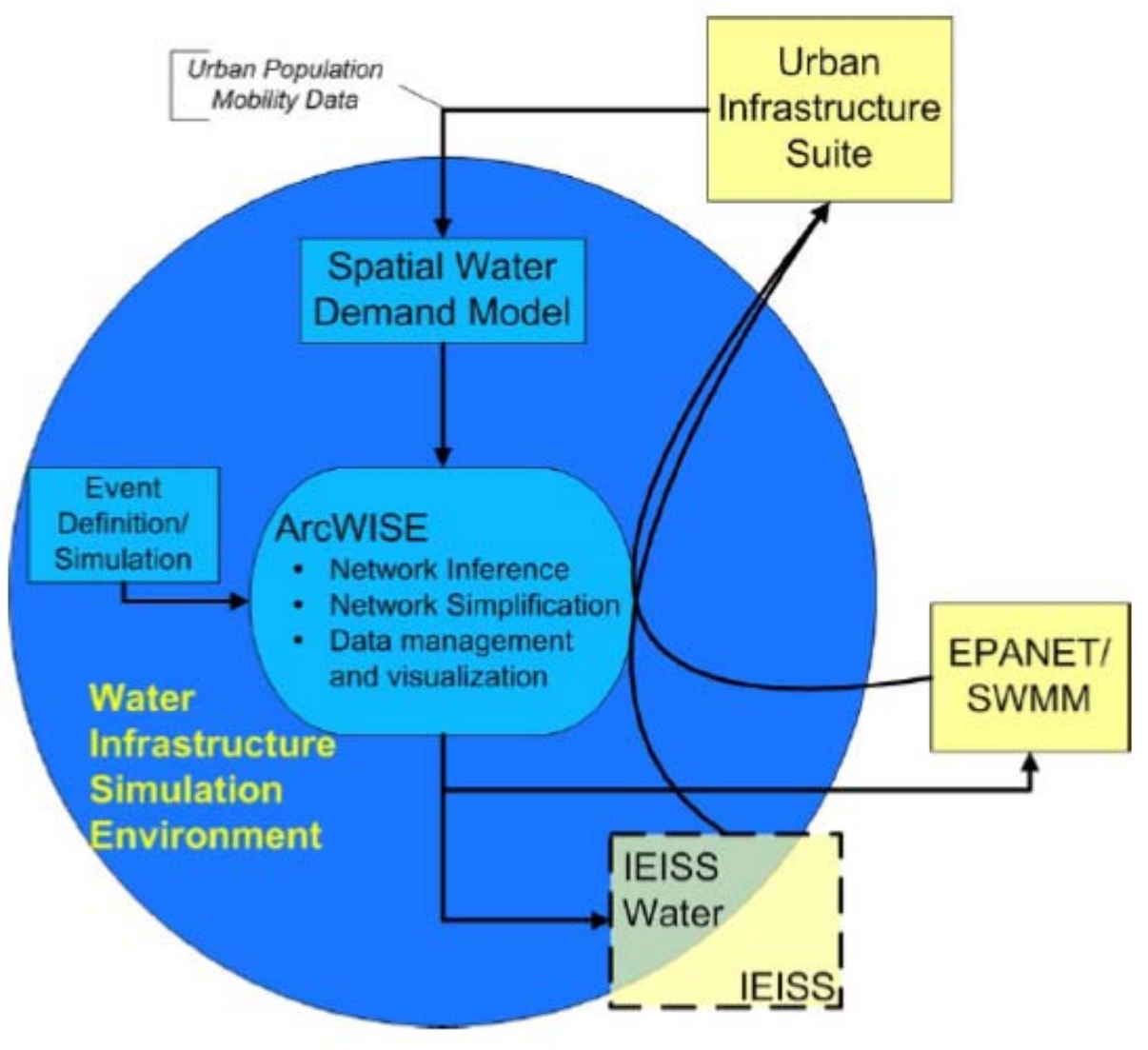




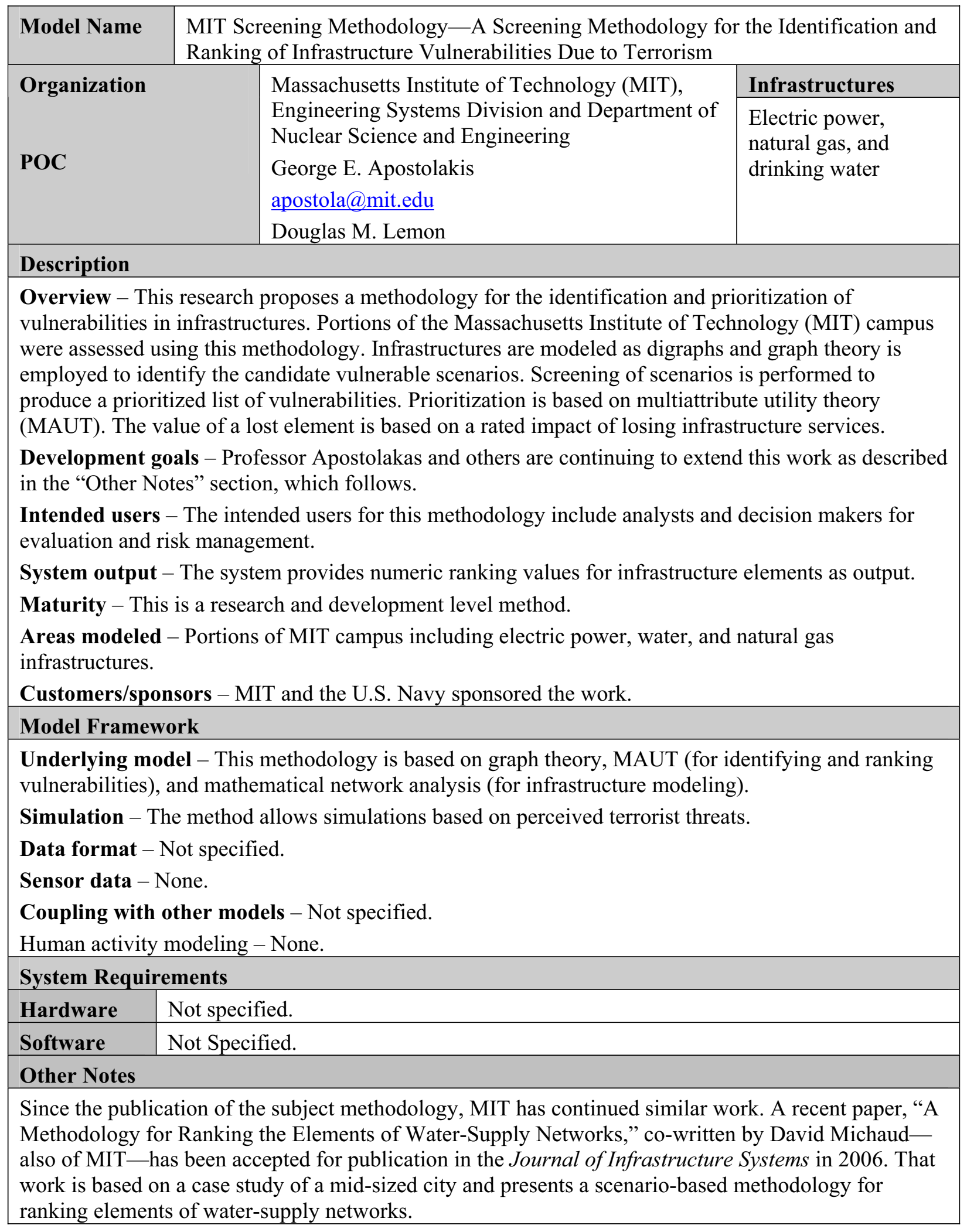




\section{References}

Apostolakas, G., and Lemon, D. (2005). "A Screening Methodology for the Identification and Ranking of Infrastructure Vulnerabilities Due to Terrorism," Risk Analysis, Vol. 25, No. 2, pp. 361-376. 


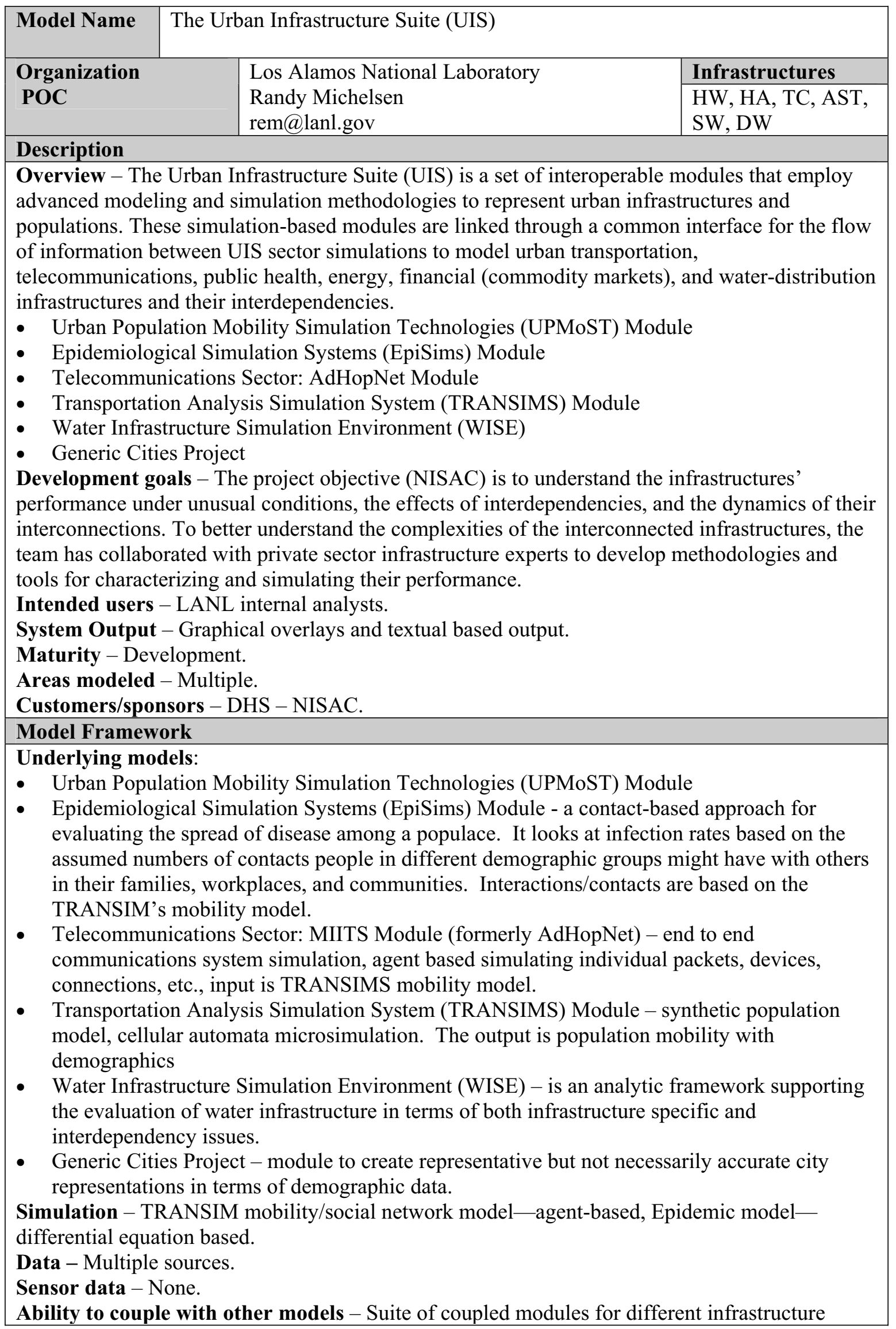


sectors.

Human Activity modeling - Yes. Mobility and Social Interaction Model.

System Requirements

\begin{tabular}{|l|l|}
\hline Hardware & Large models require a Linux Cluster. \\
\hline Software & Linux, various. \\
\hline Other Notes
\end{tabular}

Other Notes

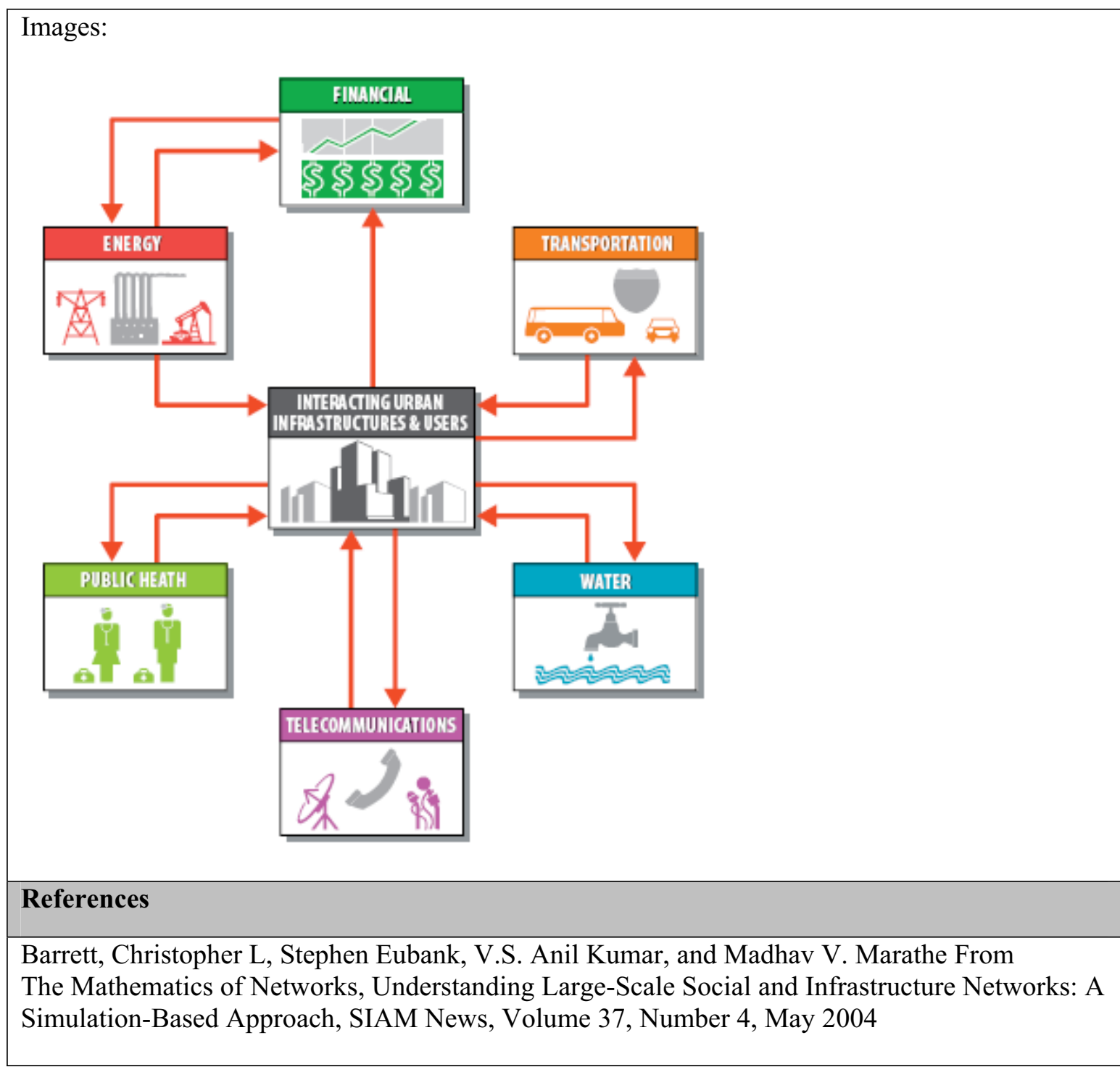




\section{REFERENCES}

1. Congressional Research Service Report for Congress. 2002 Critical Infrastructures: Background, Policy and Implementation. Available online at http://www.iwar.org.uk/cip/resources/pdd63/crs-report.pdf.

2. Congressional Research Service Report for Congress. 2002 Critical Infrastructures: Background, Policy and Implementation. Available online at http://www.iwar.org.uk/cip/resources/pdd63/crs-report.pdf.

3. http://www.tswg.gov

4. Executive Order, 13010. Critical Infrastructure Protection. Federal Register. Vol. 61. No. 138. July 17, 1996. pp. 3747-3750.

5. Executive Order, 13130 National Infrastructure Assurance Council, Federal Register, Vol. 64, No. 137, July 19, 1999. pp. 38535-38536.

6. Executive order 13231 Critical Infrastructure Protection in the Information Age. Federal Register. Vol. 66. No. 202. October 18, 2001. pp. 53063-53071. The NIAC is established on page 53069.

7. D. Mussington, "Concepts for Enhancing Critical Infrastructure Protection: Relating Y2K to CIP Research and Development.” RAND:Science and Technology Institute, Santa Monica, CA, 2002, p 29.

8. Layton, L. and D. Phillips. 2001. Train Sets Tunnel Afire, Shuts Down Baltimore. Available online via < http://www.washingtonpost.com/ac2/wp-dyn?pagename=article\&node=\&contentId=A175422001Jul18>, accessed March 28, 2002.

9. Ratner, A. 2001. Train derailment severs communications. Available online via $<$ http://www.baltimoresun.com/news/local/bal-email19.story?coll=bal-home-headlines $>$, accessed March 28, 2002.

10. Little, R. and P. Adams. 2001, Tunnel fire choking East Coast rail freight. Available online via $<$ http://www.baltimoresun.com/news/local/bal-te.bz.freight20jul20.story?coll= bal-home-headlines $>$, Accessed March 28, 2002.

11. M. Dunn, and I.Wigert. International CIIP Handbook 2004: An Inventory and Analysis of Protection Policies in Fourteen Countries. Zurich: Swiss Federal Institute of Technology: 2004, p. 243.

12. D. D. Dudenhoeffer, M. R. Permann, and M Manic, "CIMS: A Framework For Infrastructure Interdependency Modeling And Analysis." Submitted to Proceedings of the 2006 Winter Simulation Conference, L. F. Perrone, F. P. Wieland, J. Liu, B. G. Lawson, D. M. Nicol, and R. M. Fujimoto. Piscataway, New Jersey: Institute of Electrical and Electronics Engineers, 2006.

13. S. Rinaldi, J. Peerenboom, and T. Kelly. "Identifying, Understanding, and Analyzing Critical Infrastructure Interdependencies," IEEE Control Systems Magazine, IEEE, December 2001, pp. 11-25.

14. U.S. Department Of Energy Office of Critical Infrastructure Protection. 2001. Critical Infrastructure Interdependencies: Impact of the September 11 Terrorist Attacks on the World Trade Center, A Case Study, 2001, p. 10.

15. UNITED STATES CONGRESS, "U.S.A. Patriot Act", 2001, http://www.epic.org/privacy/terrorism/hr3162.html.

16. UNITED STATES CONGRESS, "U.S.A. Patriot” Act, 2001, http://www.epic.org/privacy/terrorism/hr3162.html 
17. United States Joint Forces Command, Operational Net Assessment (ONA) Concept Of Operations For Millennium Challenge 02 (MC-02), October 2001.

18. Hammes, T. The Sling and the Stone, Zenith Press, St. Paul MN, 2004, p.2.

19. United States Joint Forces Command, The Joint Warfighting Center, Joint Doctrine Series Pamphlet 4, Doctrinal Implications of Operational Net Assessment (ONA), 2004.

20. LandScan, http://www.ornl.gov/sci/landscan/index.html.

21. Los Alamos National Laboratory, http://lanl.gov/orgs/d/nisac/, $\mathrm{http}: / / \mathrm{www}$. sandia.gov/mission/homeland/programs/critical/nisac.html.

22. National Energy Technology Laboratory, http://www.netl.doe.gov/onsite_research/Facilities/energy.html.

23. Technical Support Working Group, http://www.tswg.gov.

24. Federal Business Opportunities, http://www.fbo.gov/spg/USAF/AFMC/ AFRLRRS/Reference\%2DNumber\%2DBAA\%2D06\%2D07\%2DIFKA/SynopsisP.html.

25. Amin, M. "National Infrastructures as Complex Interactive Networks", Chapter 14 in Automation, Control, and Complexity: New Developments and Directions, Samad \& Weyrauch (Eds.), John Wiley and Sons, March 2000, Table 14.1.

26. Schmitz, W. and K. A. Neubecker. 2003. Architecture of an Integrated Model Hierarchy: Work Package 6, Deliverable D6.2, ACIP Technical Report IST-2001-37257: 32. Available via http://www.iabg.de/acip/doc/wp6/D62_architecture.pdf, Accessed April 1, 2006. 